Escola Politécnica da Universidade de São Paulo

\author{
Rafael Valadares Leite
}

\title{
Desenvolvimento de um Espectrômetro Nuclear Digital de Radiação Gama
}




\section{Rafael Valadares Leite}

\section{Desenvolvimento de um Espectrômetro Nuclear Digital de Radiação Gama}

\begin{abstract}
Dissertação apresentada ao Departamento de Engenharia de Telecomunicações e Controle da Escola Politécnica da Universidade de São Paulo para avaliação da dissertação do candidato à obtenção do Título de Mestre em Engenharia.
\end{abstract}

Área de atuação:

Engenharia de Sistemas

Orientador:

Prof. Fuad Kassab Junior

São Paulo 
Este exemplar foi revisado e alterado em relação à versão original, sob responsabilidade única do autor e com a anuência de seu orientador.

São Paulo, de novembro de 2006.

Assinatura do autor

Assinatura do orientador 


\section{FICHA CATALOGRÁFICA}

Leite, Rafael Valadares

Desenvolvimento de um espectrômetro nuclear digital de radiação Gama / R.V. Leite. --- ed.rev. -- São Paulo, 2006.

p.

Dissertação (Mestrado) - Escola Politécnica da Universidade de São Paulo. Departamento de Engenharia de Telecomunicações e Controle.

1.Espectroscopia de raio gama 2.Geofísica nuclear 3.Equipamentos nucleares I.Universidade de São Paulo. Escola Politécnica. Departamento de Engenharia de Telecomunicações e Controle II.t. 
Dedicatória:

À Regina, minha mãe, que deu todo o suporte durante meu curso de graduação e outras etapas da minha vida que me fez chegar até este mestrado. 


\section{Agradecimentos}

Gostaria de agradecer especialmente a três pessoas que me ajudaram na implementação do projeto e testes no laboratório de Instrumentação Geofísica no Instituto de Astronomia, Geofísica e Ciências Atmosféricas da Universidade de São Paulo (IAG-USP):

Ao professor Francisco Yukio Hiodo do Instituto de Geofísica pela grande participação, sempre disposto a ajudar e por permitir a utilização de um detector de iodeto de sódio necessário para a conclusão deste projeto.

Ao Nilton Silva por ter me ajudado com a montagem do circuito eletrônico e contribuir com informações de um equipamento que ele já tinha trabalhado.

Ao Geofísico Jorge Silva pela ajuda no laboratório que ele conhece bem.

Também agradeço:

Ao meu orientador Fuad Kassab Jr. pela orientação e ter me incentivado a ingressar no mestrado logo após a conclusão da graduação.

À Joelle Quaini por estar ao meu lado e pela ajuda na finalização do mestrado.

Aos Geofísicos Dionísio Uendro, Leandro Moutinho, Luciano Konzen e Henrique Dalpozzo que me ajudaram a adquirir algum conhecimento em espectrometria gama em 2003 o que me fez amadurecer o tema do projeto.

À Ana Teresa Contier pela ajuda no texto da dissertação.

Ao João Paulo Martins pela ajuda no texto. 


\section{Resumo}

O método nuclear gamaespectrométrico vem ganhando espaço em diversas aplicações como fornecer a informação médica em um paciente ou de uma galáxia distante, detectar radioatividade para fins de segurança e medir a concentração de radioelementos em um mineral ou rocha. Esta dissertação apresenta um projeto e implementação de um espectrômetro gama digital conectado a um conjunto detector contendo cristal cintilador de iodeto de sódio dopado com tálio. O hardware é baseado em um dispositivo lógico programável da família CoolRunner II da Xilinx e um conversor analógico-digital de $80 \mathrm{MHz}$ da Analog Devices. A aquisição de dados é executada em um computador pessoal comum. As linguagens de programação utilizadas foram VHDL e C\#. O objetivo desta dissertação é apresentar todas as etapas necessárias para o desenvolvimento de um gamaespectrômetro digital e inclui pesquisa bibliográfica, estudo do equipamento, modelagem dos cristais, simulação do projeto de um gamaespectrômetro, montagem do circuito eletrônico, desenvolvimento do processamento e lógica do circuito, criação do software de aquisição dos dados em tempo real e apresentação dos resultados obtidos. 


\begin{abstract}
The gammaspectrometric method has been used for diverse applications as to supply the medical information in a patient or a distant galaxy, to detect radioactivity at airport and to measure the concentration of radioelements in a mineral or rock. This work presents a digital gammaspectrometer project and implementation for acquisition of radiometric data, the spectrometer is connected to a gamma-ray detector $\mathrm{NaI}(\mathrm{Tl})$. The two main components in hardware are complex programmable logical device of the family CoolRunner II Xilinx and an $80 \mathrm{MHz}$ analog to digital converter of brand Analog Devices. The acquisition of data is executed in a common personal computer. The programming languages used are VHDL and C\#. The objective of this work is to present all the needful stages for the digital gammaspectrometry development that includes theorem, equipment studying, crystal modeling, gammaspectrometry modeling and simulation, electronic circuit assembly, processing and logic circuit development, data acquisition software in real time development and presentation of results.
\end{abstract}




\section{Sumário}

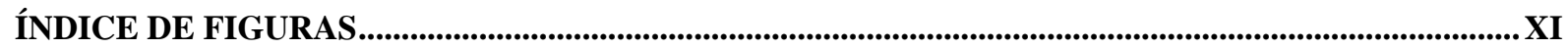

ÍNDICE DE TABELAS .............................................................................................................. XIV

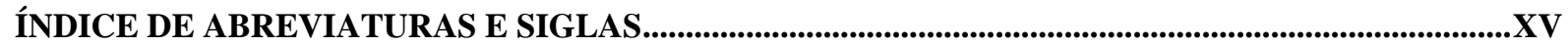

ÍNDICE DE SÍMBOLOS ...........................................................................................................

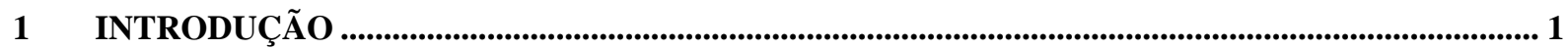

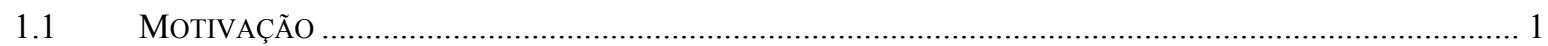

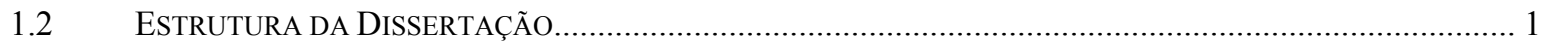

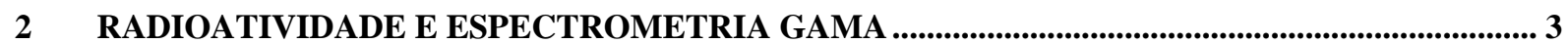

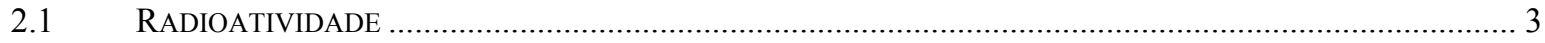

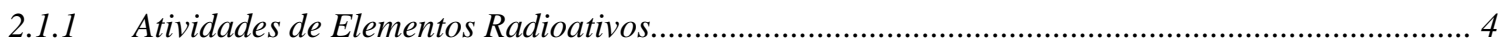

2.1.2 Interação de Fótons Gama com a Matéria ………….................................................................... 5

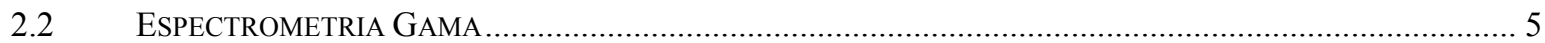

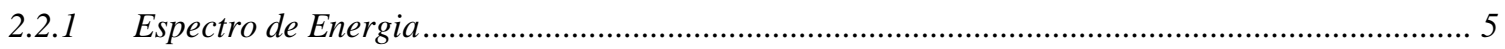

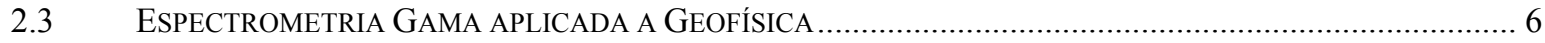

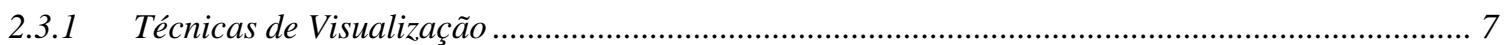

3 GAMAESPECTRÔMETRO .................................................................................................................. 9

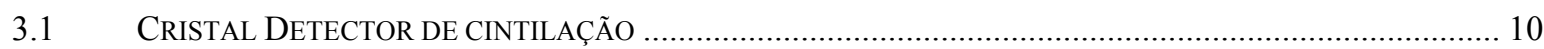

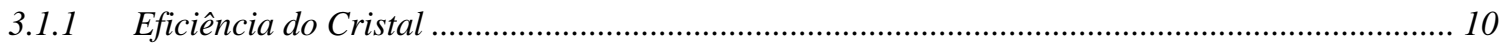

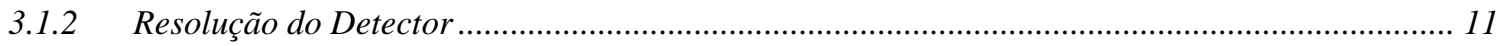

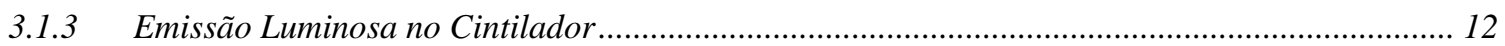

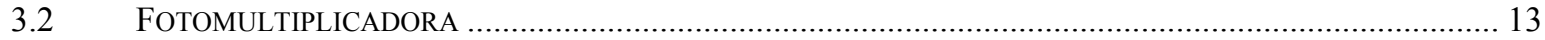

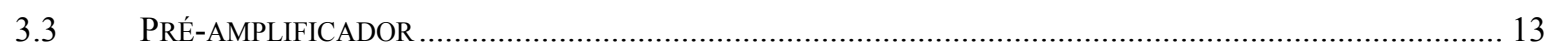

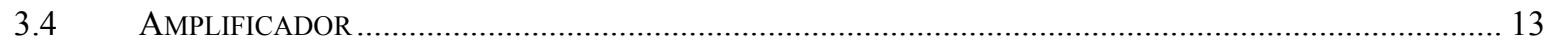

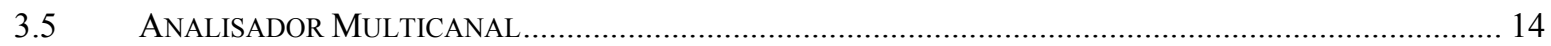

3.6 COMPUTADOR

4 ESTUDO DE DESENVOLVIMENTO DO PROJETO …................................................................ 15

4.1 MODELAGEM DOS SENSORES E FONTES DE RADIAÇÃO EM INTERFACE MATLAB .............................. 16

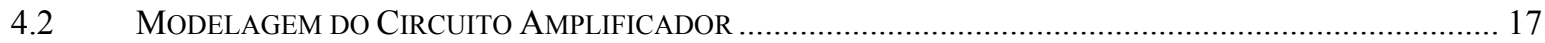




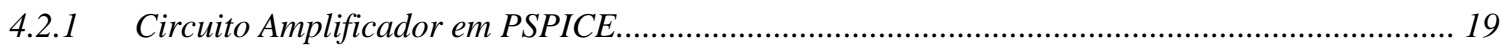

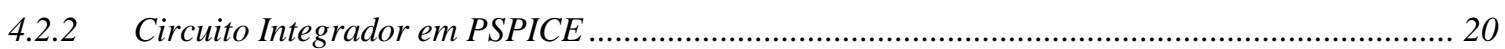

4.2.3 Circuito Amplificador digital em MATLAB ................................................................. 21

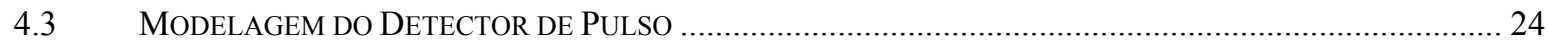

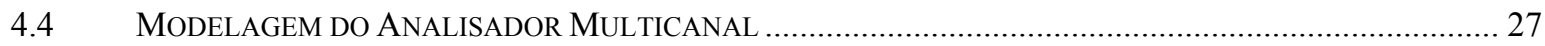

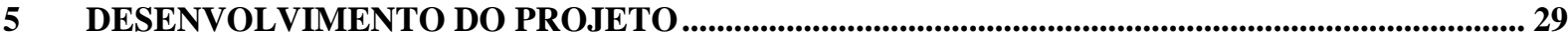

5.1 Parte Prática 1: Montagem da Placa Eletrônica do Projeto .............................................. 29

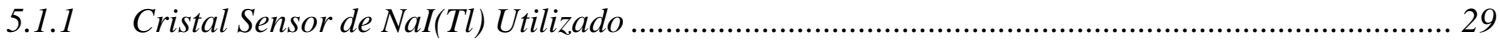

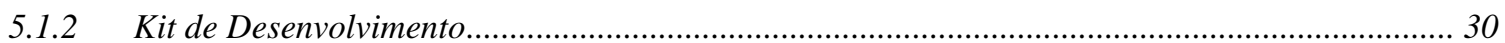

5.1.3 Determinação da pinagem do Circuito Lógico Programável .................................................. 30

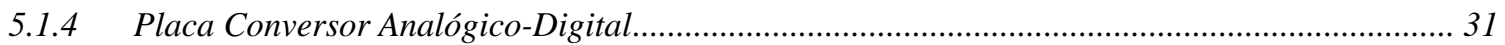

5.2 PARTE PrÁtica 2: Software de AquiSiçÃo de Dados............................................................... 33

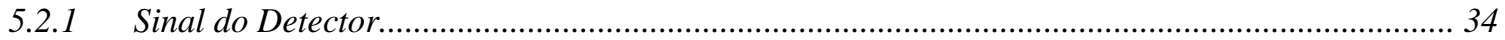

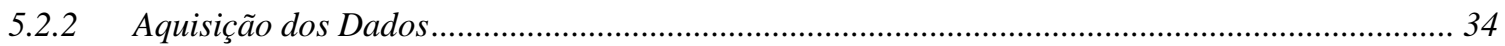

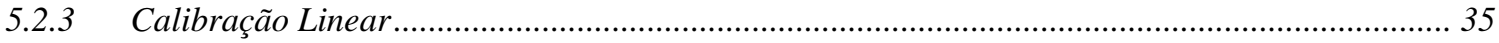

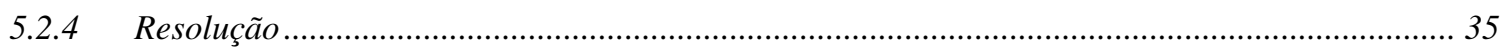

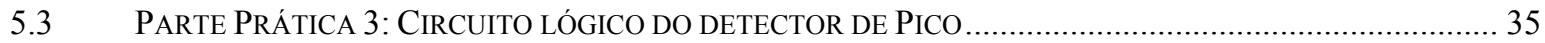

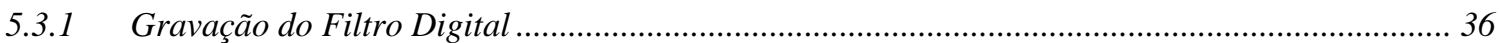

5.3.2 Sistema Lógico Indicador de deteç̧ão de pulso individual ......................................................... 38

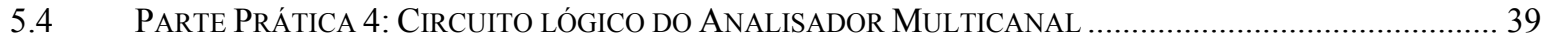

5.4.1 Contagem de Pulsos e Montagem do Espectro de Energia...................................................... 39

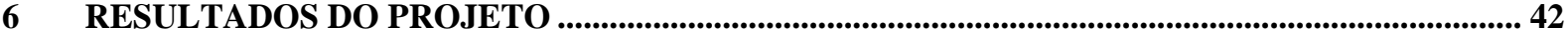

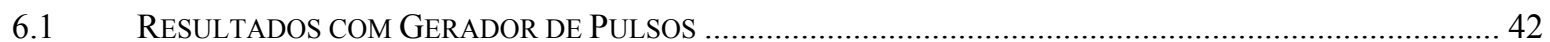

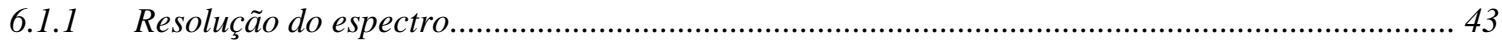

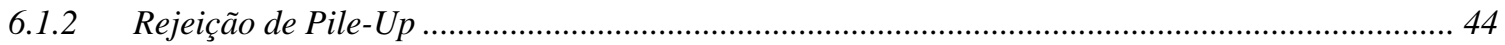

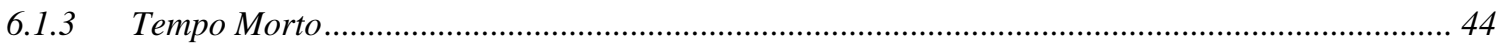

6.2 RESULTADOS COM AMOSTRAS RADIOATIVAS ARTIFICIAIS.......................................................... 44

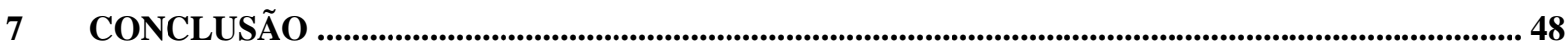

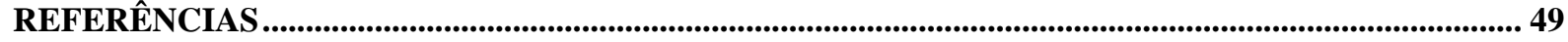




\section{Índice de Figuras}

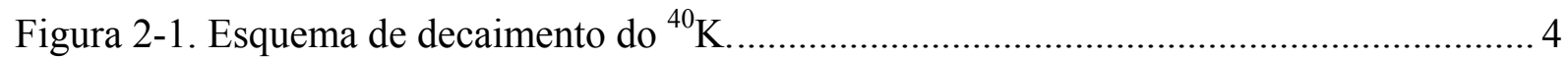

Figura 2-2. Simulação do fluxo de raios gama do potássio. Modificado de [4]. ...................... 6

Figura 2-3. Variação média de K, U \& Th para determinadas rochas. Modificado de [4] ........ 7

Figura 2-4. Mapa 3D topográfico da contagem de potássio ................................................. 8

Figura 2-5. Mapa 3D da superfície modelada em corte superficial. ..................................... 8

Figura 3-1. Diagrama do fluxo de sinais no espectrômetro nuclear. NaI(T1): cristal cintilador; PMT: tubo fotomultiplicador; HV: fonte de alta voltagem; Pré-Amp: pré-amplificador; Amp: amplificador; MCA: analisador multicanal; Comp: computador. Modificado de [8].

Figura 3-2. Eventos ocorridos no cristal cintilador até a emissão de luz captada pela fotomultiplicadora

Figura 3-3. Coeficiente de atenuação linear do cristal NaI(Tl). Modificado de [5].

Figura 3-4. Interação do fóton com um detector. (PE - fotoelétrico, CS - espalhamento Compton, PP - produção de pares). Extraído de [5] .................................................... 11

Figura 3-5. Definição de FWHM. Extraído de [10]................................................................ 12

Figura 3-6. Sinal de saída do pré-amplificador e sinal de pulsos gerados por um amplificador

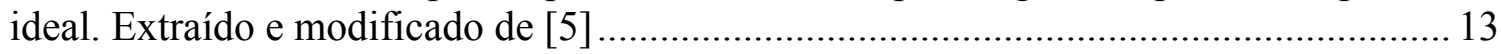

Figura 3-7. Espectro de energia do elemento Césio. Extraído e modificado de [5]................. 14

Figura 4-1. Esquema de um gamaespectrômetro digital ......................................................... 15

Figura 4-2. Modelo do espectrômetro realizado em Simulink com funções em MATLAB.... 16

Figura 4-3. Circuito CR derivador. Extraído de [9] ........................................................... 17

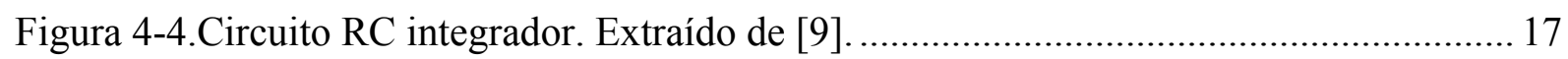

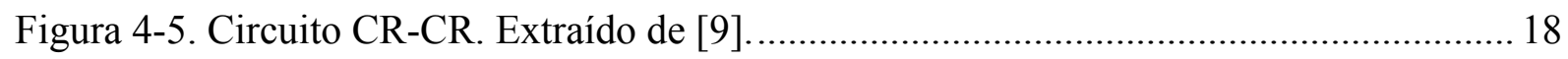

Figura 4-6. Circuito de cancelamento de pólo-zero. Extraído de [9] .................................... 18

Figura 4-7. Circuito amplificador modelado no PSpice..................................................... 19

Figura 4-8. Resposta de 3 tipos de circuitos amplificadores................................................ 19

Figura 4-9. Circuito integrador (esquerda) e o resultado obtido (direita).............................. 20

Figura 4-10. Circuito amplificador logarítmico modelado no PSpice. .................................. 21 
Figura 4-11. Circuito amplificador em MATLAB.

Figura 4-12. Resultado de simulação do amplificador com o modelo do gamaespectrômetro desenvolvido. 22

Figura 4-13. Circuito amplificador em tempo contínuo e discreto em MATLAB. 23

Figura 4-14. Circuito lógico similar à equação 4.7. 23

Figura 4-15. Comparação da amplitude de diferentes filtros amplificadores. 24

Figura 4-16. Circuito de detecção de novo pulso. Extraído de [9]. 25

Figura 4-17. Demonstração de detecção e eliminação de pile-up. Extraído de [5]...... .25

Figura 4-18. Bloco Detector de Pulso do modelo. 26

Figura 4-19. Simulação do bloco Detector de Pulso. 26

Figura 4-20. Bloco Analisador Multicanal do modelo. 27

Figura 4-21. Espectro de energia de uma simulação do modelo completo do

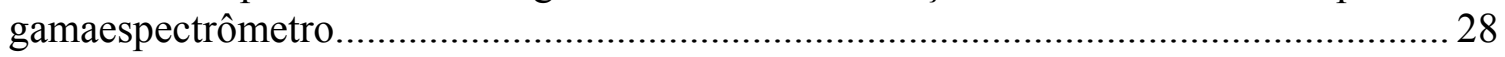

Figura 5-1. Diagrama de blocos do projeto desenvolvido. 29

Figura 5-2. Foto do detector $\mathrm{NaI}(\mathrm{Tl})$ utilizado com seu cabo coaxial do sinal de saída. 29

Figura 5-3. Foto do kit de desenvolvimento com suas adaptações. 30

Figura 5-4. Dois tipos de circuitos acopladores recomendado pela Analog Devices. 32

Figura 5-5. Sinal convertido pelo sistema de acoplamento Single-Ended. 32

Figura 5-6. Diagrama de bloco do sistema de aquisição de dados. 33

Figura 5-7. Janela do sistema de aquisição de dados. 34

Figura 5-8. Visualização do sinal discreto proveniente do detector. 34

Figura 5-9. Diagrama de bloco do sistema detector de pico. 35

Figura 5-10. Diagrama das portas de entrada e bloco do sistema detector de pico. 36

Figura 5-11. Código de realização dos filtros digitais do sinal de entrada. 37

Figura 5-12. Simulação em Matlab/Simulink.

Figura 5-13. Forma do pulso de entrada (esquerda) e após tratamento com o filtro digital (direita). .38

Figura 5-14. Função discriminadora de pulso. 38

Figura 5-15. Função eliminador de Pile-Up. 39 
Figura 5-16. Diagrama de bloco do sistema do analisador multicanal.

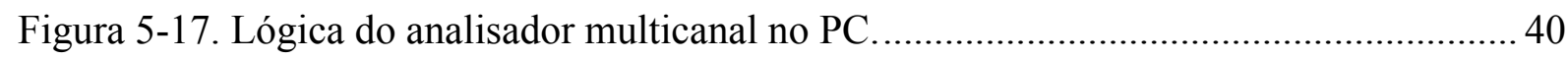

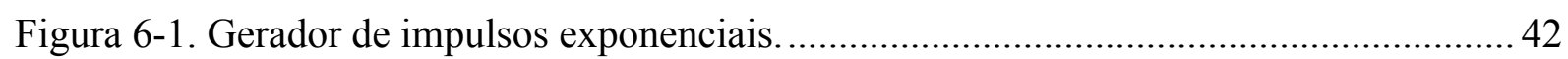

Figura 6-2. Sinal alongado do impulso de entrada no filtro digital........................................ 43

Figura 6-3. Espectro gerado pelo gerador de impulsos exponenciais. .................................. 43

Figura 6-4. Simulação de empilhamento de dois pulsos próximos........................................ 44

Figura 6-5. Pulso de saída do pré-amplificador do detector $\mathrm{NaI}(\mathrm{Tl})$ utilizado. ...................... 45

Figura 6-6. Simulação em Matlab da resposta nos dois filtros utilizados.............................. 45

Figura 6-7. Espectro gerado pelo equipamento com uma amostra de $\mathrm{Cs}^{137} \ldots \ldots \ldots \ldots \ldots \ldots \ldots \ldots . . . . . . . . . . . .66$

Figura 6-8. Espectro gerado pelo equipamento com uma amostra de Cobalto....................... 46

Figura 6-9. Detecção de dois pulsos mesmo quando empilhados utilizando o Filtro 2.......... 47 


\section{Índice de Tabelas}

TABELA 3-1. FUNCIONAMENTO DE CADA BLOCO DO ESPECTRÔMETRO NUCLEAR................. 9 TABELA 5-1. DESCRIÇÃO DA PINAGEM DO SINAL DE ENTRADA DISCRETO E CONECTOR A

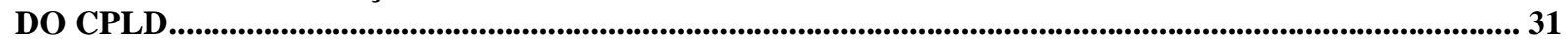

TABELA 5-2. DESCRIÇÃO DO PINAGEM DO CONECTOR B, SAÍDA PARA O PC............................... 31 TABELA 5-3. DESCRIÇÃo DA MÉDIA DO INTERVALO NECESSÁRIO PARA CADA OPERAÇÃO

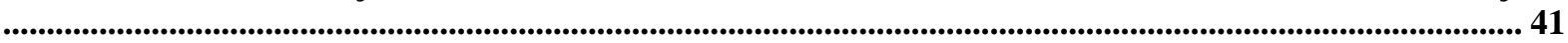




\section{Índice de Abreviaturas e Siglas}

ADC Conversor Analógico-Digital (Analog to Digital Converter)

AmpOp Amplificador Operacional.

CPLD Dispositivos Lógicos Programáveis Complexos (Complex Programmable Logic Devices)

CS Espalhamento Compton (Compton Scattering)

C $++\quad$ Linguagem de Programação $\mathrm{C}$ orientada a objetos

C\# Linguagem de Programação C-Sharp

DC Corrente Contínua (Direct Current)

DSP Processador Digital de Sinais (Digital Signal Processor)

FPGA Matriz de Portas Programáveis em Campo (Field Programmable Gate Array)

FWHM Máxima largura na meia altura (Full Width at Half Maximium)

IAG Instituto de Astronomia, Geofísica e Ciências Atmosféricas

LGNA Laboratório de Geofísica Nuclear Aplicada

LED Diodo emissor de luz (Light Emissor Diode)

MCA Analisador multicanal (Multi Channel Analyzer)

MSPS Milhões de amostragem por segundo (Millions Samples per Second)

$\mathrm{NaI}(\mathrm{Tl}) \quad$ Iodeto de sódio ativado com tálio

PC Computador Pessoal (Personal Computer)

PE Efeito Fotoelétrico (Photoeletric)

PMT Tubo Fotomultiplicador (PhotoMultiplier Tube)

PP Efeito Produção de pares (Pair Production)

VHDL Linguagem de Descrição de Hardware de Circuitos de Velocidade Muito Alta (Very High Speed Integrated Circuits Hardware Description Language) 


\title{
Índice de Símbolos
}

\author{
Co Radioelemento Cobalto \\ Cs Radioelemento Césio \\ eV Eletron-Volt \\ K Radioelemento Potássio \\ Rn Radioelemento Radônio \\ Th Radioelemento Tório \\ U Radioelemento Urânio \\ VDC Voltagem em corrente contínua \\ Vpp Tensão pico a pico \\ $\alpha \quad$ Partícula Alfa \\ $\beta \quad$ Partícula Beta \\ $\gamma \quad$ Raio Gama
}




\section{Introdução}

Métodos nucleares são amplamente aplicados em diversas áreas, como medicina, geração de energia, biologia, arqueologia, geofísica, agronomia e segurança radioativa.

Todos os métodos de instrumentação nuclear são utilizados para se detectar as fontes radioativas produzidas ou naturais. A detecção é feita através da interação desta radiação com um detector especial.

Equipamentos eletrônicos são utilizados em conjunto com esses detectores especiais de radiação para definir a energia ou dose de radiação recebida. Um tipo de equipamento muito utilizado é o dosímetro que mede a exposição de radiação presente no local. Outro tipo de equipamento é o gamaespectrômetro, que resulta na obtenção do espectro de energia de radiação gama.

Neste projeto será desenvolvido um espectrômetro para detectores sólidos de radiação gama. Um gamaespectrômetro pode fornecer a informação médica de um paciente, informações de uma galáxia distante, auxiliar na segurança radioativa em aeroportos, medir a concentração de radioelementos em um mineral ou rocha, etc.

\subsection{Motivação}

$\mathrm{O}$ interesse pelo equipamento gamaespectrômetro ocorreu durante o período de estudo do mestrado quando tive contato direto com o método geofísico gamaespectrométrico utilizado por uma empresa de aerolevantamento geofísico.

O objetivo desta dissertação é desenvolver um espectrômetro de raios gama e assim entender o funcionamento e seu desenvolvimento, não apenas utilizar o equipamento importado como uma caixa preta.

A realização deste projeto permite ter contato com diversas tecnologias como processamento digital de sinais, comunicação, eletrônica analógica e digital, controle, programação, visualização gráfica e algoritmos.

Devido a grande performance e baixo custos dos processadores de sinais atuais, deseja-se desenvolver um espectrômetro totalmente digital, eliminando certas desvantagens dos circuitos analógicos como derivas e variações de propriedades físicas dos componentes, de forma mais rápida e a menor custo. $\mathrm{O}$ projeto vai permitir discutir, analisar e aplicar inovações tecnológicas neste equipamento.

\subsection{Estrutura da Dissertação}

A dissertação é composta de sete capítulos que são descritos a seguir.

1. Introdução: Introdução geral.

2. Radioatividade e Espectrometria Gama: Descrição dos princípios básicos sobre a radiação nuclear, características e seus efeitos. 
3. Gamaespectrômetro: Descrição do funcionamento do equipamento, detecção de raios gama e formação do espectro de energia.

4. Estudo de Desenvolvimento do Projeto: Desenvolvimento de um modelo de um gamaespectrômetro em MATLAB para estudo das diferentes técnicas que poderiam ser aplicadas no projeto. Este estudo serve também para examinar o que é possível e o melhor caminho antes do início da execução do projeto.

5. Desenvolvimento do Projeto: Descrição do circuito eletrônico, software de aquisição de dados, detector digital de pico e analisador multicanal desenvolvidos neste projeto.

6. Resultados do Projeto: Resultados obtidos com o equipamento projetado.

7. Conclusão: Conclusão geral de todo o trabalho realizado. Análise dos resultados e sugestões para uma futura implementação. 


\section{Radioatividade e Espectrometria Gama}

A radioatividade natural pode ser definida como desintegração espontânea de certos núcleos atômicos. Quando ocorre o decaimento radioativo espontâneo, ela é acompanhada pela emissão de partículas carregadas (alfa ou beta) ou de fótons gama [1].

Com a espectrometria gama é possível obter informações da concentração de determinados radioelementos no ambiente, através do espectro de energia de raios gama.

\subsection{Radioatividade}

Todos os materiais existentes na natureza são constituídos de átomos ou suas combinações. $\mathrm{O}$ núcleo do átomo é formado, basicamente, por partículas de carga positiva, denominadas prótons e de partículas de mesma massa, mas sem carga, denominadas nêutrons. O número de nêutrons no núcleo pode ser variável, pois eles não têm carga elétrica. Com isso, um mesmo elemento químico pode ter núcleos de massas diferentes. Átomos de um mesmo elemento químico com massas diferentes são denominados isótopos [2].

Alguns isótopos são instáveis tendo seu núcleo muito energético por ter excesso de partículas ou de carga. Por serem instáveis decaem para núcleos mais estáveis pela emissão de radiação ionizante. O processo de estabilização do núcleo ocorre por quatro diferentes processos:

- Emissão Alfa $(\alpha)$ : Processo de estabilização do núcleo através da emissão de partículas alfa, um grupo de partículas positiva, composta de dois prótons e dois nêutrons, o que corresponde a um núcleo de hélio $(\mathrm{He})$. O processo de decaimento libera uma energia que corresponde à soma das energias da partícula alfa e do núcleo residual em recuo. Por exemplo, o isótopo ${ }_{92}^{238} U$ decai seguindo o esquema: [1]

$$
{ }_{92}^{238} U \rightarrow{ }_{90}^{234} \mathrm{Th}+{ }_{2}^{4} \mathrm{He}+\Delta Q \text {, onde } \Delta Q=4,916 \mathrm{MeV}
$$

- Emissão Beta $(\beta)$ : Processo de estabilização do núcleo através da emissão de uma partícula negativa, um elétron, resultante da conversão de um nêutron em um próton [2].

- Captura Eletrônica: O núcleo absorve um elétron da camada mais interna, com a conseqüente transformação de um próton num nêutron [3].

A emissão de radiação ionizante geralmente é de partículas alfa $(\alpha)$ ou beta $(\beta)$, que possuem massa, carga elétrica e velocidade, sendo a velocidade dependente do valor de sua energia.

- Emissão Gama $(\gamma)$ : Após a emissão de uma partícula alfa $(\alpha)$ ou beta $(\beta)$, o núcleo resultante desse processo, ainda com excesso de energia, procura estabilizar-se, emitindo esse excesso em forma de onda eletromagnética de alta freqüência, denominada radiação gama que não possui massa e se propaga na velocidade da luz. Radiações gama são definidas por sua energia, medida em eletron-volt (eV). 


\subsubsection{Atividades de Elementos Radioativos}

Cada radioisótopo é caracterizado por sua taxa de desintegração, que é proporcional ao número de núcleos presentes. Então o número de núcleos $(d N)$ que decaem durante um curto período de tempo $(d t)$ é proporcional ao número de núcleos presentes $(N)$.

$$
\frac{d N}{d t}=-\lambda N
$$

Resolvendo a equação (1) temos:

$$
N=N_{0} \cdot \exp (-\lambda \cdot t)
$$

Onde $\lambda$ é a constante de decaimento [1].

Alguns isótopos radioativos podem decair por mais de um processo. O isótopo ${ }^{40} K$, por exemplo, pode decair por emissão de partícula $\beta^{-}$, por captura eletrônica ou por emissão de partícula $\beta^{+}$. O esquema geral de decaimento do ${ }^{40} K$ é apresentado na Figura 2-1, onde também são indicadas as possibilidades de cada decaimento. Os processos que emitem radiação gama, em seu decaimento, têm uma energia específica na emissão da radiação gama.

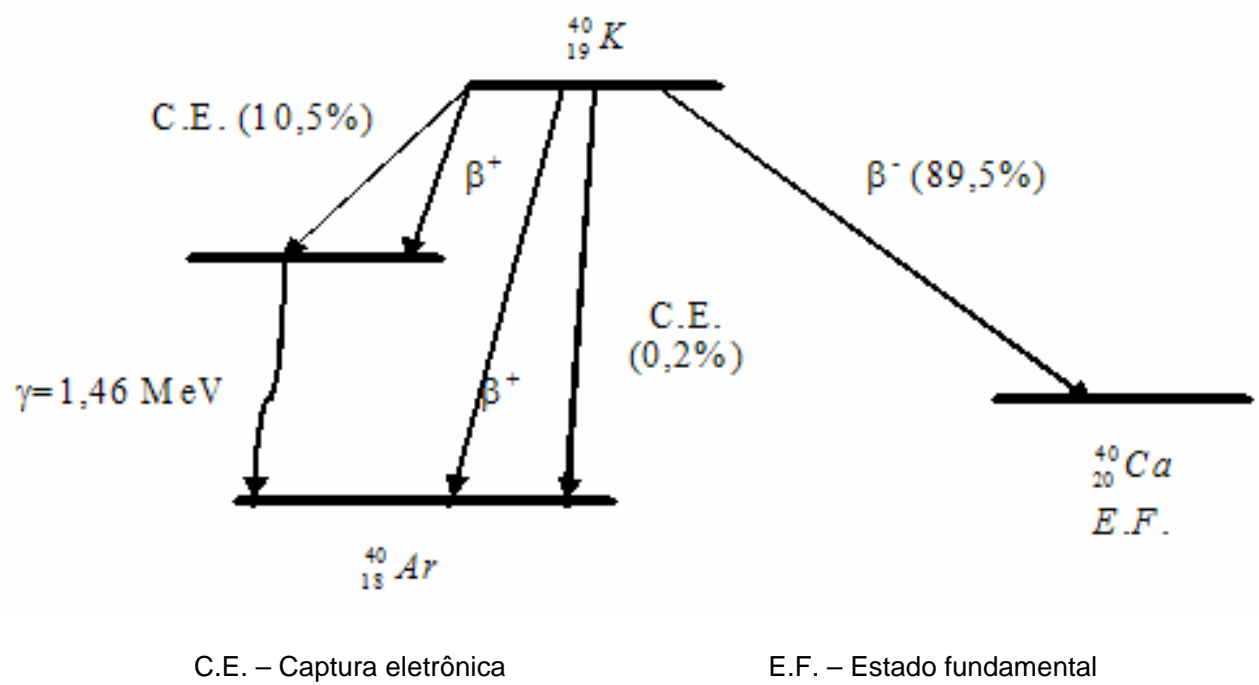

Figura 3-1. Esquema de decaimento do ${ }^{40} \mathrm{~K}$.

Alguns radionuclídeos ao decaírem produzem novos radionuclídeos. Por exemplo, o ${ }_{92}^{238} U$ decai por emissão alfa para o ${ }_{90}^{234} \mathrm{Th}$. Esse isótopo de Tório por sua vez emite uma partícula $\beta^{-}$ e transmuta para o isótopo ${ }_{91}^{234} \mathrm{~Pa}$ do Protactínio, que também é radioativo. Quando ocorre decaimentos em seqüência, tem-se uma série radioativa. O ${ }_{92}^{238} U$ é o pai de uma série radioativa natural que acaba produzindo, depois da emissão de 8 partículas alfa e 6 partículas beta, o isótopo ${ }^{206} \mathrm{~Pb}$ que é estável. [1] 
Existem mais duas séries radioativas naturais: a do isótopo ${ }_{90}^{232} \mathrm{Th}$ que termina com o isótopo ${ }^{208} \mathrm{~Pb}$, conhecida como série do Tório, e a do isótopo ${ }^{235} \mathrm{U}$ que termina com o isótopo ${ }^{207} \mathrm{~Pb}$. Essa última série recebe, por razões históricas, o nome de série do actínio.

As fontes de radiação gama natural podem ser divididas em 3 grupos [4]:

o ${ }^{40} \mathrm{~K},{ }^{238} \mathrm{U},{ }^{235} \mathrm{U}$ e ${ }^{232} \mathrm{Th}$;

o isótopos originados do decaimento do ${ }^{238} \mathrm{U},{ }^{235} \mathrm{U}$ e ${ }^{232} \mathrm{Th}$;

o isótopos criados por fenômenos como interação dos raios cósmicos com a Terra e a atmosfera.

\subsubsection{Interação de Fótons Gama com a Matéria}

Os fótons gama dos decaimentos radioativos interagem com a matéria através de três processos [5]:

Efeito fotoelétrico: O fóton de radiação gama incidente remove um elétron de uma das camadas mais internas do átomo (camada $\mathrm{K}$ ou L). A energia do fóton incidente é totalmente absorvida no processo como energia cinética do elétron.

Efeito Compton: O fóton de radiação gama interage com elétrons das camadas mais externas do átomo que possuem energia de ligação muito inferior a sua. A radiação gama incidente desloca o elétron cedendo parte de sua energia. A energia do fóton não é totalmente absorvida e produz a emissão de um fóton gama cuja energia é a diferença entre a energia do fóton incidente menos a energia absorvida pelo elétron de recuo.

Produção de Pares: Ocorre quando a energia do fóton incidente é superior a 1,022 MeV. Nesse processo, a radiação gama é absorvida na proximidade de um núcleo dando origem a um par de fótons de energia de $511 \mathrm{keV}$ cada.

\subsection{Espectrometria Gama}

Um dos motivos de se utilizar a radiação gama é o seu poder de penetração. A partícula alfa é facilmente atenuada por uma folha de papel, a partícula beta por alguns centímetros de alumínio e o raio gama necessita de vários centímetros de concreto para ser totalmente absorvido.

A radiação gama interage com a matéria e através de detectores especiais consegue-se medir a energia incidente neste detector. Com um equipamento interligado neste detector obtém-se o espectro de energia, que é a contagem para cada intervalo de energia durante um intervalo de tempo.

\subsubsection{Espectro de Energia}

Os nuclídeos gama emissores emitem radiação com energias bem definidas. Alguns isótopos podem emitir mais de uma radiação gama, cada uma com sua energia característica. 
O espectro de emissão de um nuclídeo gama emissor, em teoria, tem o aspecto de um espectro de linhas, cada uma caracterizada por uma energia bem definida. No espectro da figura 2-2 podemos determinar a concentração de potássio em um ambiente, conforme a intensidade da energia de $1460 \mathrm{keV}$ do ${ }^{40} \mathrm{~K}$.

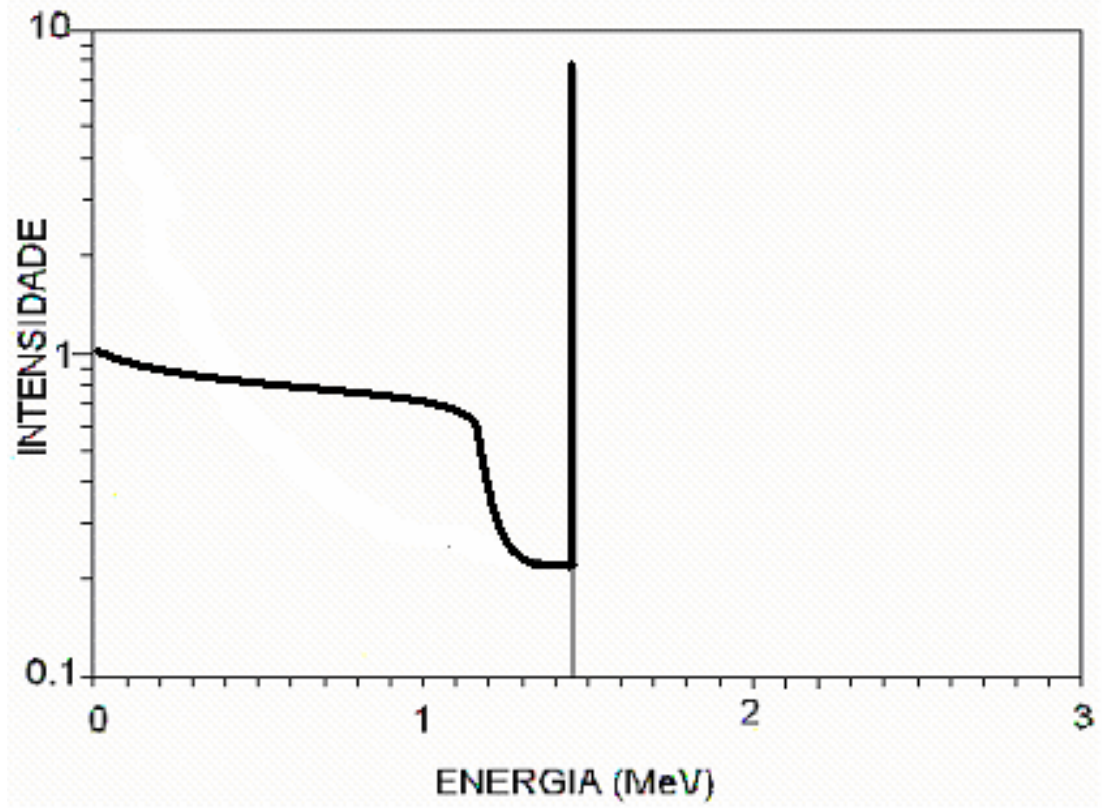

Figura 3-2. Simulação do fluxo de raios gama do potássio. Modificado de [4].

Qualquer que seja o tipo de detector utilizado, parte dos fótons é totalmente absorvida por efeito fotoelétrico e parte sofre espalhamento Compton. Além disso, se a energia do fóton for superior a $1022 \mathrm{keV}$, existe a possibilidade de ocorrer produção de pares.

A principal conseqüência de existirem diferentes tipos de interação da radiação gama com a matéria é que os espectros gama, gerados por um detector ideal, correspondem a uma superposição do espectro de linhas de emissão, com um espectro contínuo produzido pelo espalhamento Compton. Além disso, duas linhas espectrais adicionais associadas à absorção parcial da energia do fóton incidente são geradas quando ocorre produção de pares no detector.

\subsection{Espectrometria Gama aplicada a Geofísica}

Toda a radiação gama detectável dos materiais da rocha e solo, vêm basicamente da desintegração de três elementos de maior interesse: Urânio (U), tório (Th) e potássio $(\mathrm{K})$. [6]

As mudanças na concentração dos três elementos citados acompanham as principais mudanças da litologia podendo este método orientar um reconhecimento geológico em muitas áreas, indicando processos geológicos preliminares como a ação de soluções mineralizadores ou processos metamórficos, como também processos geológicos secundários. Estes dados podem ser úteis para: [7]

- Mapeamento geológico como uma ferramenta indireta para exploração econômica de minerais. 
- Exploração de depósitos de urânio.

- Aplicações especiais tais como a exploração de diamantes ajudando no reconhecimento da localização do kimberlite.

- Exploração de depósitos do cobre onde a alteração de potássio causa um aumento na assinatura radiométrica do mapa.

- Exploração para o ouro usando a associação de Au-U.

- Exploração de efeito radiométrico sobre depósitos de hidrocarbonetos.

Normalmente, os dados de interpretação são obtidos do espectro de freqüência de energia. Estes dados são processados através de correções, como correção de fundo e de Compton, para fornecer apenas concentrações dos elementos K, U e Th na crosta terrestre.

Além das correções, outros processos, como filtragem e nivelamento, são usados no processamento para aumentar a exatidão e a utilidade dos dados para geração de mapas radiométricos.

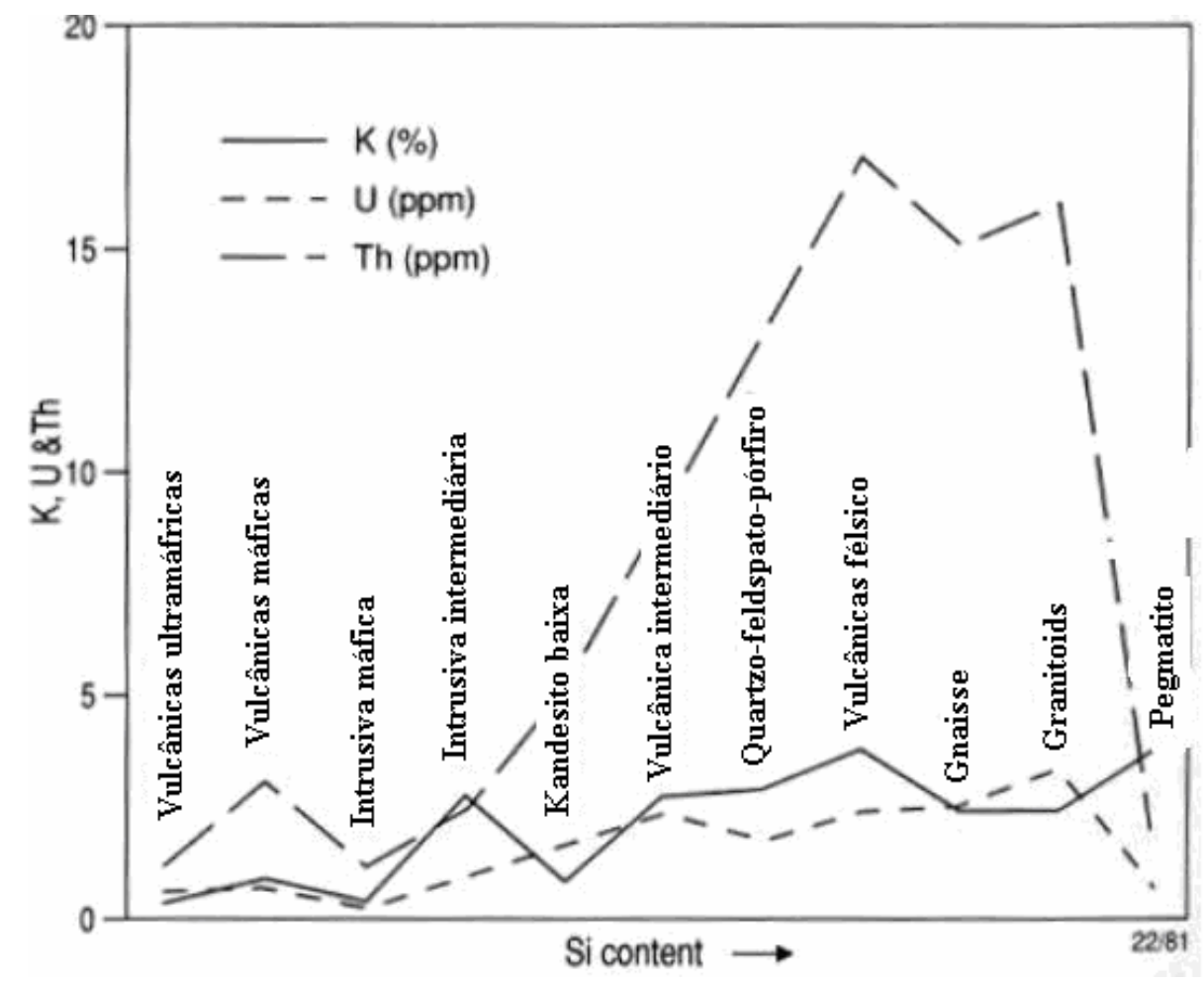

Figura 3-3. Variação média de K, U \& Th para determinadas rochas. Modificado de [4]

Na figura 2-3 é mostrada a concentração dos três tipos de radioelementos estudados nos diferentes tipos de litologia.

\subsubsection{Técnicas de Visualização}

As representações de duas dimensões (2D) dos dados podem ser feitas por mapas de curvas de contorno e imagens. Há sempre uma perda de resolução comparativamente à representação 
1D. A filtragem ao longo das linhas de vôo necessita ter o comprimento de onda de corte maior do que o dobro do intervalo de amostragem para não haver perda de resolução.

Em cada ponto da malha do mapa 2D, a anomalia é estimada a partir dos dados sobre os pontos de aquisição. O método de interpolação utilizado é a mínima curvatura, método eficiente para malhas regulares. $O$ tamanho da célula da malha regular não deve ser superior a $1 / 8$ do comprimento de onda de corte de filtragem dos dados. Um mapa de imagem é formado por matriz de pixels, superposta à malha regular interpolada. Cada pixel recebe uma cor extraída de uma escala que associa valores de anomalia a cores.

A figura 2-4 é uma amostra do resultado de um software de mapeamento 3D tendo o eixo $\mathrm{z}$ representando a altitude do solo.

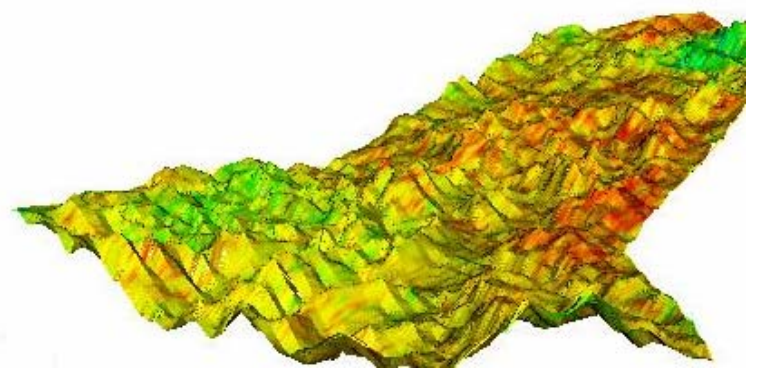

Figura 3-4. Mapa 3D topográfico da contagem de potássio

É possível visualizar diferentes planos de diferentes profundidades de uma mesma região como mostrado na figura 2-5.

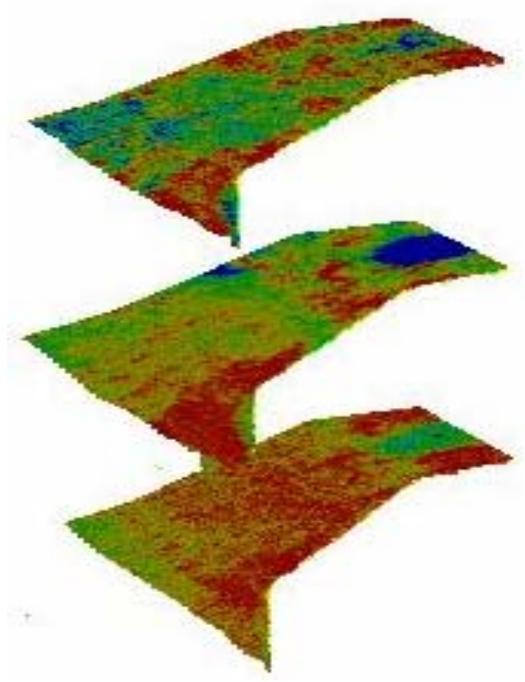

Figura 3-5. Mapa 3D da superfície modelada em corte superficial. 


\section{Gamaespectrômetro}

O gamaespectrômetro é um equipamento capaz de converter as energias dos fótons gama incidentes em espectro de freqüência de energia.

Existem dois tipos de cristais detectores de raios gama: cristais do tipo cintilador e semicondutor. O cristal do tipo semicondutor, usualmente de Germânio (HPGe), tem uma resolução melhor que do cristal cintilador, mas é usado somente em laboratório pelo alto custo e a necessidade de mantê-lo em temperaturas baixas através de nitrogênio liquido [1].

A Figura 3-1 mostra um diagrama do fluxo de sinais de um gamaespectrômetro utilizando cristais cintiladores. O conjunto de cristais converte a energia dos fótons gama em pulsos elétricos e o espectrômetro de raios gama converte estes pulsos elétricos em espectro de freqüência de energia. [8]

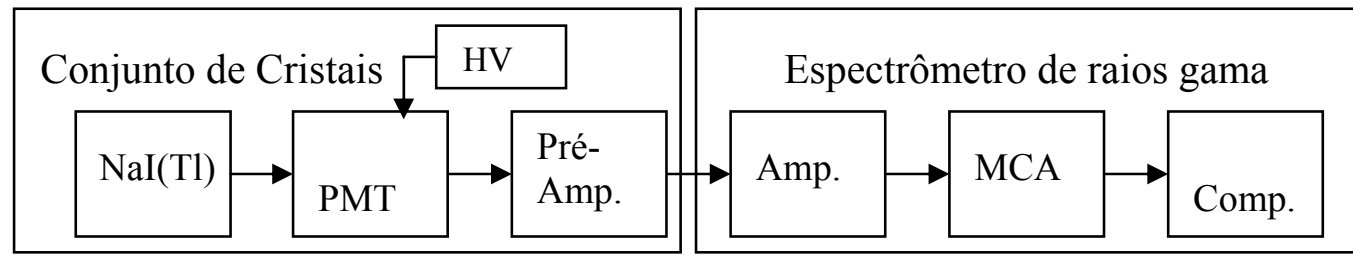

Figura 4-1. Diagrama do fluxo de sinais no espectrômetro nuclear. NaI(Tl): cristal cintilador; PMT: tubo fotomultiplicador; HV: fonte de alta voltagem; Pré-Amp: pré-amplificador; Amp: amplificador; MCA: analisador multicanal; Comp: computador. Modificado de [8].

A função básica destes blocos é converter sinais de entrada em sinais desejados na saída. A tabela 3-1 descreve a funcionalidade de cada bloco.

Tabela 4-1. Funcionamento de cada bloco do espectrômetro nuclear.

\begin{tabular}{|l|l|l|}
\hline \multicolumn{1}{|c|}{ Bloco } & \multicolumn{1}{|c|}{ Entrada/Saída } & \multicolumn{1}{c|}{ Descrição } \\
\hline Cristal cintilador & raios gama/luz & Converte o fóton da radiação em luz UV \\
\hline $\begin{array}{l}\text { tubo } \\
\text { fotomultiplicador }\end{array}$ & Luz/corrente elétrica & $\begin{array}{l}\text { Converte em corrente elétrica a luz } \\
\text { incidente do cristal. Alimentado por alta } \\
\text { voltagem. }\end{array}$ \\
\hline pré-amplificador & Corrente/tensão & Amplifica o sinal de saída do foto-tubo \\
\hline Amplificador & Tensão/pulsos elétricos & $\begin{array}{l}\text { Gera pulsos individuais para cada fóton } \\
\text { proporcional a energia }\end{array}$ \\
\hline Analisador multicanal & Pulsos/espectro & $\begin{array}{l}\text { Realiza a contagem de energia incidente } \\
\text { no canal correspondente }\end{array}$ \\
\hline Computador & espectro/contagem & Análise estatística e correções de dados \\
\hline
\end{tabular}


A seguir serão detalhadas as funcionalidades dos 6 blocos destacados acima.

\subsection{Cristal Detector de cintilação}

Os materiais cintiladores como $\mathrm{NaI}(\mathrm{Tl})$, iodeto de sódio ativado com tálio, são utilizados para converter fótons de radiação em sinal luminoso. A figura 3-2 mostra um resumo da seqüência de eventos que ocorrem dentro do cristal cintilador. [9]

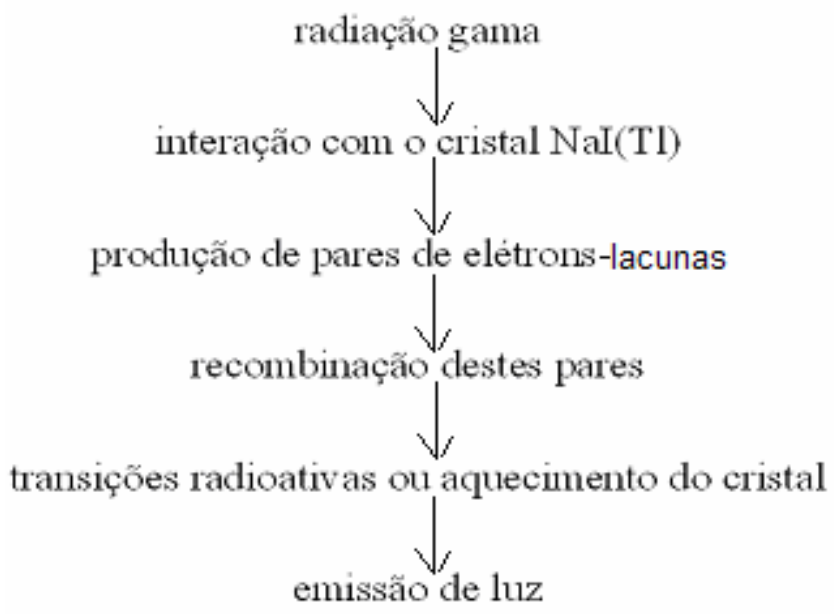

Figura 4-2. Eventos ocorridos no cristal cintilador até a emissão de luz captada pela fotomultiplicadora

Para cintilações do $\mathrm{NaI}(\mathrm{Tl})$, o intervalo de emissão luminosa está centrado em $415 \mathrm{~nm}$. Sem o ativador, no caso do iodeto de sódio o ativador é o tálio, o cristal produziria fótons longe da faixa visível da fotomultiplicadora que tornaria a detecção de luz difícil e o próprio material absorveria os fótons emitidos antes de chegarem à fotomultiplicadora.

\subsubsection{Eficiência do Cristal}

A eficiência do cristal é a relação da energia absorvida com a energia do fóton incidente no cristal. O fato de que em alguns casos não ocorre a absorção total de energia do fóton incidente está relacionado com diversas características do cristal como dimensão e blindagem.

Recordando os fundamentos da radiação gama, existem três tipos de interações de raios gama com o cristal. Vemos na Figura 3-3 que o tipo de material influencia na probabilidade de ocorrência de cada tipo de interação em função da energia.

Efeitos fotoelétricos usualmente ocorrem em energias baixas e efeitos de produção de pares ocorrem em energias altas. Se o tipo de material tender a ocorrer mais efeito fotoelétrico do que outro, este provavelmente terá um melhor coeficiente de absorção. 


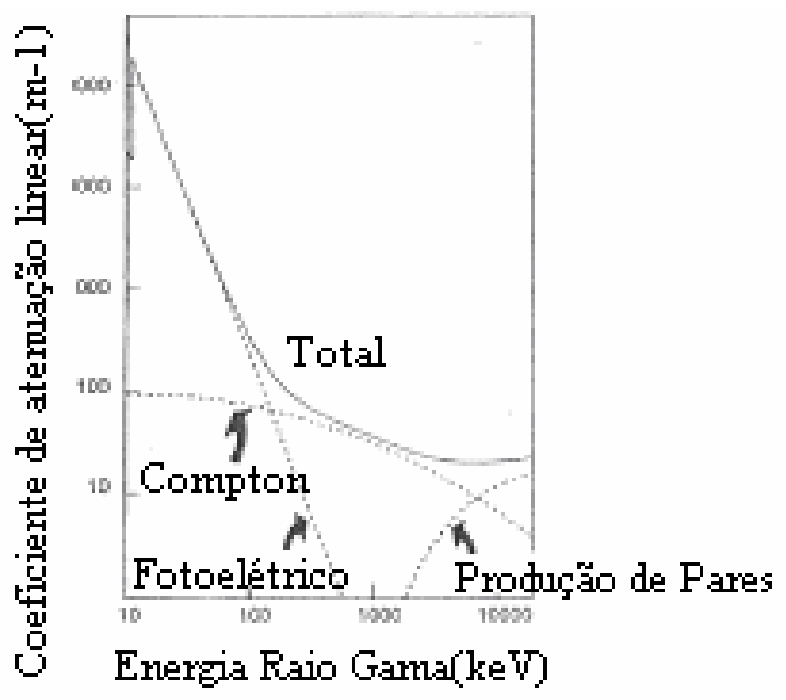

Figura 4-3. Coeficiente de atenuação linear do cristal NaI(Tl). Modificado de [5].

Na figura 3-4 vemos que quanto maior as dimensões do cristal, melhor será o coeficiente de absorção, pois, há maior número de interações do fóton gama incidente com o cristal antes do fóton escapar.

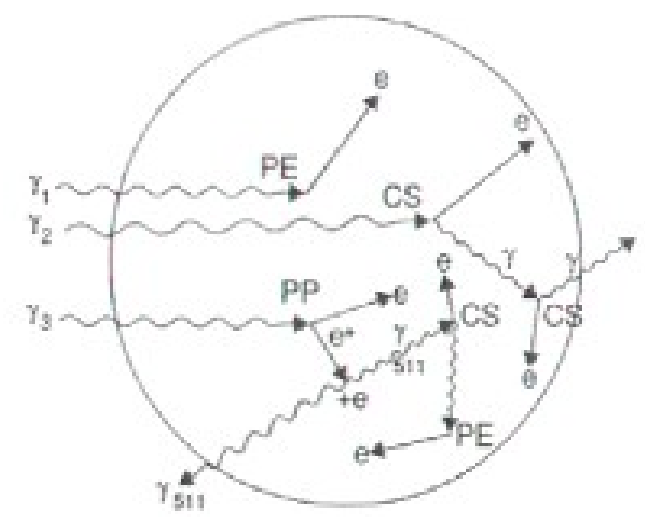

Figura 4-4. Interação do fóton com um detector. (PE - fotoelétrico, CS - espalhamento Compton, PP produção de pares). Extraído de [5].

\subsubsection{Resolução do Detector}

Os três principais fatores que afetam a resolução são: Produção de cargas no cristal, detecção de cargas na fotomultiplicadora e ruído eletrônico na detecção de pulsos.

A energia necessária para produzir-se um fotoelétron no fotocatodo da fotomultiplicadora é $170 \mathrm{eV}$. O desvio padrão da produção destas cargas é raiz quadrada do número de cargas, $\sigma= \pm \sqrt{n}$. O resultado da ativação $\mathrm{NaI}$ é um cristal que converte aproximadamente $12 \%$ da energia das partículas gama incidentes através de fótons de luz. A fotomultiplicadora coleta $20 \%$ das cargas produzidas pelo cristal. Com isto podemos estimar a resolução, $R=\frac{\sqrt{n}}{n} \times 100$, para uma energia de $1332.5 \mathrm{keV}$ é de $7,28 \%$. No caso do cristal semicondutor de Germânio que possui outras características e necessidade de $2,96 \mathrm{eV}$ para produção de um par elétronlacuna, a incerteza é de $0,218 \%$ para a mesma energia (fator de 0.03 em relação a NaI). [9] 
Ruídos eletrônicos interferem no sinal processado pelo pré-amplificador, amplificador e analisador multicanal. A amplitude dos ruídos costuma ser bem menor que a amplitude do sinal que se deseja ler, tendo uma incerteza pequena em relação às citadas anteriormente.

Um método para a determinação da resolução é a definição da máxima largura na meia altura (FWHM). A FWHM é definida como a largura $\Delta E$ a meia altura da distribuição gaussiânica, dividido pela energia central Eo do centróide $H_{0}$, como mostrado na figura 3-5 [10].

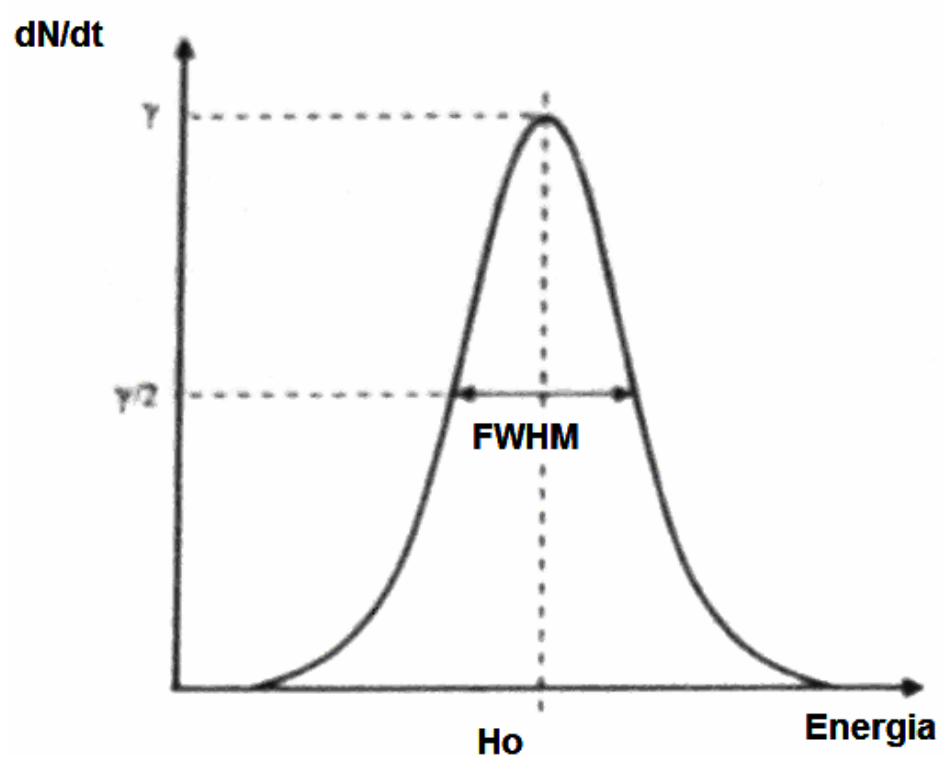

Figura 4-5. Definição de FWHM. Extraído de [10].

Quanto menor o valor de FWHM, melhor a qualidade do sensor, na discriminação de energia. Uma outra definição da resolução é uma razão mostrada em percentual, mostrada na equação 3.1 .

$$
R(\%)=\frac{F W H M}{H_{0}} \cdot 100
$$

Quanto menor o valor de $R$, melhor a qualidade do sensor.

\subsubsection{Emissão Luminosa no Cintilador}

A excitação do ativador decai exponencialmente com o tempo, devido ao efeito de luminescência.

A meia-vida do estado do ativador excitado é muito curta, em torno de $230 \mathrm{~ns}$ para cristal de $\mathrm{NaI}(\mathrm{Tl})$. Isto ocorre devido à transição do estado excitado para o estado normal do elétron. Também pode ocorrer excitação térmica para um nível metaestável antes de ser de-excitado o que torna a meia-vida destas excitações mais longas que as normais. $\mathrm{O}$ decaimento lento proporcional da luz emitida por estas de-excitações longas é chamada de fosforescência. Em cristais $\mathrm{NaI}(\mathrm{Tl})$, por exemplo, onde a meia-vida da cintilação primaria é $230 \mathrm{~ns}, 9 \%$ da luz total é emitida como fosforescência com um tempo de decaimento de $150 \mathrm{~ms}$. [9] 


\subsection{Fotomultiplicadora}

A fotomultiplicadora é uma válvula de alto vácuo de vidro dotado de uma janela óptica, um fotocatodo e uma série de eletrodos chamados dínodos. A luz do cintilador libera elétrons do fotocatodo pelo efeito fotoelétrico. Estes elétrons não são em número ou energia suficientes para existir detecção confiável pela eletrônica convencional. Entretanto num tubo fotomultiplicador, estes são atraídos por uma diferença de potencial alta pelo dínodo mais próximo. [8]

Os fotoelétrons são focalizados sobre o primeiro dínodo com energia suficiente para liberar vários novos elétrons para cada fotoelétron, multiplicando-os. A segunda geração de elétrons é atraída para o segundo dínodo onde um grande grupo da terceira geração de elétrons é emitido. No último dínodo, elétrons suficientes estão disponíveis para formar um pulso de corrente adequado para a detecção na entrada do pré-amplificador. [8]

A capacidade de discriminação de alturas de pulso (resolução) do sistema de detecção depende da coleta do maior número possível de fótons criados pela radiação gama incidente. O ganho de multiplicação de elétrons na fotomultiplicadora é um valor de $10^{7}$ a $10^{10}$ elétrons no anodo (base da fotomultiplicadora) para cada fóton incidente no fotocatodo [5].

\subsection{Pré-amplificador}

A carga coletada no anodo da fotomultiplicadora é relativamente pequena. Um préamplificador, em geral na base do fototubo, é utilizado para converter o pulso de corrente num pulso de tensão proporcional à carga transferida do anodo para o pré-amplificador.

\subsection{Amplificador}

O sinal de saída do pré-amplificador possui decaimento devido ao efeito de luminescência e fosforescência do cristal cintilador citado anteriormente. A cada novo fóton absorvido pelo cristal é gerado um impulso com amplitude proporcional à energia do fóton gama absorvido.

O que interessa para o analisador multicanal é a amplitude de cada pulso e quantos deles são detectados. A função do amplificador é gerar e conformar pulsos individuais para cada cintilação de radiação incidente no cristal e amplificar sua amplitude para uma melhor leitura pelo analisador multicanal. [5]

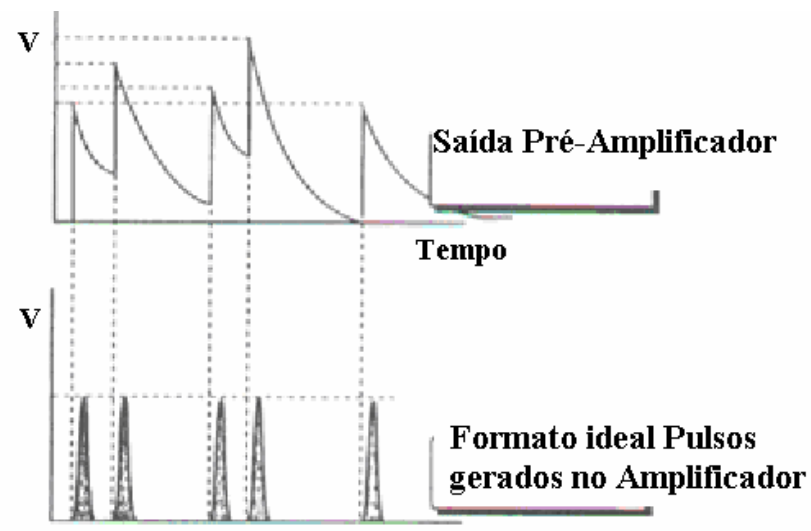

Figura 4-6. Sinal de saída do pré-amplificador e sinal de pulsos gerados por um amplificador ideal.

Extraído e modificado de [5] 
$\mathrm{Na}$ figura 3-6 são mostrados o sinal de entrada do amplificador e o formato dos pulsos desejados na saída.

\subsection{Analisador Multicanal}

$\mathrm{O}$ analisador multicanal tem a função de detectar cada pulso individualmente e medir sua respectiva amplitude, realizando a contagem destes pulsos em canais de energia, formando um espectro de freqüência de energia armazenado em memória na forma de histograma.

Os nuclídeos gama emissores emitem radiação com energias bem definidas. No caso do ${ }^{137} \mathrm{Cs}$, por exemplo, a energia de radiação gama emitida é de $661,6 \mathrm{keV}$. Na figura 3-7 podemos observar o espectro de energia do elemento Césio, onde se tem uma contagem alta no canal da faixa de energia que se encontra em $661,6 \mathrm{keV}$. Há também contagens em canais de energia menores referentes ao efeito Compton e em canais de energia maiores pelo efeito pile-up, que é o empilhamento de dois pulsos próximos. [5]

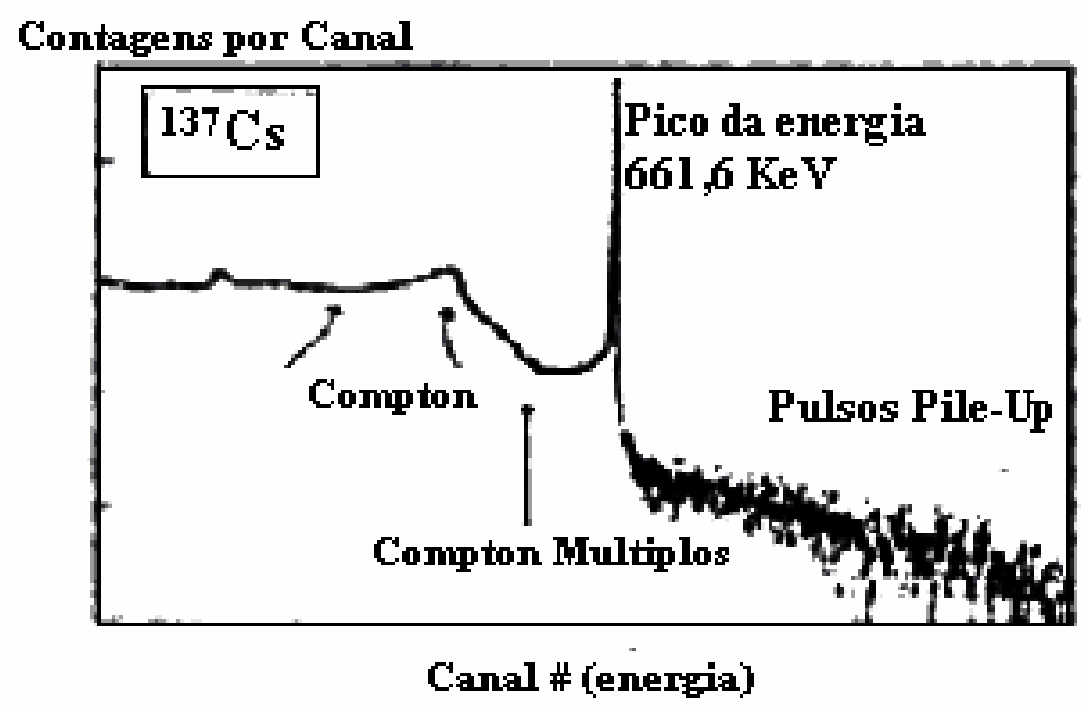

Figura 4-7. Espectro de energia do elemento Césio. Extraído e modificado de [5]

\subsection{Computador}

O computador realiza correções, processamento e armazenamento dos dados adquiridos no analisador multicanal. Também realiza a interface gráfica, permitindo a visualização do espectro de freqüência de energia. 


\section{Estudo de Desenvolvimento do Projeto}

O gamaespectrômetro digital é formado por: detector de radiação, eletrônica do detector e armazenador de dados. Na figura 4-1, pode-se ver um diagrama de um gamaespectrômetro digital.

Neste projeto usou-se um conjunto detector $\mathrm{NaI}(\mathrm{Tl})$ existente e seu sistema de polarização de alta voltagem. O objetivo do projeto é o desenvolvimento do circuito do equipamento gamaespectrômetro digital e o sistema de aquisição de dados.

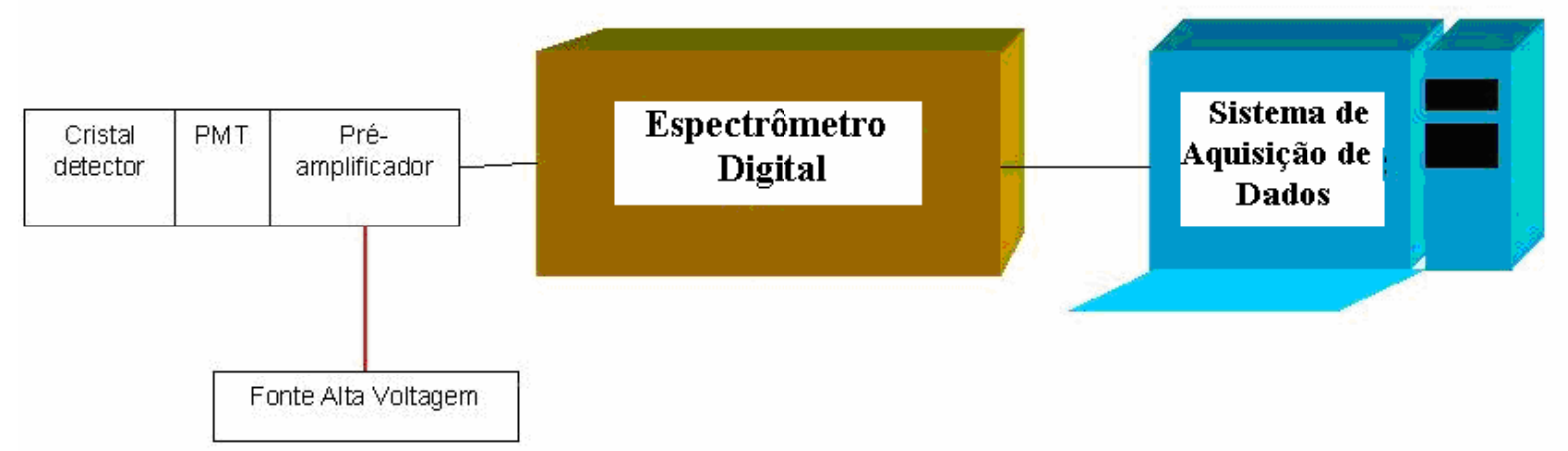

Figura 5-1. Esquema de um gamaespectrômetro digital

Comparando com o diagrama teórico do gamaespectrômetro da figura 3-1, a eletrônica do sistema espectrômetro digital substitui o bloco do amplificador e analisador multicanal. $\mathrm{O}$ sistema de aquisição de dados substitui o bloco do computador.

Neste capítulo será descrito todo o estudo do planejamento do projeto, as possibilidades para execução e tomada de decisões comparando diferentes aspectos. $\mathrm{O}$ estudo tem como principais pontos:

- Modelo de um detector de fótons gama: Primeiro foi feito um modelo do comportamento do sinal de saída do pré-amplificador para verificar as necessidades para se implementar o projeto.

- Circuito amplificador: Verificar a necessidade de se amplificar o sinal, ampliando a faixa de entrada do conversor analógico digital, sem exceder o valor máximo. Estudo de um circuito integrador para conformar o pulso.

- Conversor Analógico Digital: Verificação da taxa de amostragem mínima para o projeto sem perda de resolução.

- Detector de Pico Digital: Estudo de algoritmos para detectar pulsos individuais e relacionar estes com sua energia específica. Estudo do tipo de componente utilizado para execução da lógica do detector.

- Analisador Multicanal: Estudo da estrutura de dados e comunicação com o PC. 


\subsection{Modelagem dos sensores e fontes de radiação em Interface MATLAB}

O projeto de modelo dos sensores tem como objetivo modelar as fontes de radiação, os detectores de fótons gama e o gamaespectrômetro. Com este modelo é possível evitar várias dificuldades no estudo, pois realizam-se simulações antes de entrar em laboratório.

\section{Modelo Espectrômetro de raios Gama}

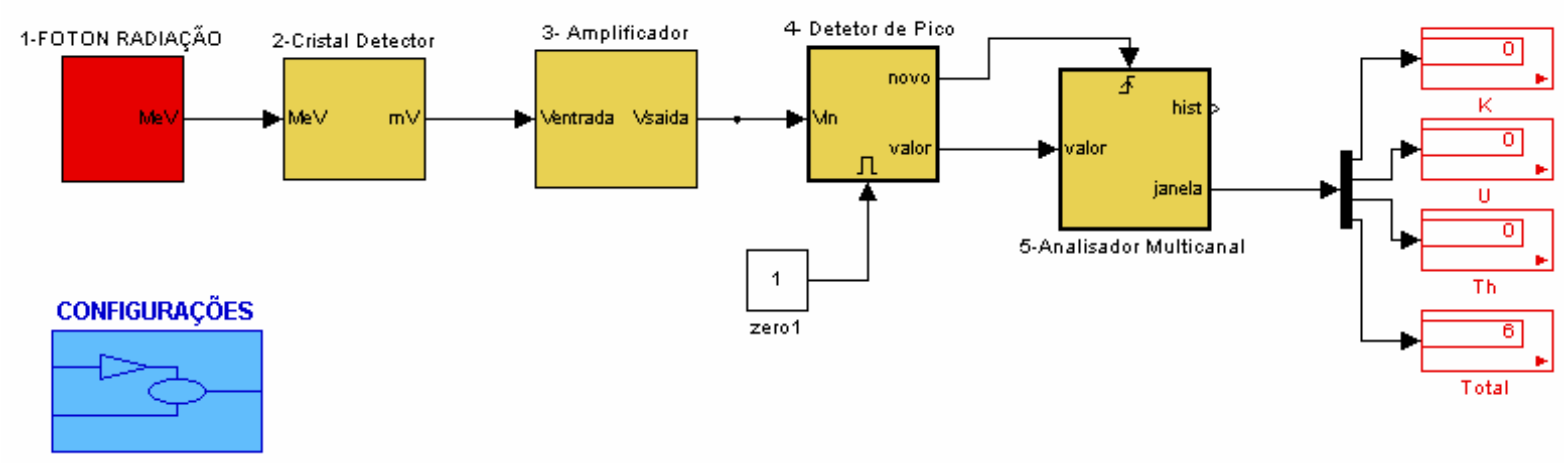

Figura 5-2. Modelo do espectrômetro realizado em Simulink com funções em MATLAB.

O modelo é dividido em blocos (veja figura 4-2) que são detalhados abaixo:

1-Fóton de Radiação: gera os pulsos de energia que incidem no cristal em relação ao tempo. Estes pulsos são gerados através da função de Poisson tendo o valor de $\lambda$ a quantidade de pulsos por segundo dividido pela freqüência de leitura da função. A função é gerada para 5 energias diferentes.

2-Cristal: possui três partes básicas. A primeira parte determina a energia absorvida pelo cristal do fóton incidente através de diversas interações até o fóton escapar do conjunto.

A segunda parte determina a incerteza da produção de pares elétron-lacuna da energia absorvida e a incerteza da coleta deste na saída do detector com a fotomultiplicadora.

E a terceira parte determina o sinal da saída do pré-amplificador. Ela apresenta o decaimento da energia detectada pelo cristal e converte a energia em voltagem elétrica, função do subsistema pré-amplificador do modelo de blocos não simplificado.

3- Amplificador: Circuito em sinal contínuo que transforma os impulsos de entrada em pulsos individuais mais largos.

4- Detector de Pulso: Possui algoritmo para a detecção de novo pulso, determina o valor relacionado do impulso do sinal e elimina empilhamento de pulsos para verificar o comportamento do projeto antes de sua implementação prática.

5- Analisador Multicanal (MCA): Este subsistema armazena cada pulso detectado e o valor de energia relacionado à amplitude deste pulso. Transforma estes impulsos em um espectro de contagem de energia.

6- Configurações: Este subsistema permite mudar diferentes parâmetros relacionados ao modelo, como dimensão do cristal, número de canais do espectro, taxa de amostragem do ADC, etc. 


\subsection{Modelagem do Circuito Amplificador}

O amplificador possui dois propósitos principais:

1) Amplificar o sinal do pré-amplificador;

2) Conformar o pulso numa forma conveniente para o processamento posterior, a detecção de pulso.

Em ambos os casos o amplificador deve sempre preservar a informação de interesse, que é a relação entre a amplitude de entrada e saída (amplificação linear). O amplificador deve ter uma resposta muito rápida para acompanhar o tempo de subida do impulso.

A remodelagem do pulso é importante para aumentar a relação sinal-ruído. O tempo de duração do novo pulso não deve ser muito longo para evitar o empilhamento de pulsos (pileup) [9].

Um método de encurtamento do pulso (diminuir a largura do pulso) é usar um filtro passa-alta (tipo CR derivador) mostrado na figura 4-3.
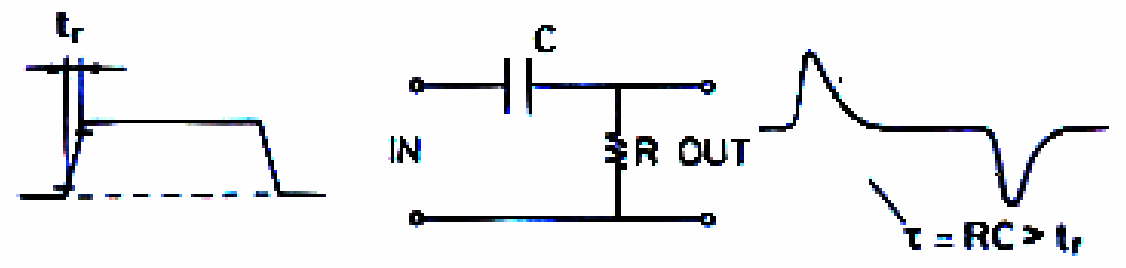

Figura 5-3. Circuito CR derivador. Extraído de [9].

Complementando o filtro $\mathrm{CR}$ usou-se o filtro passa-baixa (tipo RC integrador) que funciona bem se a constante do tempo for maior que a largura do pulso [9]. A principal aplicação é eliminação dos ruídos, suavizando flutuações aleatórias em alta freqüência. Este filtro afeta o tempo de subida do sinal, como visto na figura 4-4.

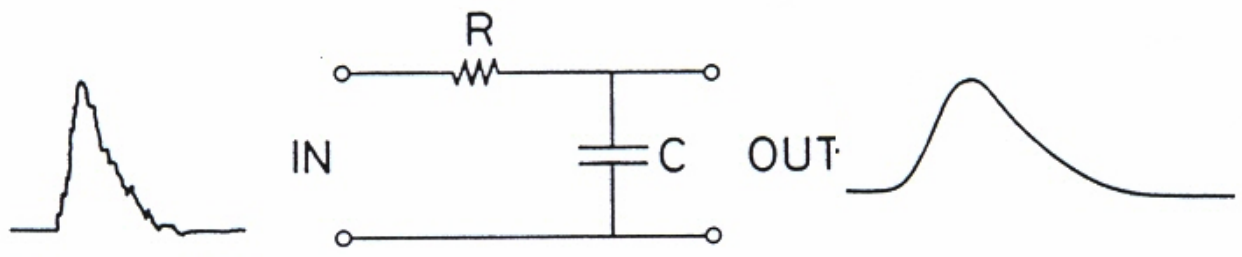

Figura 5-4.Circuito RC integrador. Extraído de [9].

Os dois tipos de filtros possuem freqüência de corte mostrada na equação 4.1. O filtro derivador atenua freqüências abaixo de freqüência de corte e o filtro integrador atenua freqüências acima da freqüência de corte.

$$
f C=\frac{1}{2 \cdot \pi \cdot R \cdot C}
$$

Filtros CR-RC são usados para remodelar a forma do pulso enviando o sinal através de filtros $\mathrm{CR}$ derivador e $\mathrm{RC}$ integrador em cascata. Na maioria dos casos, a relação sinal-ruído ótima é 
obtida igualando-se a constante de tempo do circuito CR e RC. O valor absoluto da constante de tempo depende das características particulares do pulso. Um circuito CR-RC típico é mostrado na figura 4-5 com a forma resultante do pulso.

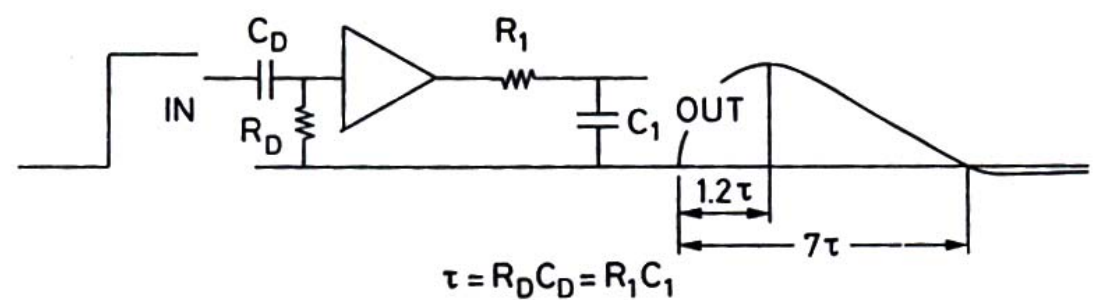

Figura 5-5. Circuito CR-CR. Extraído de [9].

Um dos efeitos indesejados do filtro CR-RC é a presença de um nível negativo no pulso de saída. Isto é um problema para a análise da amplitude do pulso, pois, se um segundo pulso aparecer enquanto o nível de saída ocasionado pelo primeiro ainda estiver negativo, ocasionará uma diferença na leitura da amplitude do segundo pulso remodelado na saída. Isto ocorre quando o circuito CR-RC se comportar como um circuito estável subamortecido.

Este subnivelamento pode ser corrigido por um circuito de cancelamento de pólo-zero mostrado na figura 4-6. A correção é feita com a adição de um resistor paralelo no capacitor no circuito CR com um valor ajustado para igualar um dos pólos com o zero acrescentado pelo resistor na transformada de Laplace deste circuito [9].
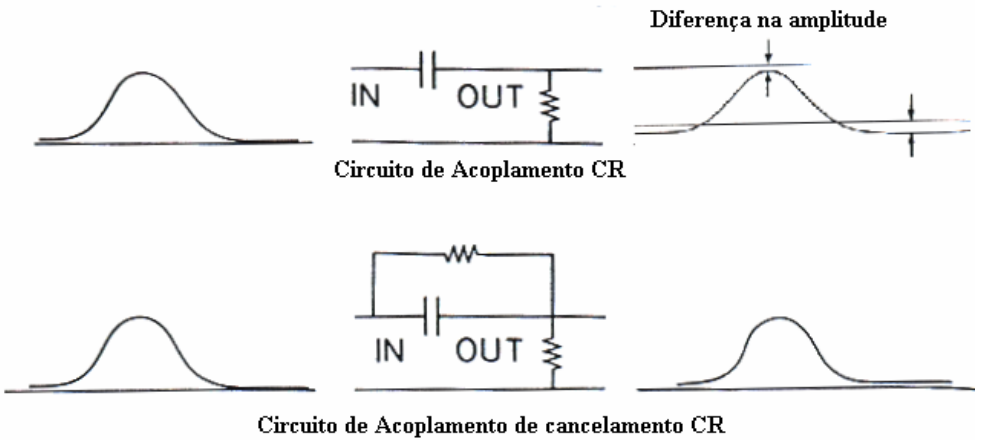

Figura 5-6. Circuito de cancelamento de pólo-zero. Extraído de [9].

Uma forma de pulso teoricamente desejada para cada impulso de entrada seria um pulso gaussiano, melhorando a performance. Uma aproximação de um pulso semigaussiano pode ser formada com uma rede consistindo de um circuito derivador seguido de 4 circuitos integradores em cascata formando um circuito CR-RC-RC-RC-RC. A desvantagem deste circuito em cascata é a largura maior do pulso em relação ao circuito CR-RC que prejudica a leitura em altas taxas de contagem por ocorrer empilhamento de pulsos [9].

Estes circuitos são analógicos e foram abordados para sabermos o que é necessário para se obter um amplificador ótimo. O problema destes circuitos analógicos é a difícil calibração de valores exatos em capacitores e resistores, variações não lineares com o tempo e temperatura e a alta aquisição de ruídos. A seguir iremos realizar o modelo de diferentes filtros baseados na teoria CR-RC sem os problemas dos circuitos analógicos. 


\subsubsection{Circuito Amplificador em PSPICE}

Utilizou-se o software OrCAD PSpice Student para simular o circuito amplificador teórico demonstrado acima. Primeiro modelou-se um impulso com decaimento num período de aproximadamente 2 microsegundos. Então foram realizados os circuitos mostrados na figura 4-7.

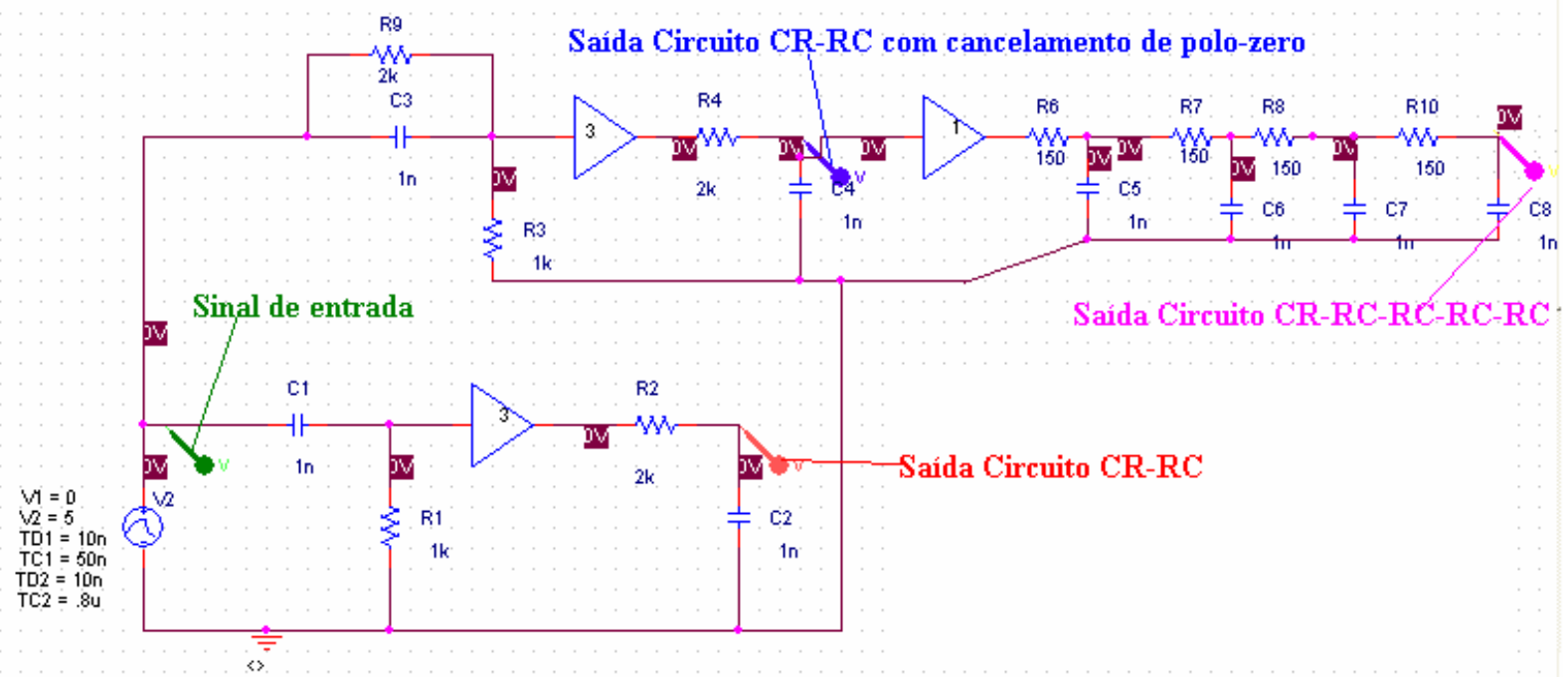

Figura 5-7. Circuito amplificador modelado no PSpice.

Foi realizada a simulação deste circuito e se obtiveram 4 gráficos, um do pulso de entrada modelado e os outros de três sinais de saída do circuito CR-RC, circuito com cancelamento de pólo-zero e circuito CR-RC-RC-RC-RC. Os circuitos foram modelados diversas vezes para analisar as formas de onda e poder ajustar os parâmetros (valores dos diferentes resistores e capacitores) para se obter formas de ondas esperadas na teoria, como pode ser visto na figura 4-8.

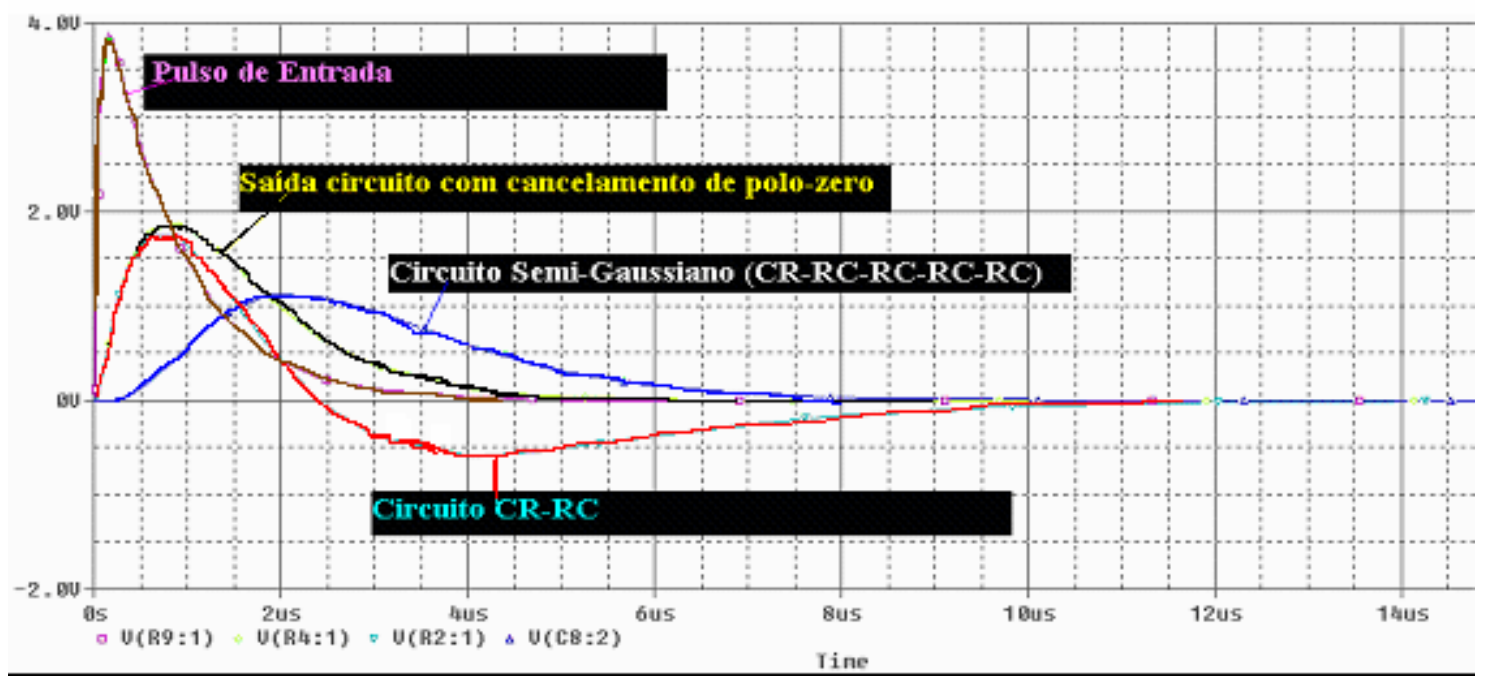

Figura 5-8. Resposta de 3 tipos de circuitos amplificadores.

O circuito semigaussiano obteve uma forma de onda desejada, mas com uma largura de pulso que deverá ser diminuída. 


\subsubsection{Circuito Integrador em PSPICE}

Um dos métodos utilizados para circuitos amplificadores em espectrômetros é a utilização de amplificadores operacionais nos circuitos. Um exemplo é o circuito integrador cuja simulação do comportamento pode ser vista na figura 4-9.
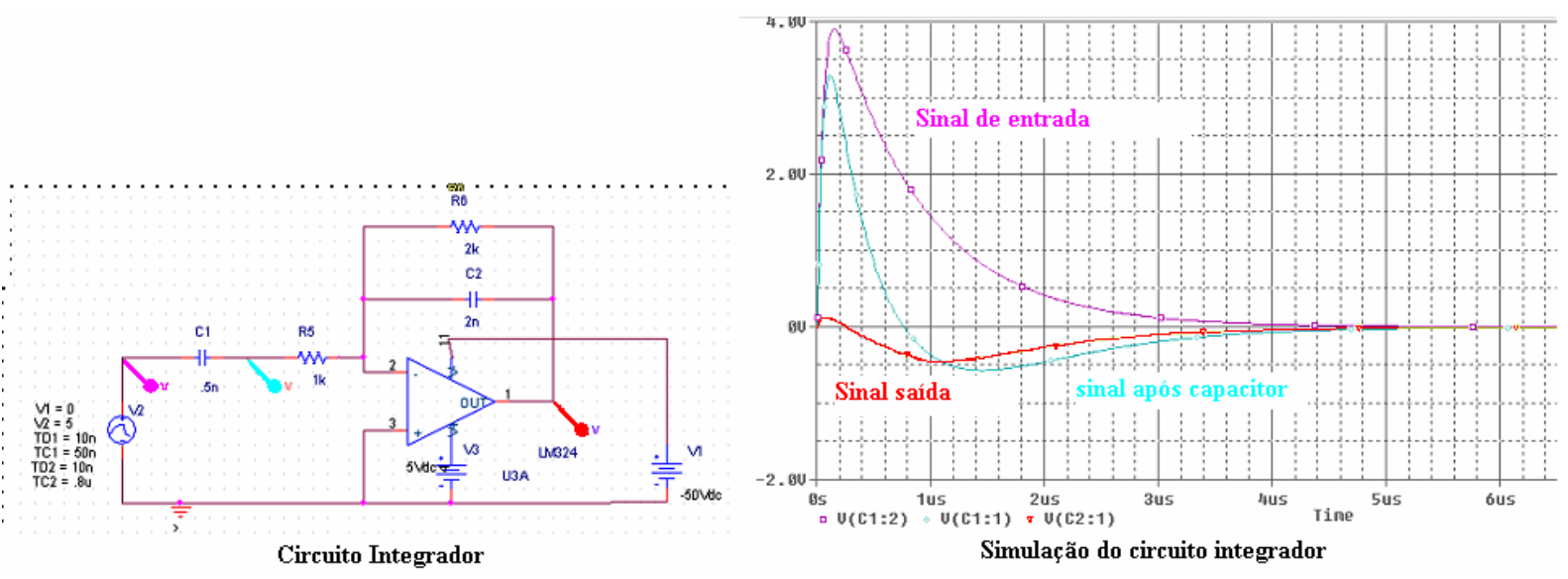

Figura 5-9. Circuito integrador (esquerda) e o resultado obtido (direita).

Vimos que com o circuito integrador temos a forma do pulso similar à forma de pulso inversa do circuito semigaussiano. Não foi necessário utilizar circuito de cancelamento de pólo-zero e o período do pulso de saída foi de aproximadamente 4 microsegundos.

Lembrando que em um capacitor $V=q / C$, onde $q$ é a carga elétrica, e a carga elétrica é a integral da corrente elétrica em função do tempo, então temos:

$$
V o=-\frac{1}{R_{5} \cdot C_{2}} \int V i . d t \text { onde } R_{5} \cdot C_{2}=\tau
$$

Ou seja, a tensão de saída é igual à integração da tensão de entrada ao longo do tempo.

Também pode ser usado circuito amplificador logarítmico para remodelar o pulso de entrada. Se o elemento de realimentação for um componente não linear, o resultado será um amplificador logarítmico. O resultado é mostrado na figura 4-10 e sua tensão de saída, Vo, será:

$$
V o=a \cdot \ln \left(b \cdot \frac{V i}{R}\right) \quad \text { onde } a \text { e } b \text { são constantes. }
$$

No resultado da figura 4-10 vemos a forma de pulso de saída. O diodo serve para não ser realizada a operação logarítmica (equação 4.3) quando o valor do sinal de entrada for negativo. $\mathrm{O}$ offset da saída do sinal deve-se a presença do diodo. 


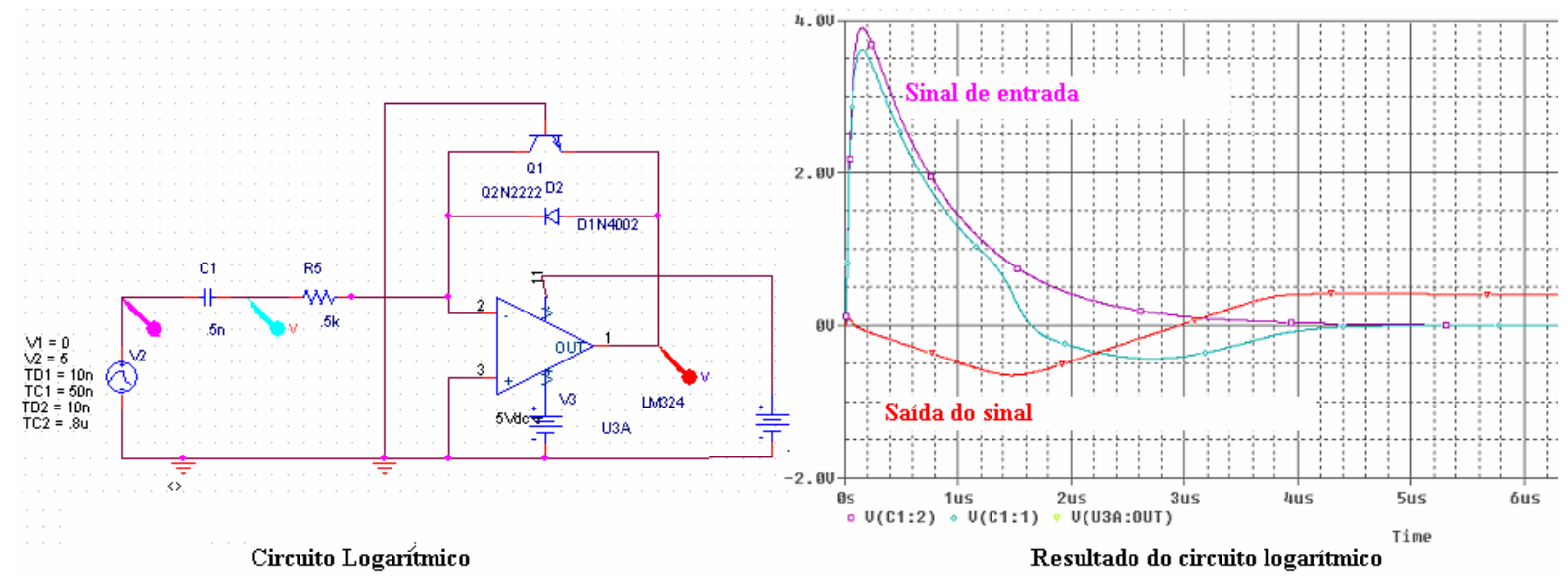

Figura 5-10. Circuito amplificador logarítmico modelado no PSpice.

\subsubsection{Circuito Amplificador digital em MATLAB}

Neste item foi usado o software MATLAB/Simulink, um programa matemático que permite realizar circuitos em blocos. Os circuitos amplificadores simulados em PSpice serão convertidos utilizando a transformada de Laplace.

As transformadas de Laplace [11] dos circuitos CR-derivador e RC-integrador são:

$$
H_{\text {Derivador }}(s)=\frac{s}{s+\frac{1}{\tau}} \quad H_{\text {Integrador }}(s)=\frac{1}{\tau . s+1} \quad \text { onde } \tau=R . C
$$

Na figura 4-11 é apresentado o bloco do circuito amplificador no modelo do espectrômetro, com as mesmas características do modelo utilizado em PSpice na figura 4-7.

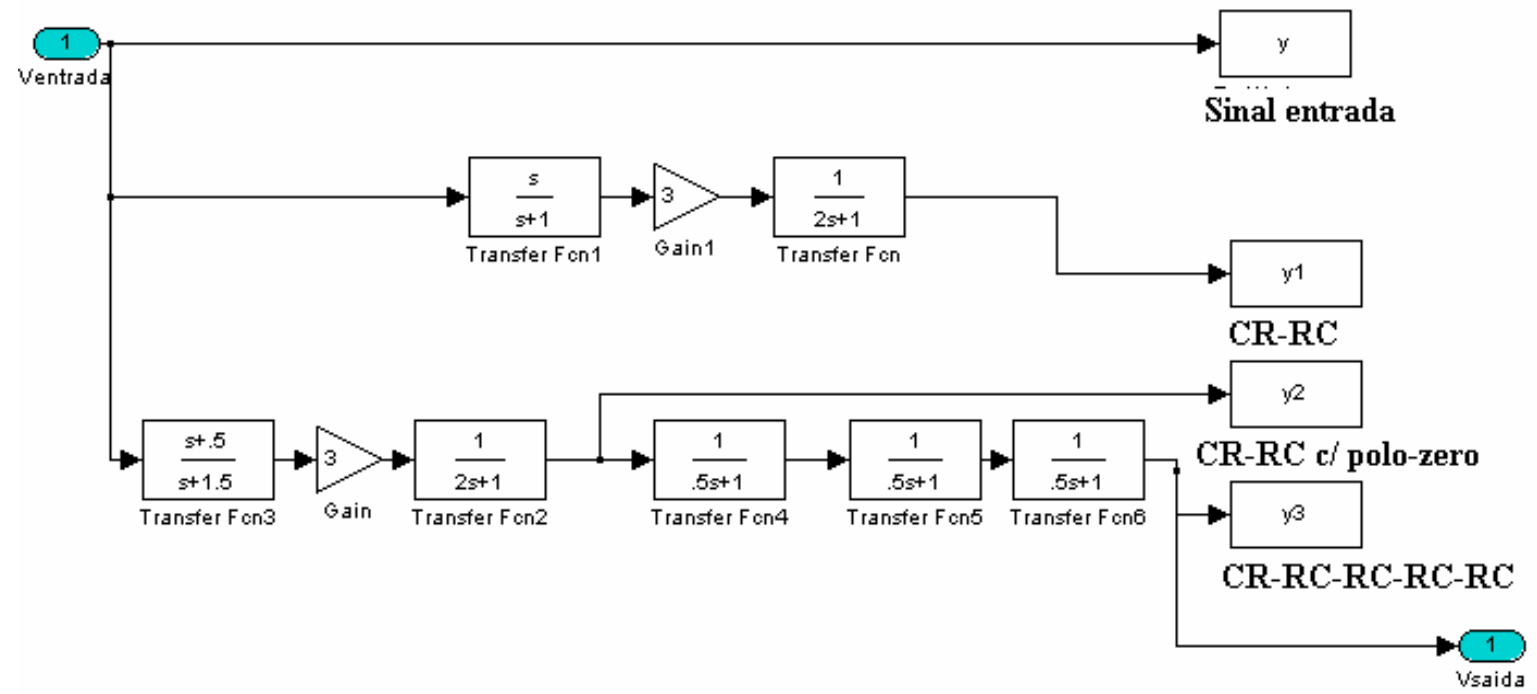

Figura 5-11. Circuito amplificador em MATLAB.

Na figura 4-12 é vista a forma de onda em uma simulação com o modelo da figura 4-11. 


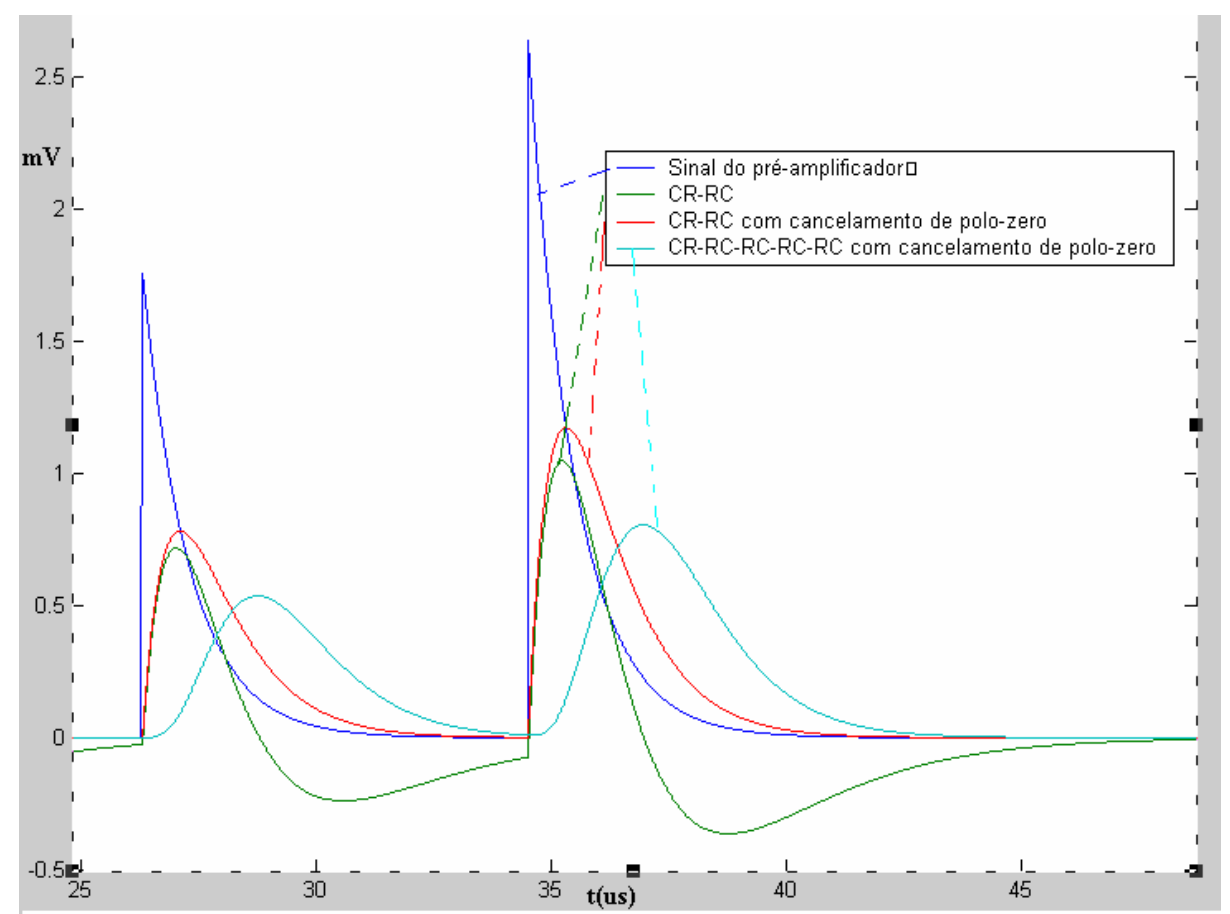

Figura 5-12. Resultado de simulação do amplificador com o modelo do gamaespectrômetro desenvolvido.

Verificou-se que a saída utilizada no bloco amplificador é o pulso do circuito CR-RC-RCRC-RC simulado no PSpice.

A transformada de Laplace é utilizada para circuitos de sinal contínuo, ou seja, circuitos analógicos. Para a realização do modelo acima necessitaria utilizar componentes eletrônicos analógicos como indutor, capacitor e resistores. Como a intenção é utilizar dispositivos digitais para realizar o circuito detector de pulso, modelou-se este mesmo circuito amplificador em um circuito de sinal discreto, ou seja, um circuito digital. O sinal em tempo discreto é obtido utilizando um conversor analógico-digital (ADC) com uma freqüência de amostragem específica.

Para realizar um circuito digital de processamento de sinais é importante usar a transformada $\mathrm{Z}$ para converter circuitos analógicos para circuitos digitais. Um método de aproximação da transformada de Laplace para Z é o método de Tustin [12], mostrado na equação 4.5.

$$
s=\frac{2 .}{T s}\left(\frac{z-1}{Z+1}\right), \text { onde Ts é o tempo de amostragem em segundos. }
$$

Convertendo o circuito CR-RC-RC-RC-RC da figura 4-11 para amostragem de 20 e $80 \mathrm{MHz}$ [13], obtemos o circuito mostrado na figura 4-13. 
Filtro Amplificador Contínuo (desejado)

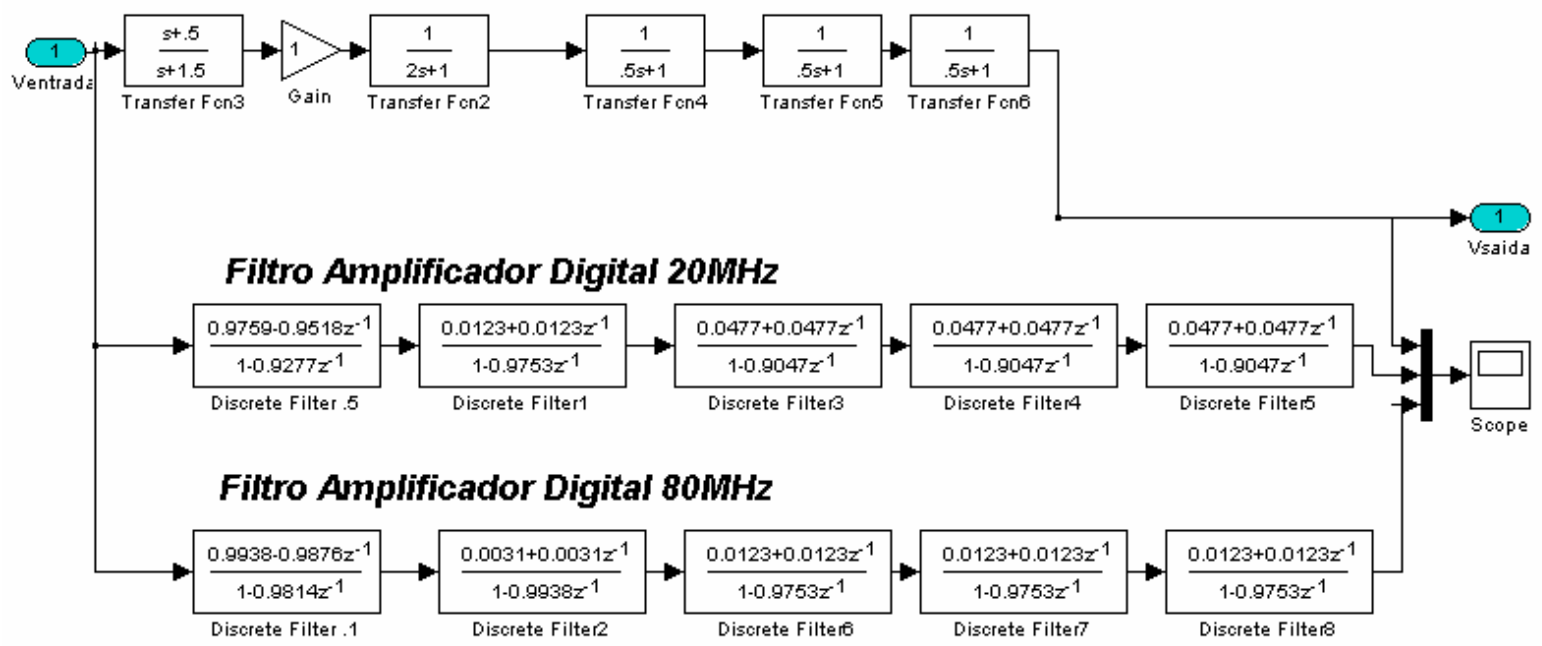

Figura 5-13. Circuito amplificador em tempo contínuo e discreto em MATLAB.

A função de transferência em transformada $Z$ é facilmente realizável em circuitos digitais através de uma transformação matemática simples, como mostrado nas equações 4.6 e 4.7. $\mathrm{O}$ filtro $H(Z)$

$$
H(Z)=\frac{Y(z)}{X(z)}=\frac{a-b . z^{-1}}{1-c \cdot z^{-1}}
$$

Pode ser matematicamente representado por

$$
y[k]=a \cdot x[k]+b \cdot x[k-1]-c \cdot y[k-1]
$$

Ou representado por circuitos lógicos como mostrado na figura 4-14 [12].

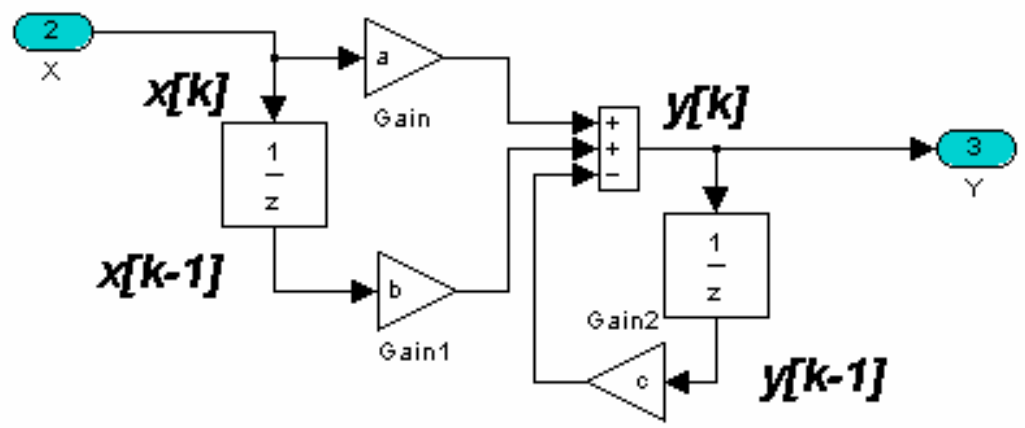

Figura 5-14. Circuito lógico similar à equação 4.7.

A equação matemática pode ser programada em microcontrolador, DSP ou em dispositivo lógico programável como CPLD e FPGA.

Para este projeto, foi escolhido o uso de dispositivo lógico para se ter um ganho na velocidade de processamento do sinal de entrada. Um dispositivo lógico programável realiza processamento de sinais através de blocos de operações que são operados paralelamente 
enquanto o DSP ou microcontrolador processa sinais com seqüências de instruções em um processador central. Escolheu-se utilizar CPLD por ter um custo menor que FPGA.

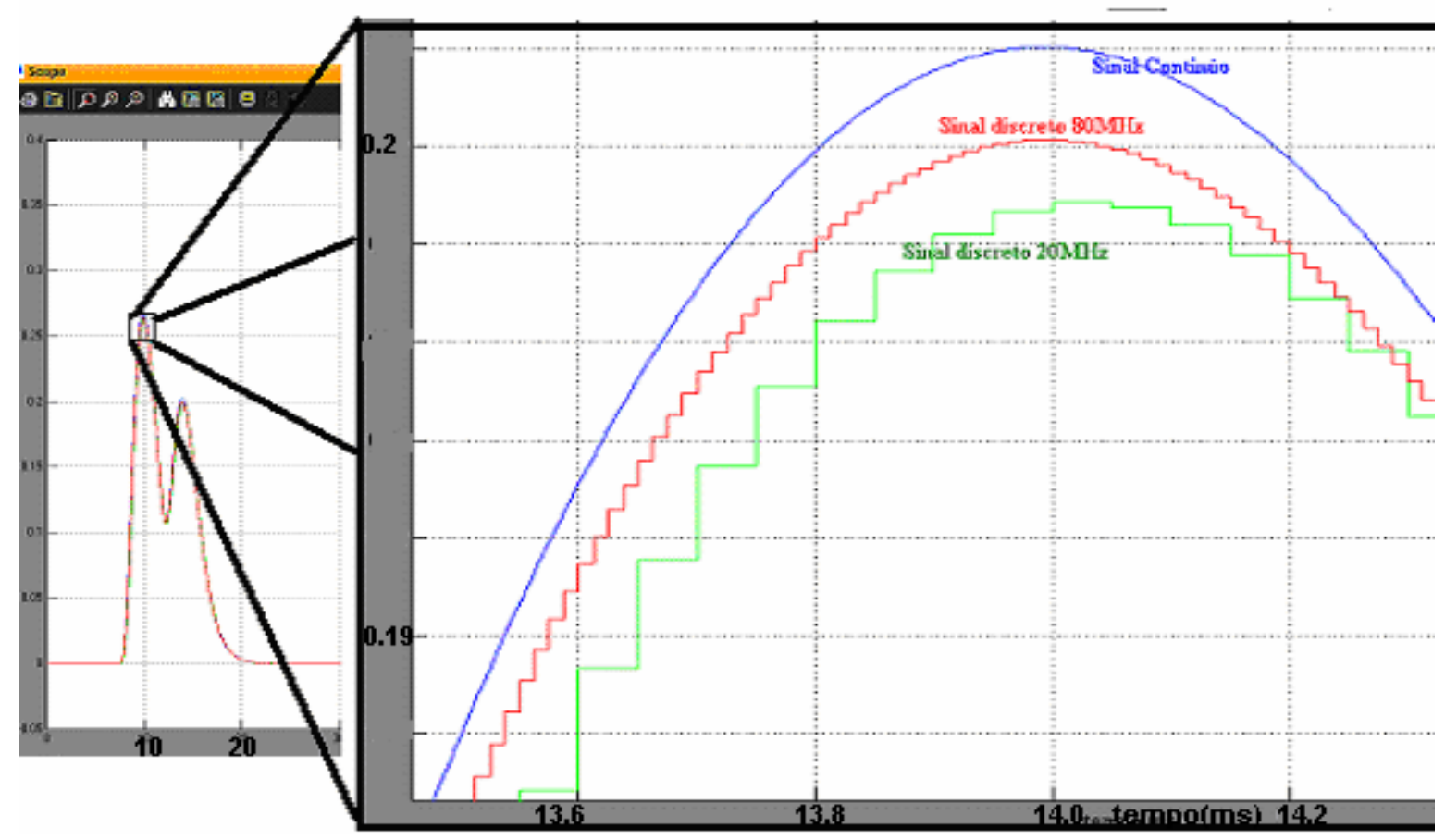

Figura 5-15. Comparação da amplitude de diferentes filtros amplificadores.

Numa simulação mostrada na figura 4-15 vimos que há diferenças entre as amplitudes do filtro contínuo e dos filtros digitais na taxa de amostragem em 20 e $80 \mathrm{MHz}$. Esta diferença se deve ao arredondamento dos coeficientes a até 4 casas decimais dos filtros digitais. A diferença é aceitável, pois é proporcional em diferentes amplitudes. Como o importante é manter a relação linear da amplitude de entrada com a amplitude do pulso individual de saída verificou-se que um conversor analógico de $20 \mathrm{MHz}$ é suficiente para ser utilizado em um espectrômetro com pulsos de duração de 2 microsegundos, tendo 40 amostras por pulso não se perde a informação da amplitude.

\subsection{Modelagem do Detector de Pulso}

O detector de pulso é um dispositivo que organiza pulsos recebidos pelo amplificador de acordo com sua amplitude. O Detector de Pulso possui três funções principais:

1) Detectar novo pulso na saída do amplificador;

2) Eliminação de empilhamento de pulsos (pile-up);

3) Mensurar o pulso proveniente do amplificador relacionado à energia incidente no detector.

A detecção de um novo pulso é um circuito muito simples. Foi determinado um nível de sinal mínimo para que o circuito detecte um novo pulso, assim ignorando variações pequenas de tensão. Este nível é chamado de threshold, e basta utilizar um comparador tendo como saída nível alto se o sinal de entrada é maior que o nível threshold como mostrado na figura 4-16. Este circuito será descrito como um circuito discriminador de pulso lento [9]. 


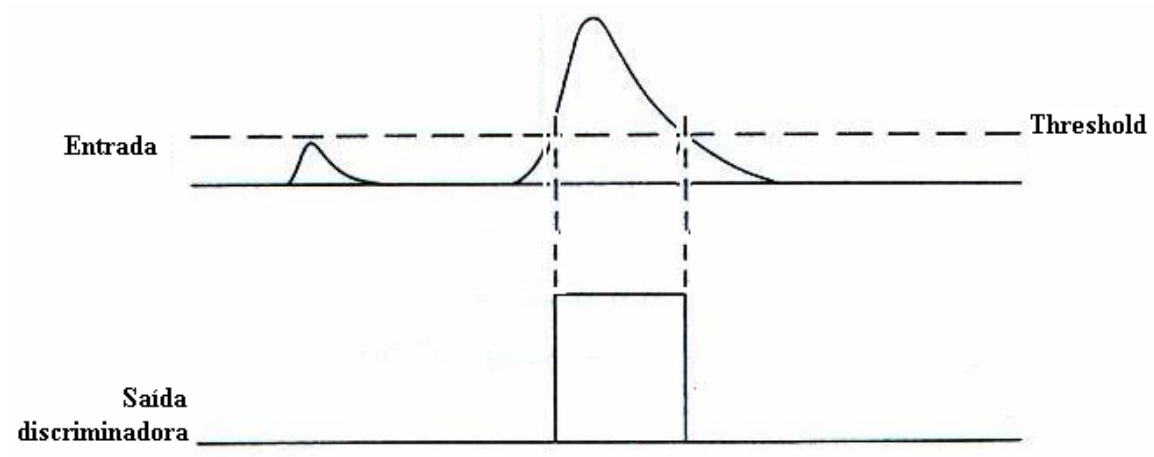

Figura 5-16. Circuito de detecção de novo pulso. Extraído de [9].

Aplicando um circuito diferenciador CR-CR teremos a segunda derivada do pulso que deve ser detectado. Este circuito será chamado de discriminador rápido, daí podemos discriminar apenas o início de subida de um pulso. Então se um segundo pulso for detectado pelo discriminador rápido enquanto o discriminador lento ainda acusa a ocorrência de um pulso, teremos um sinal lógico demonstrando a ocorrência de pile-up [5]. Um exemplo pode ser visto na figura 4-17.

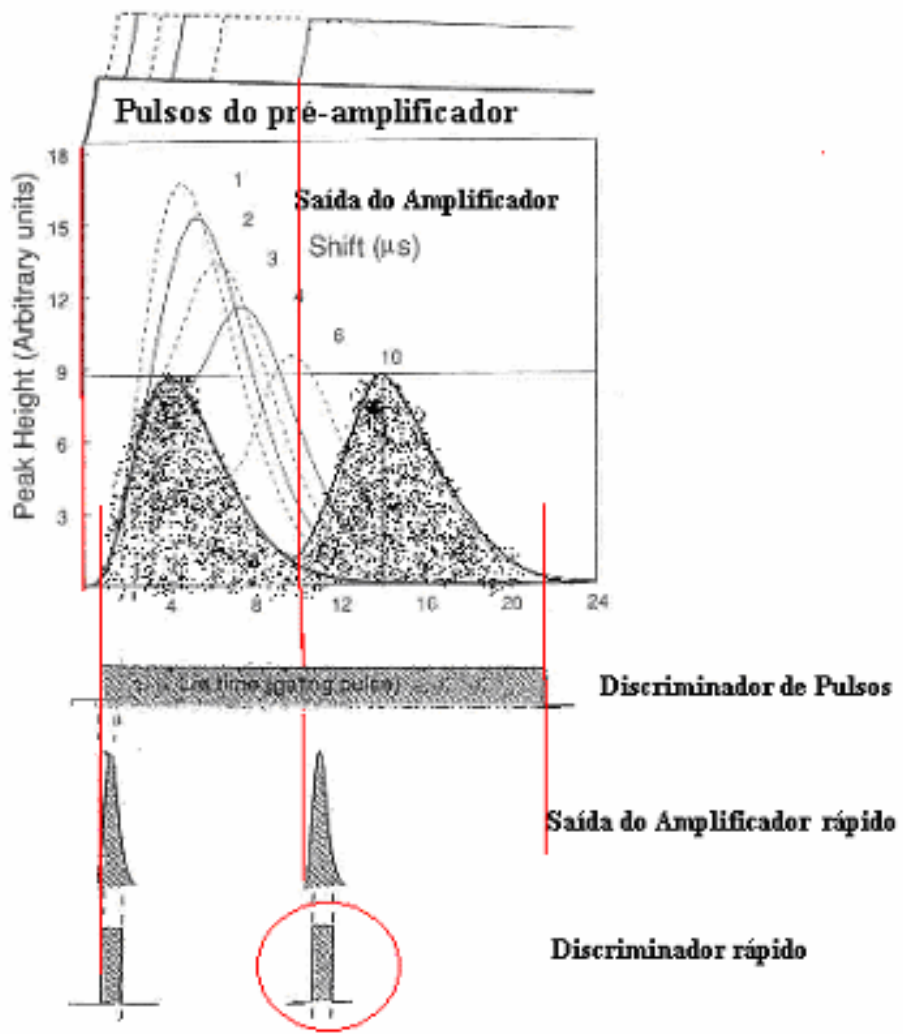

Figura 5-17. Demonstração de detecção e eliminação de pile-up. Extraído de [5].

$\mathrm{O}$ circuito mensurador de pulso irá funcionar quando o sinal do circuito discriminador de pulso estiver ativo. Este circuito é bem simples e irá determinar o valor máximo enquanto o pulso estiver sendo detectado, informando sua amplitude. Além de determinar apenas o valor máximo, este circuito pode também somar todos os valores durante a detecção do pulso, informando a área do pulso de entrada. 
A correção do sinal de threshold deverá ser feita junto com a correção linear, que irá relacionar a tensão da amplitude do pulso com um valor de energia.

Foi modelado o Detector de Pulsos em um bloco no modelo do gamaespectrômetro em MATLAB. Este bloco realiza todas as funções de um detector de pulsos descrito anteriormente e seu modelo pode ser visto na figura 4-18.

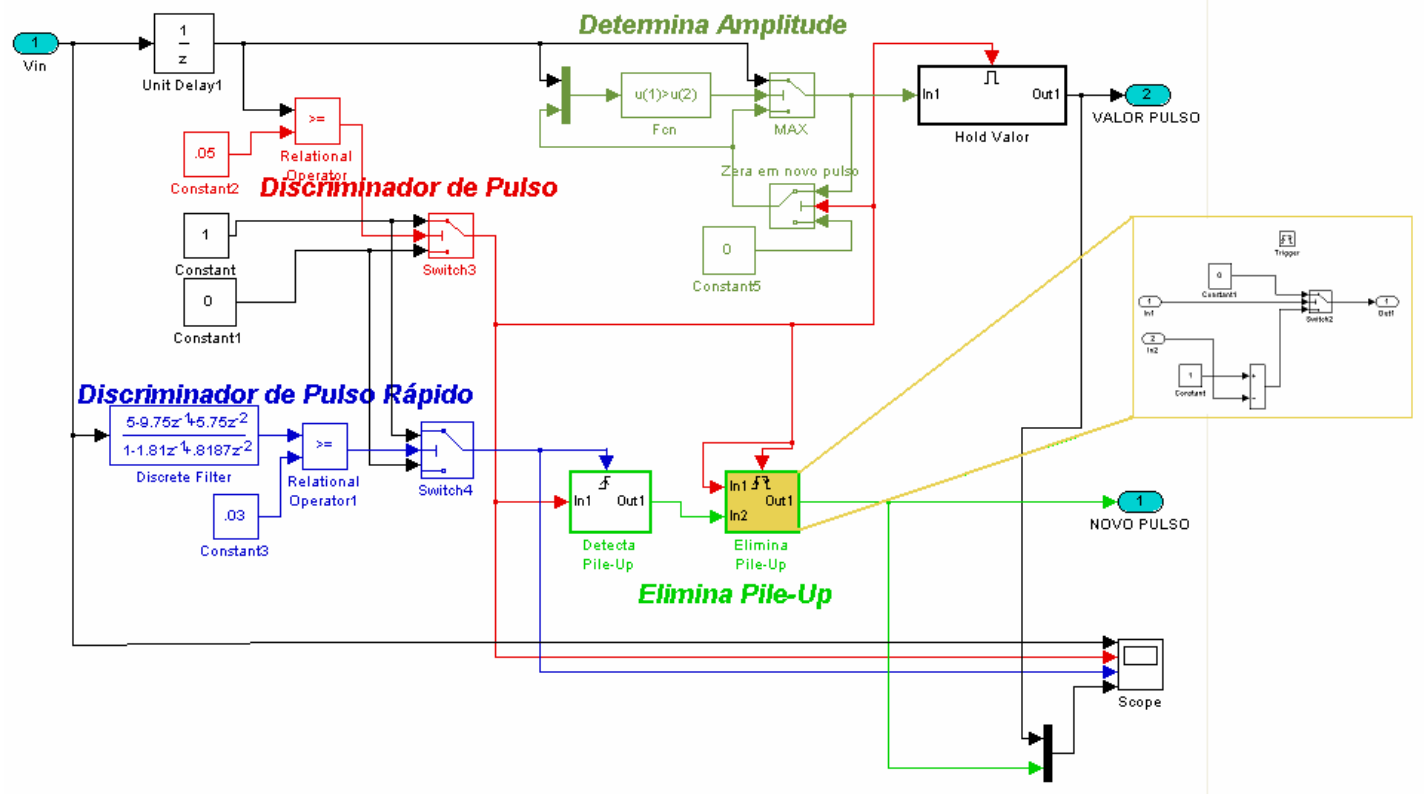

Figura 5-18. Bloco Detector de Pulso do modelo.

O bloco detector de pulso contém uma entrada que é o sinal de saída do bloco amplificador e duas saídas. Uma saída é um indicador quando um novo pulso é detectado e a outra saída é o valor da amplitude do pulso detectado.

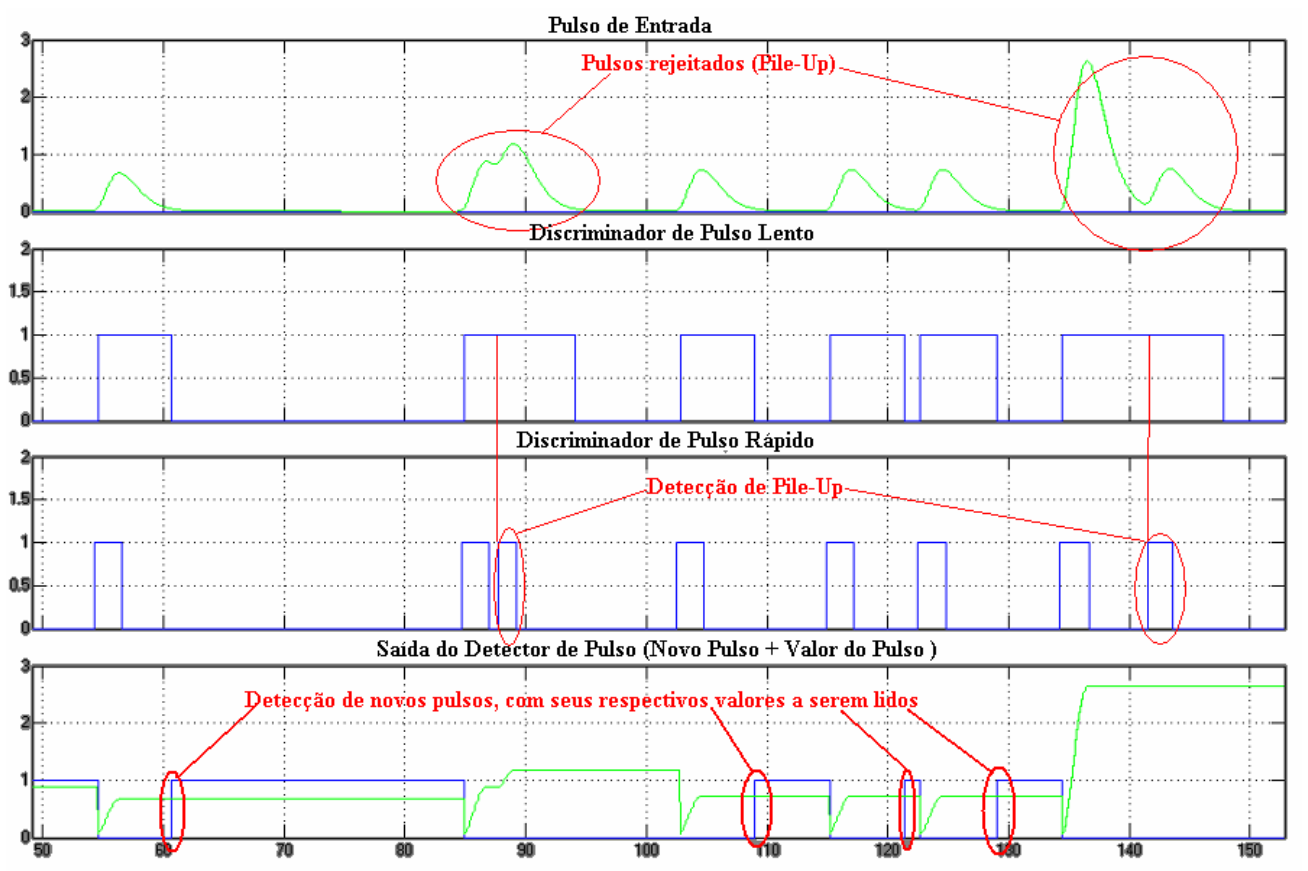

Figura 5-19. Simulação do bloco Detector de Pulso. 
Na figura 4-19 temos uma simulação dos sinais do bloco do detector de pulso, onde percebemos a rejeição de Pile-Up.

Com um circuito simples conseguiu-se simular todas as funções de um detector de pulso.

\subsection{Modelagem do Analisador Multicanal}

O Analisador Multicanal é um dispositivo que realiza o espectro de contagem de energia e possui três propósitos principais:

1) Calcular o valor da amplitude de cada pulso para obter o valor da energia do fóton incidente no detector que ocasionou este pulso.

2) Montagem do espectro de energia em um determinado período de tempo.

3) Determinar o fim do intervalo de tempo para enviar o espectro de energia ao sistema de armazenamento e zerar o espectro para a aquisição do próximo período.

Foi modelado o bloco Analisador Multicanal no modelo do espectrômetro em MATLAB. O bloco pode ser visualizado na figura 4-20. Este bloco realiza todos os três propósitos relacionados acima e ainda realiza a contagem das janelas de elementos para uma simulação mais detalhada.

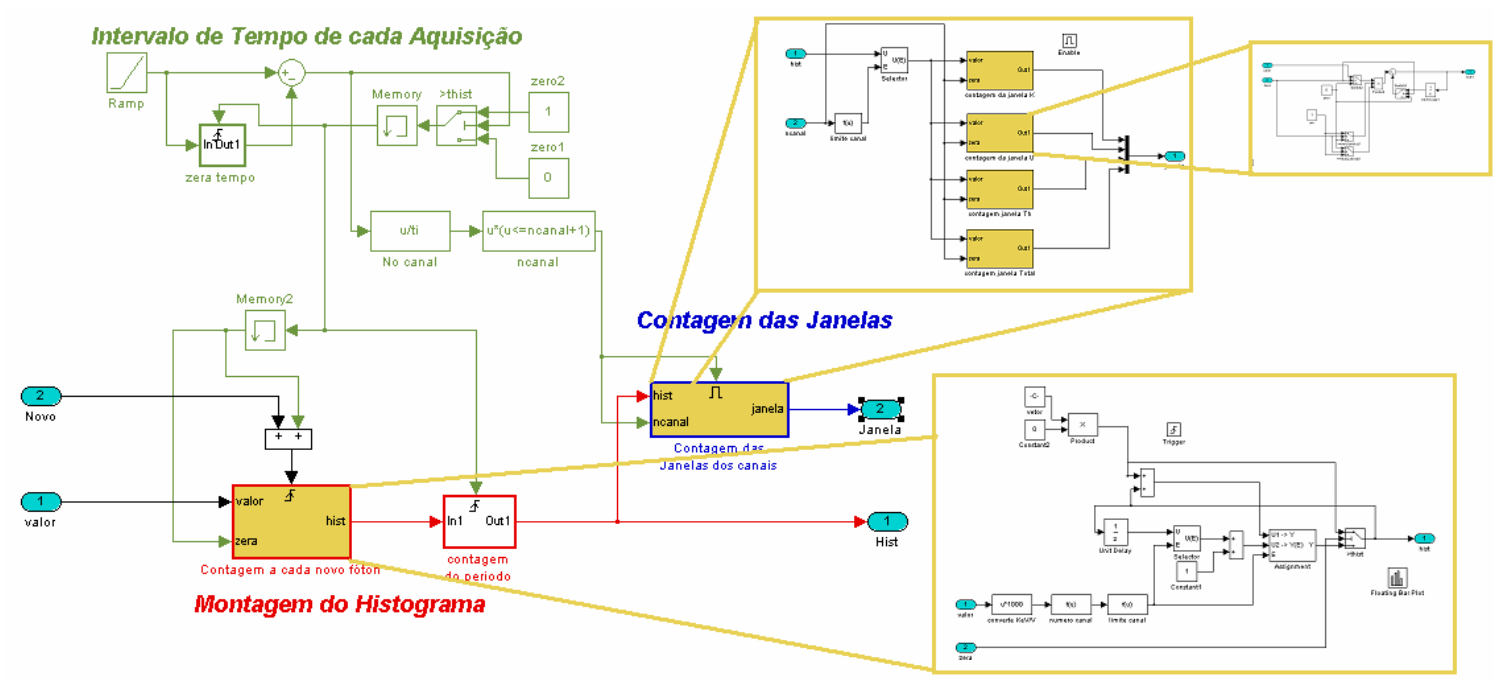

Figura 5-20. Bloco Analisador Multicanal do modelo.

Com isto, o modelo completo do gamaespectrômetro foi finalizado. $\mathrm{O}$ espectro de energia de uma simulação realizada com energias de radônio, potássio, urânio e tório, pode ser visto na figura 4-21. 


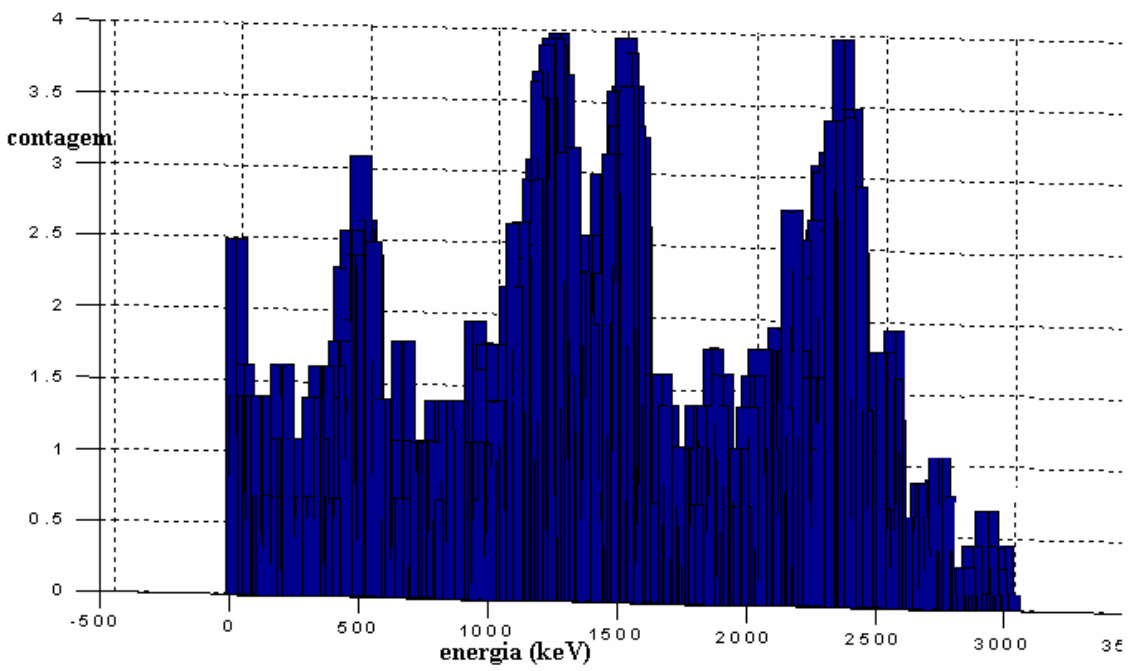

Figura 5-21. Espectro de energia de uma simulação do modelo completo do gamaespectrômetro. 


\section{Desenvolvimento do Projeto}

Neste capítulo será detalhado o desenvolvimento do projeto realizado em quatro etapas que são: Circuito eletrônico, Detector de Pulso, Analisador Multicanal e Sistema de Aquisição de Dados. O diagrama de blocos do projeto é mostrado na figura 5-1.

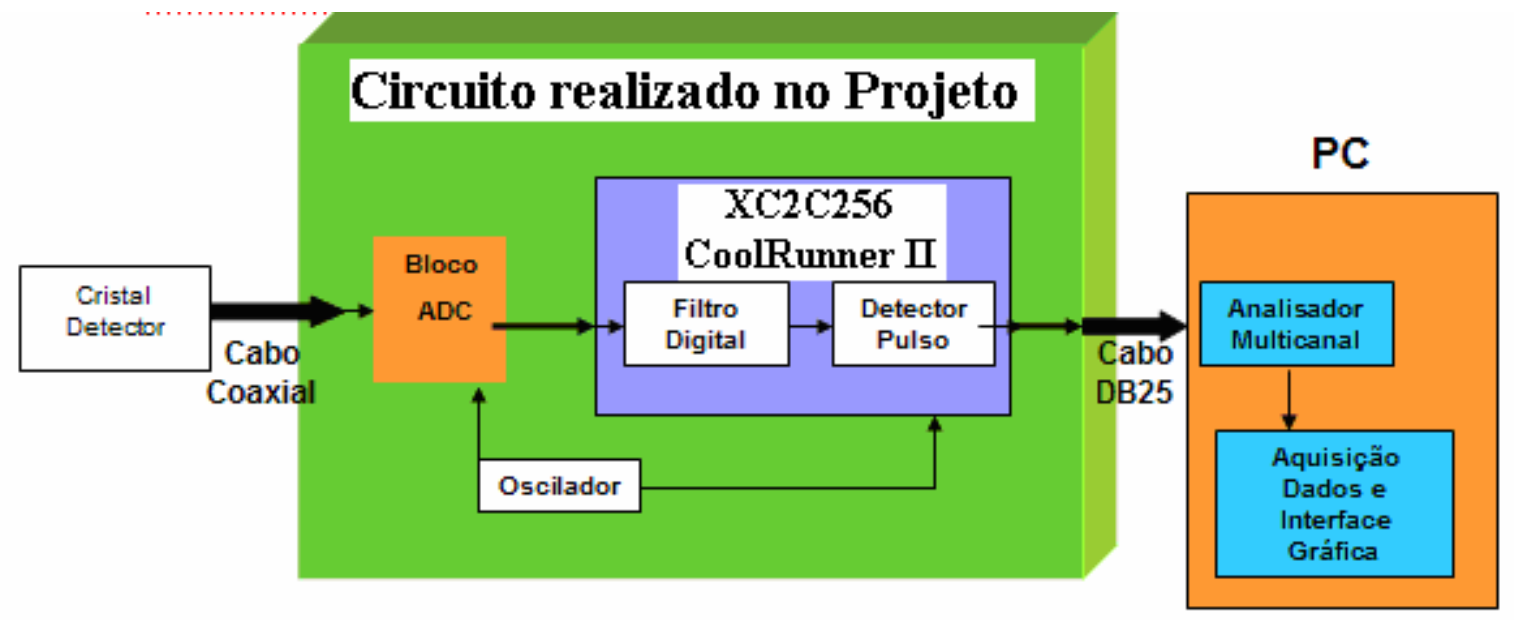

Figura 6-1. Diagrama de blocos do projeto desenvolvido.

\subsection{Parte Prática 1: Montagem da Placa Eletrônica do Projeto}

O circuito eletrônico utilizado tem como sua principal estrutura o kit de desenvolvimento Digilab XC2-XL adquirido da Digilent Inc. O kit contém um CPLD CoolRunner-II XC2C256 que será utilizado.

\subsubsection{Cristal Sensor de NaI(Tl) Utilizado}

O equipamento detector utilizado para o experimento é um ORTEC do Laboratório de Geofísica Nuclear Aplicada (LGNA) do IAG-USP.

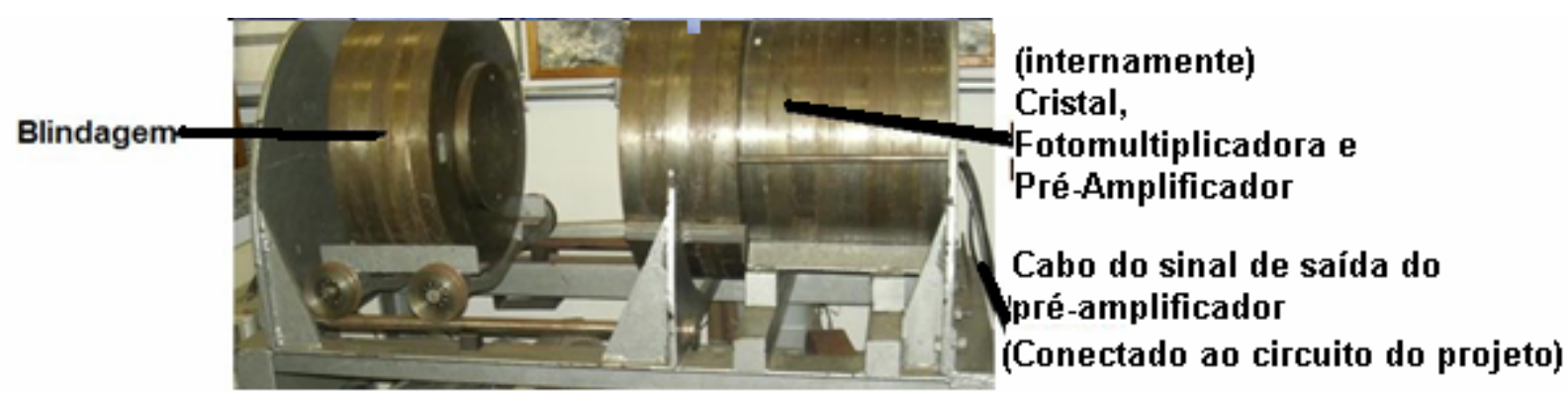

Figura 6-2. Foto do detector NaI(TI) utilizado com seu cabo coaxial do sinal de saída.

Todo o conjunto é formado pelo cristal detector, válvula foto-multiplicadora e préamplificador. Esses elementos ficam dentro de um cilindro de ferro com invólucro cilíndrico de $\mathrm{Hg}$ bidestilado para redução da interferência ambiental externa [3]. As amostras radioativas foram colocadas a $5 \mathrm{~cm}$ do cristal. O conjunto pesa 1500 kilogramas e é mostrado na figura 5-2. 
O detector deste conjunto é um cristal de $\mathrm{NaI}(\mathrm{Tl})$ de dimensão de 3 polegadas de diâmetro e 3 polegadas de altura acoplado opticamente a uma fotomultiplicadora polarizada com alta voltagem.

A base da fotomultiplicadora, modelo 276 da EG\&G Ortec, contém divisor resistivo de alimentação dos dinodos e o circuito pré-amplificador.

\subsubsection{Kit de Desenvolvimento}

O kit de desenvolvimento permite a gravação do programa desenvolvido em VHDL, plataforma fornecida pelo fabricante, através de um cabo JTAG.

A alimentação do kit é fornecida por uma fonte interna que transforma a alimentação externa de 5 a 9 volts em 3,33 volts. O kit possui um cristal oscilador de $1.843 \mathrm{MHz}$ que alimenta diretamente os dispositivos lógicos.

Os pinos de entrada e saída dos dispositivos lógicos podem ser ligados externamente ao kit através de 4 conectores de 40 pinos cada, chamados de $A, B, C$ e $D$. Os pinos do conector $A$ estão entre $A 1$ e $A 40$.

O sinal de entrada é proveniente de um conector coaxial instalado no circuito. Este sinal é convertido pelo circuito ADC e o sinal discreto é enviado para o CPLD. O CPLD realiza o processamento do sinal e a informação tratada é enviada para o computador.

O cristal oscilador do kit foi trocado por um de $80 \mathrm{MHz}$ para alimentar o conversor analógico digital. Já foi verificado que a CPLD trabalha normalmente em freqüências de 1 a $100 \mathrm{MHz}$. A figura 5-3 mostra todo o kit montado.

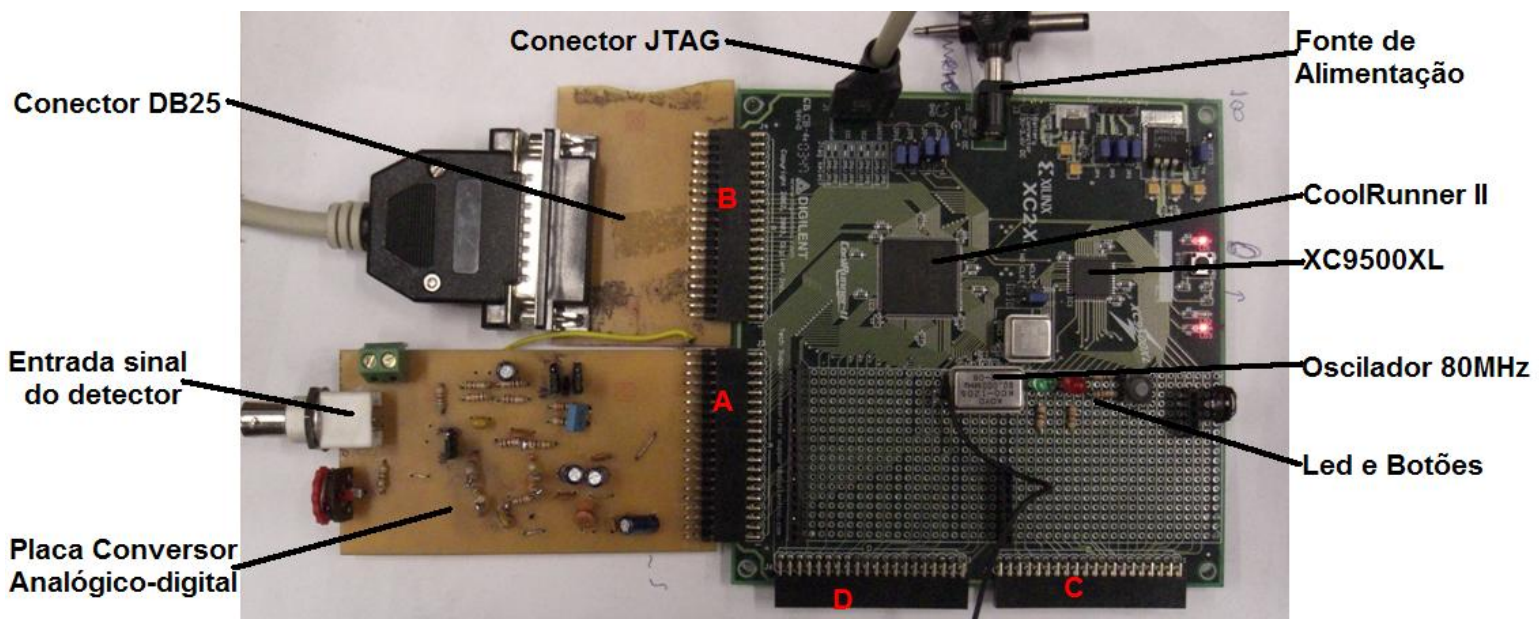

Figura 6-3. Foto do kit de desenvolvimento com suas adaptações.

\subsubsection{Determinação da pinagem do Circuito Lógico Programável}

Para a programação lógica do circuito interno do dispositivo lógico deve-se conhecer a pinagem de cada sinal de entrada ou saída.

A placa do circuito ADC é conectada diretamente no conector $A$ do kit Digilab. Os dados do sinal discreto convertido pelo ADC são conectados ao dispositivo CoolRunner-II através da pinagem mostrados na tabela 5-1. 
Tabela 6-1. Descrição da pinagem do sinal de entrada discreto e conector A do CPLD

\begin{tabular}{|c|c|c|c|}
\hline AD9236 & & \multicolumn{2}{|c|}{ CPLD } \\
\hline pino & Tipo de dados & conector & Pino \\
\hline 15 & D0 (LSB) & A35 & 7 \\
\hline 16 & D1 & A33 & 10 \\
\hline 17 & D2 & A31 & 12 \\
\hline 18 & D3 & A29 & 14 \\
\hline 19 & D4 & A27 & 16 \\
\hline 20 & D5 & A23 & 18 \\
\hline 21 & D6 & A21 & 22 \\
\hline 22 & D7 & A19 & 24 \\
\hline 25 & D8 & A17 & 26 \\
\hline 26 & D9 & A13 & 30 \\
\hline 27 & D10 & A11 & 35 \\
\hline 28 & D11 (MSB) & A3 & - \\
\hline 1 & OTR & A1 & - \\
\hline- & VCC & & 38 \\
\hline- & GND & CLOCK & \\
\hline 13 & & & \\
\hline
\end{tabular}

Os resultados do processamento executado pelo dispositivo lógico serão transmitidos para o computador de aquisição de dados através do conector $B$ do kit e conectado à porta paralela do computador. Na tabela 5-2 é descrita a pinagem entre a conexão do CPLD e PC.

Tabela 6-2. Descrição do pinagem do conector $B$, saída para o PC

\begin{tabular}{|c|c|c|c|c|}
\hline \multicolumn{2}{|c|}{ CPLD } & \multicolumn{2}{c|}{ Computador } \\
\hline pino & conector & Tipo de dados & DB25 & sinal \\
\hline 129 & B17 & D0 (LSB) & 2 & D0 \\
\hline 126 & B19 & D1 & 3 & D1 \\
\hline 124 & B21 & D2 & 4 & D2 \\
\hline 120 & B23 & D3 & 5 & D3 \\
\hline 118 & B25 & D4 & 7 & D4 \\
\hline 116 & B27 & D5 & 8 & D5 \\
\hline 114 & B29 & D6 & 9 & D6 \\
\hline 112 & B31 & D7 & 11 & S6 \\
\hline 110 & B33 & D8 & 12 & S7 \\
\hline 106 & B35 & D9 & 13 & S9 \\
\hline 104 & B37 & D10 & 15 & S3 \\
\hline 102 & B39 & D11 (MSB) & $18-25$ & GND \\
\hline 142 & B5 & RXR & - & - \\
\hline- & B1 & GND & 1 & C0 \\
\hline- & B3 & VCC & C1 \\
\hline 139 & B7 & SEL & & \\
\hline 137 & B9 & RXA & & 14 \\
\hline
\end{tabular}

\subsubsection{Placa Conversor Analógico-Digital}

O objetivo principal do projeto é realizar o bloco amplificador totalmente digital que tenha todas as características necessárias de remodelagem do pulso. Este circuito foi desenvolvido em linhas de código de programação no CPLD. 
Para deixarmos os impulsos do sinal de entrada na faixa de voltagem de conversão do conversor é realizado um circuito amplificador analógico simples, apenas para ajuste da voltagem para se ter uma maior precisão nos impulsos provenientes de raios gama entre 0 e $3000 \mathrm{keV}$ desejados.

O primeiro circuito desenvolvido foi um divisor resistivo seguido de um circuito amplificador tendo a opção de usar este amplificador como circuito integrador através de um capacitor. $\mathrm{O}$ amplificador operacional tem velocidade acima de $100 \mathrm{MHz}$ para ter um tempo de resposta rápido para o impulso de entrada. Há a opção de selecionar através de um conector se haverá um capacitor na entrada para barrar a componente contínua do sinal de entrada.

O sinal, então, será discretizado a uma taxa de amostragem de 80 milhões de amostras por segundo e resolução de 12 bits utilizando o circuito integrado AD9236 da Analog Devices. No próprio datasheet do AD9236 há dois exemplos de circuitos acopladores (veja figura 5-4).
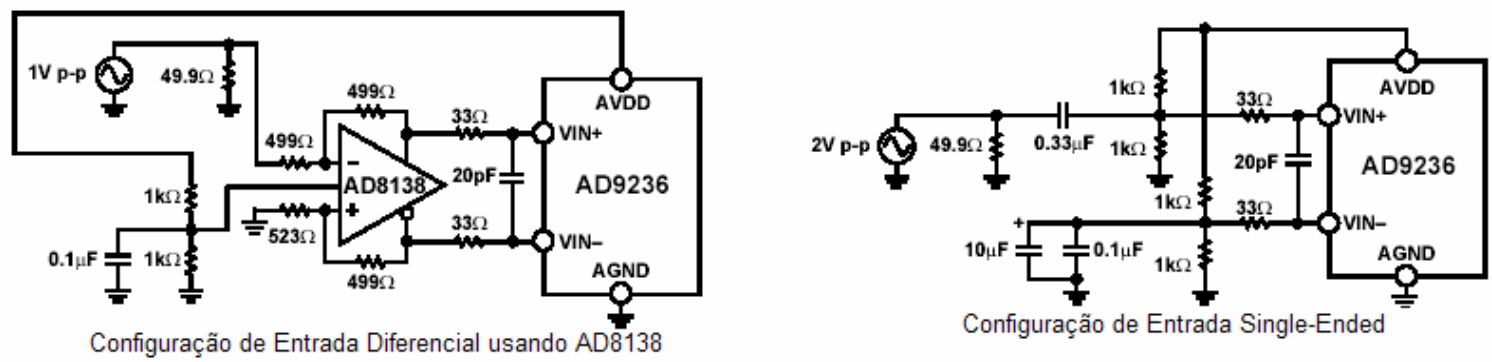

Figura 6-4. Dois tipos de circuitos acopladores recomendado pela Analog Devices.

Foram montadas as duas opções de circuito acoplador tendo a possibilidade do usuário selecionar o circuito acoplador desejado. A placa do circuito conversor foi realizada em PCB. Utilizou-se uma mesa térmica para imprimir o circuito numa placa de cobre virgem.

Além do circuito acoplador, foram decididas outras configurações na utilização do ADC. O modo selecionado foi a 'Voltagem de Referência Fixada Internamente' sendo a voltagem diferencial de entrada de 2,0 volts pico-a-pico (Vpp). A tensão utilizada foi de 3,3 V para ser compatível com a CPLD.

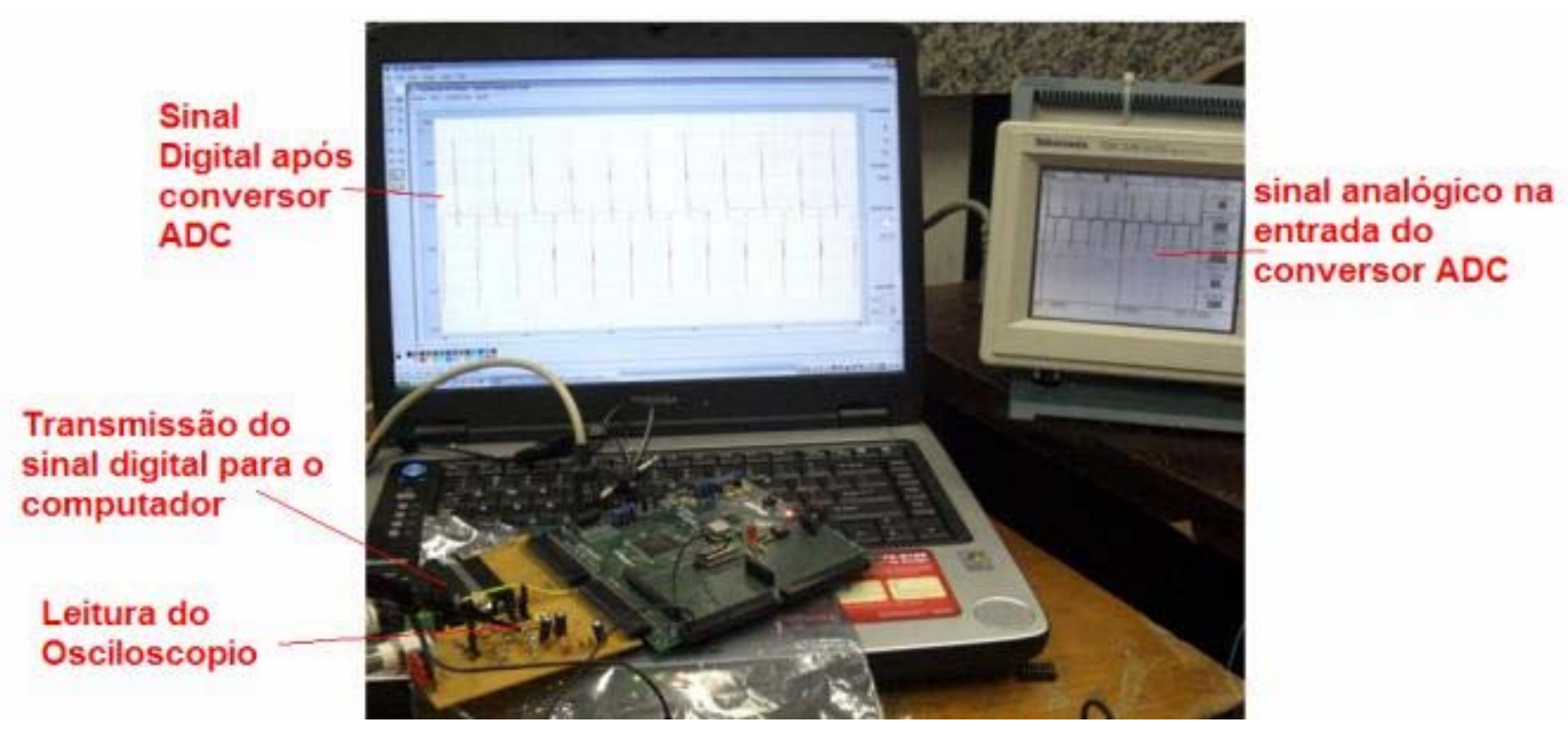

Figura 6-5. Sinal convertido pelo sistema de acoplamento Single-Ended. 
Para testar o circuito foi gerada uma onda quadrada simulando o sinal de entrada. Utilizou-se um osciloscópio para visualizar a forma de onda na entrada do conversor AD9236 neste teste. O software de aquisição de dados desenvolvido (veja item 5.2) consegue ler o sinal de saída do AD9236 em 12 bits comprovando o funcionamento do circuito como mostrado na figura 55 .

\subsection{Parte Prática 2: Software de Aquisição de Dados}

O sistema de aquisição de dados será descrito antecipadamente, apesar de ser a última etapa do projeto, porque precisou-se deste para testar a parte prática nos itens 5.3 e 5.4, assim como já foi utilizado para teste no item 5.1.

Foi desenvolvido um software de aquisição de dados para comunicação e armazenamento dos espectros de freqüência de energia processados. Na figura 5-6 é mostrado o diagrama de blocos de todo este sistema.

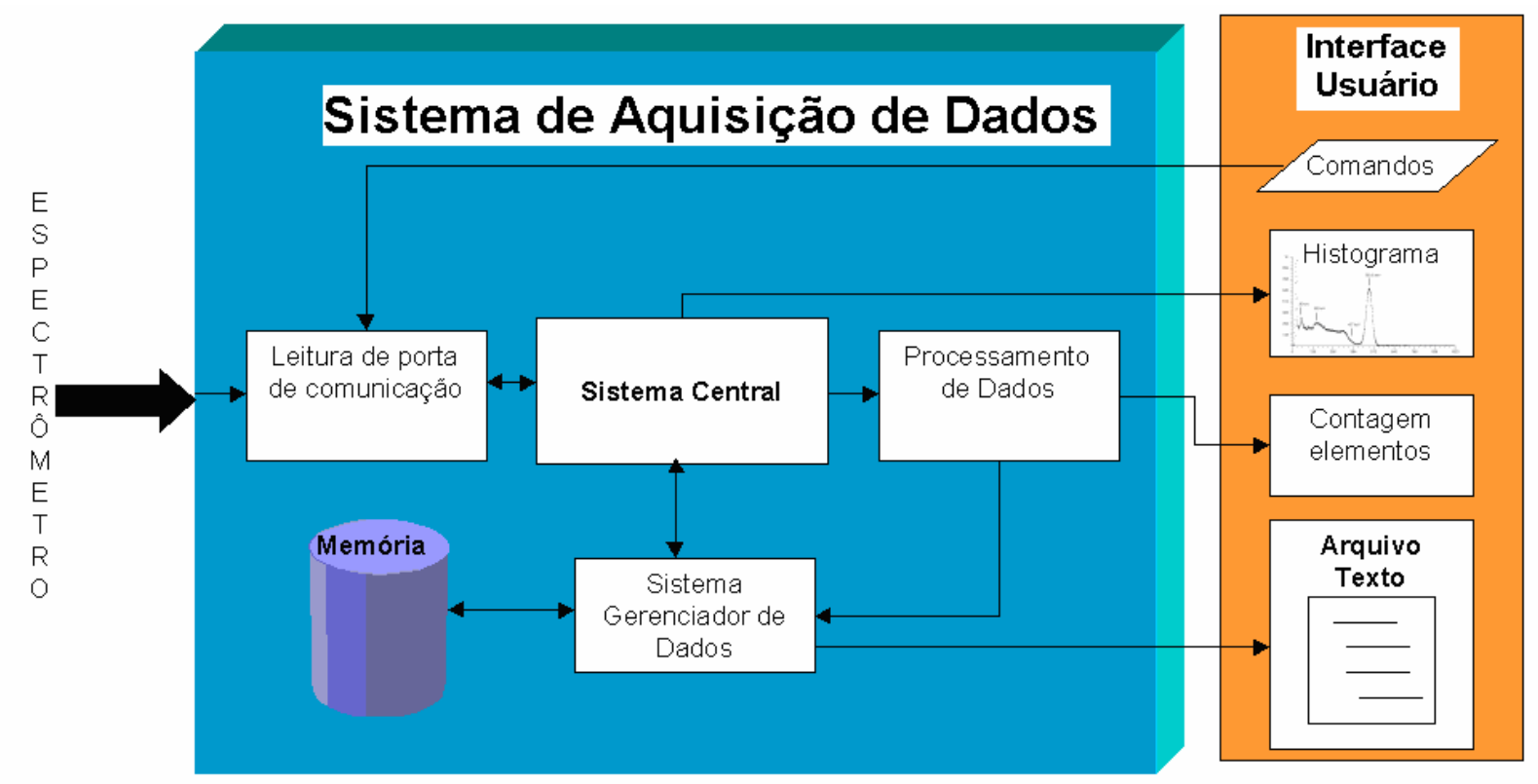

Figura 6-6. Diagrama de bloco do sistema de aquisição de dados.

Foi desenvolvida uma interface gráfica amigável com uma boa visualização do espectro como verificado na figura 5-7. Na parte direita da figura é possível visualizar a contagem de janela dos elementos de potássio, urânio e tório, da radiação cósmica e a contagem total. O usuário pode interagir com o programa através do teclado e do mouse. Também pode visualizar o gráfico com funções de zoom e mudar a escala do espectro.

É possível aumentar ou diminuir os coeficientes lineares. Para o coeficiente $A$ as escalas de mudanças são entre 512 e 4096, onde mostra o intervalo entre 0 e $3000 \mathrm{KeV}$ em sinal discreto. Para o coeficiente $B$ as escalas de mudança são entre -500 e 1000. 


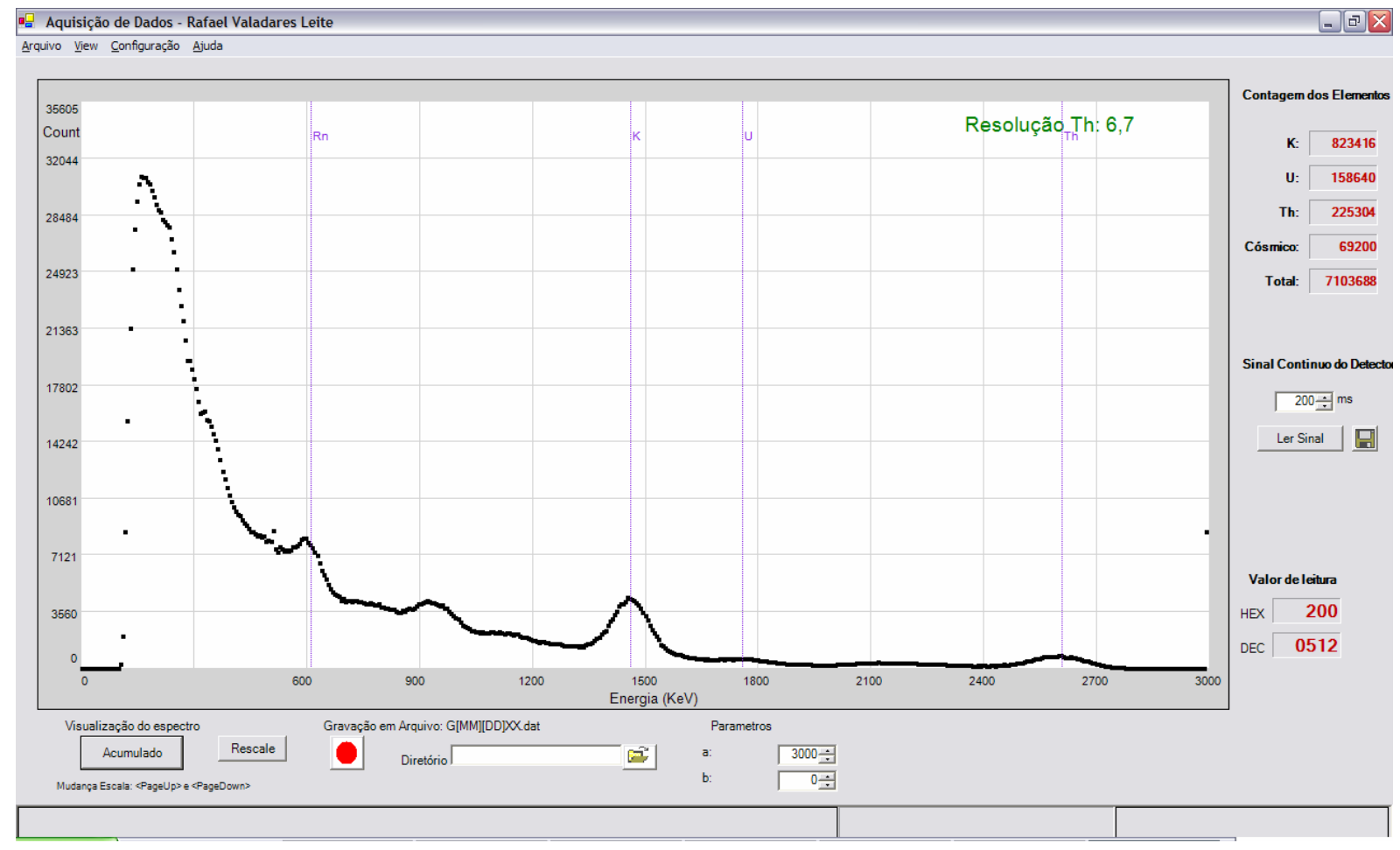

Figura 6-7. Janela do sistema de aquisição de dados.

A comunicação entre o espectrômetro digital e o computador é realizada através da porta paralela. A sincronização na recepção dos dados é realizada pelos comandos RXR e RXA.

\subsubsection{Sinal do Detector}

A análise do sinal de entrada em função do tempo permitiu durante o projeto verificar a qualidade do circuito ADC, projetar o filtro digital detector de pico e verificar a qualidade da conversão do pulso individual num valor referente à energia do pico. A visualização do sinal de uma onda quadrada é mostrada na figura 5-8. Vemos que este sistema tem a função de um osciloscópio para sinal discreto de 12 bits.

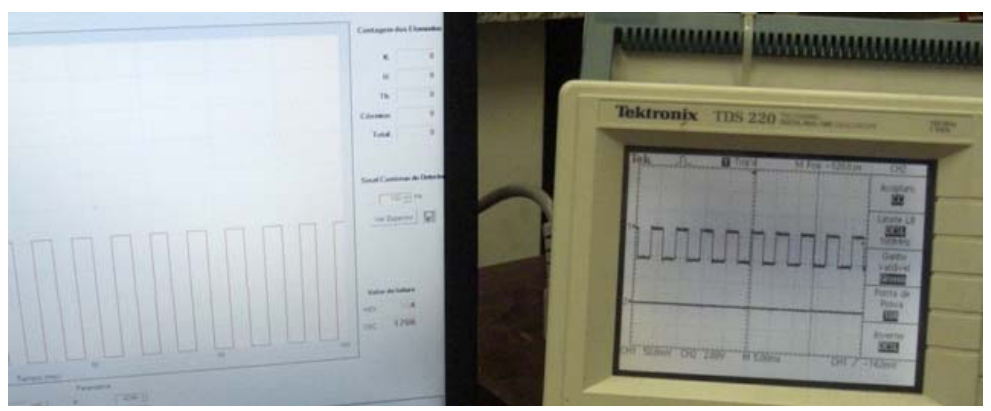

Figura 6-8. Visualização do sinal discreto proveniente do detector.

\subsubsection{Aquisição dos Dados}

A aquisição de dados é feita através do comando de gravação de arquivo. A estrutura do arquivo texto é uma linha para cada amostra. Esta linha conterá 512 colunas separadas por espaço, onde a coluna inicial representa o canal 0 e a coluna final representa o canal 511. 


\subsubsection{Calibração Linear}

A calibração linear tem a função de determinar exatamente a relação numérica da amplitude do pulso com a energia absorvida no detector que causou este impulso inicial.

No MCA existirá um fator linear que indicará a relação numérica do pulso filtrado com o número do canal. Para este detector de 512 canais, teremos uma relação de 0 a $3000 \mathrm{keV}$, onde o canal 0 representa energia entre 0 e $5,859 \mathrm{keV}$ e o canal 511 energia igual e superior a $3000 \mathrm{keV}$.

Para verificar a calibração linear, verificou-se o posicionamento dos picos mais abundantes como césio, potássio, urânio e tório no espectro de energia. No menu principal é possível visualizar os pontos nominais dos picos destes quatro elementos.

A verificação destes pontos é mais bem visualizada no modo de leitura acumulado de dados obtendo maior número de contagens.

\subsubsection{Resolução}

O sistema permite determinar automaticamente a resolução do pico de energia do elemento Césio, Potássio e Tório. A resolução é calculada por um algoritmo que verifica a meia altura do pico e divide a largura da meia altura com o valor do ponto exato do pico.

\subsection{Parte Prática 3: Circuito lógico do detector de Pico}

Na figura 5-9 vemos o diagrama de blocos do sistema detector de pico que foi implementado no dispositivo lógico programável.

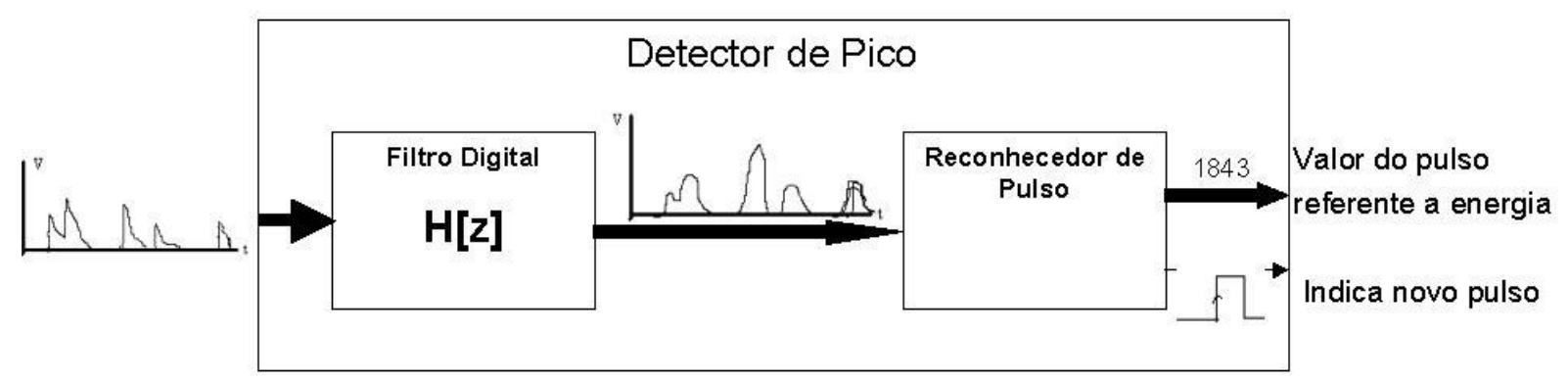

Figura 6-9. Diagrama de bloco do sistema detector de pico.

O Detector de pulso possui duas etapas: a primeira é um filtro digital para modificar a forma do sinal de entrada em pulsos individuais e a segunda é o identificador de pulso que avisará quando um novo pulso for detectado e o valor referente da energia deste pulso.

O circuito foi desenvolvido através de linhas de código de programação na linguagem VHDL e compilado no software ISE WebPack Project Navigator da Xilinx fornecido junto com o kit CPLD.

Para testar esta parte prática adotou-se uma estrutura simples. As portas de entrada e saída e os sinais auxiliares podem ser vistos na figura 5-10. 


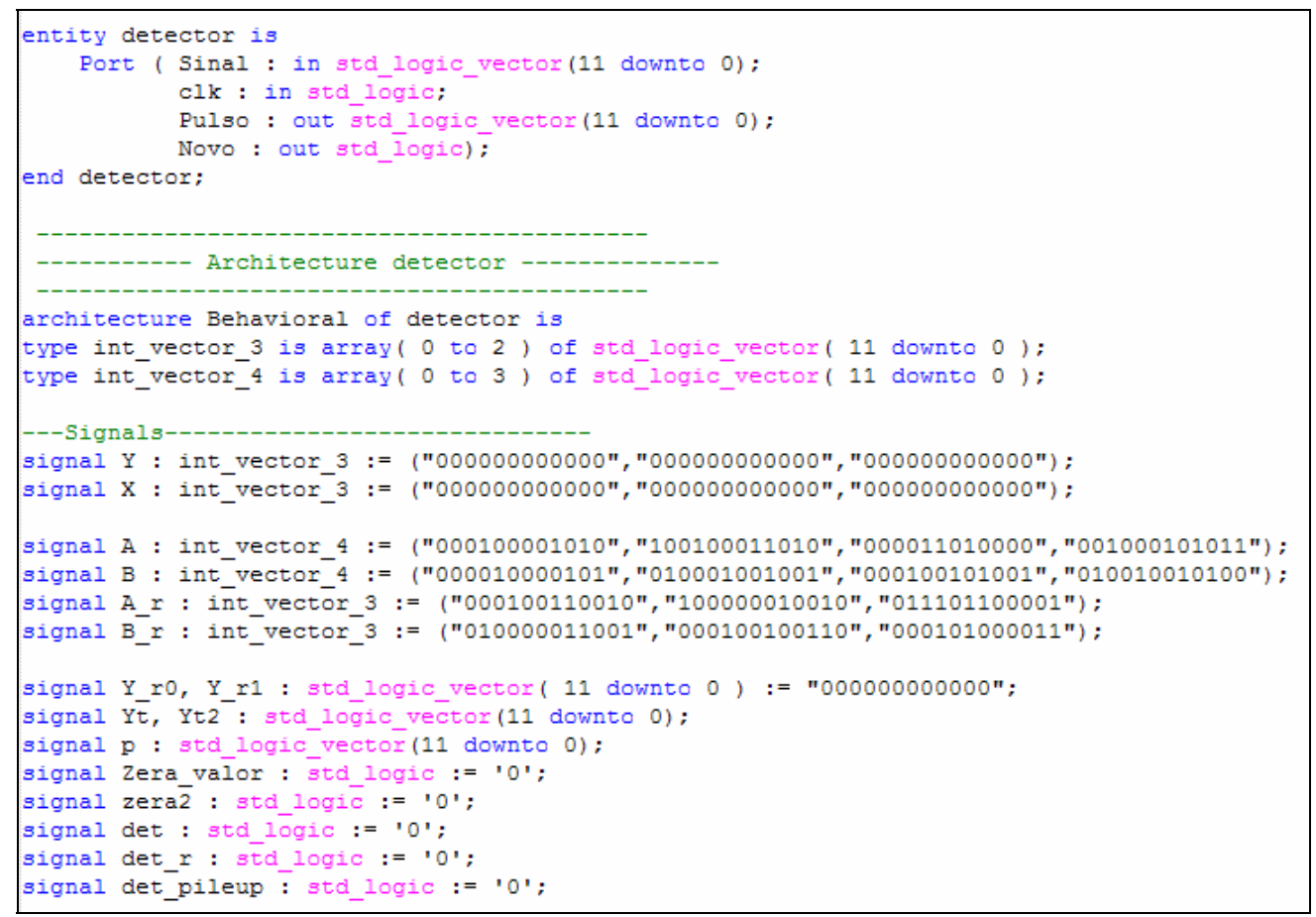

Figura 6-10. Diagrama das portas de entrada e bloco do sistema detector de pico.

Foi simulado um detector de pico com todas suas funções no Matlab (ver itens 4.2 e 4.3) e desenvolvido este mesmo detector de pico na linguagem VHDL considerando a pinagem descrita no item 5.1.3.

\subsubsection{Gravação do Filtro Digital}

A conversão do sinal de entrada Sinal foi realizada através de um filtro digital dando origem a um filtro discriminador lento e um filtro discriminador rápido utilizado para detectar empilhamento de dois pulsos. Na figura 5-11 pode-se ver o código dos filtros na linguagem VHDL.

O filtro digital é de terceira ordem (CR-RC-RC com pólo-zero) e o filtro rápido de ordem 2. O sinal convertido é mostrado no sinal $Y$. Os coeficientes de cada filtro são multiplicados por 1024, já que não foi utilizado números decimais, conseguindo, assim, uma precisão de 3 casas decimais. Após todo o cálculo, o valor de $Y$ é dividido por 1024 eliminando os 10 bits menos significativos.

O teste desta etapa foi realizado em um filtro digital para verificar a saída de um impulso de largura de 40 vezes o tempo de amostragem do filtro discreto. $\mathrm{O}$ filtro escolhido é apresentado na equação 5.1.

$$
H(Z)=\frac{0,005+0,007 \mathrm{z}^{-1}+0,002 \mathrm{z}^{-2}}{1,000-1,138 \mathrm{z}^{-1}+0,142 \mathrm{z}^{-2}}
$$




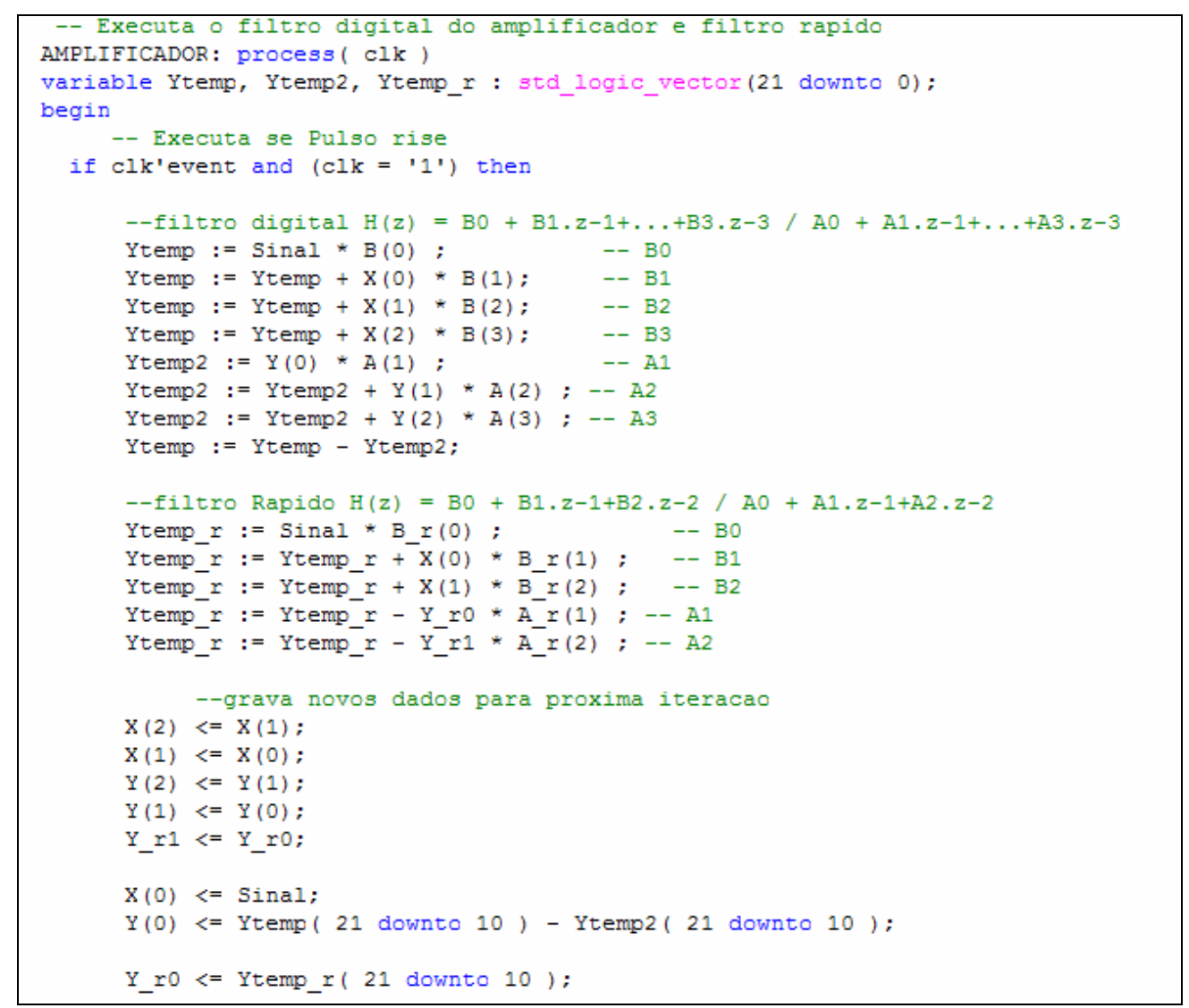

Figura 6-11. Código de realização dos filtros digitais do sinal de entrada.

Os coeficientes foram obtidos da mesma forma mostrada no capítulo 4, realizando simulação em PSpice com diferentes coeficientes até ajustar na forma de onda desejada e depois realizado a transformada $Z$ na taxa de amostragem desejada. O resultado da simulação no Matlab é mostrado na figura 5-12.

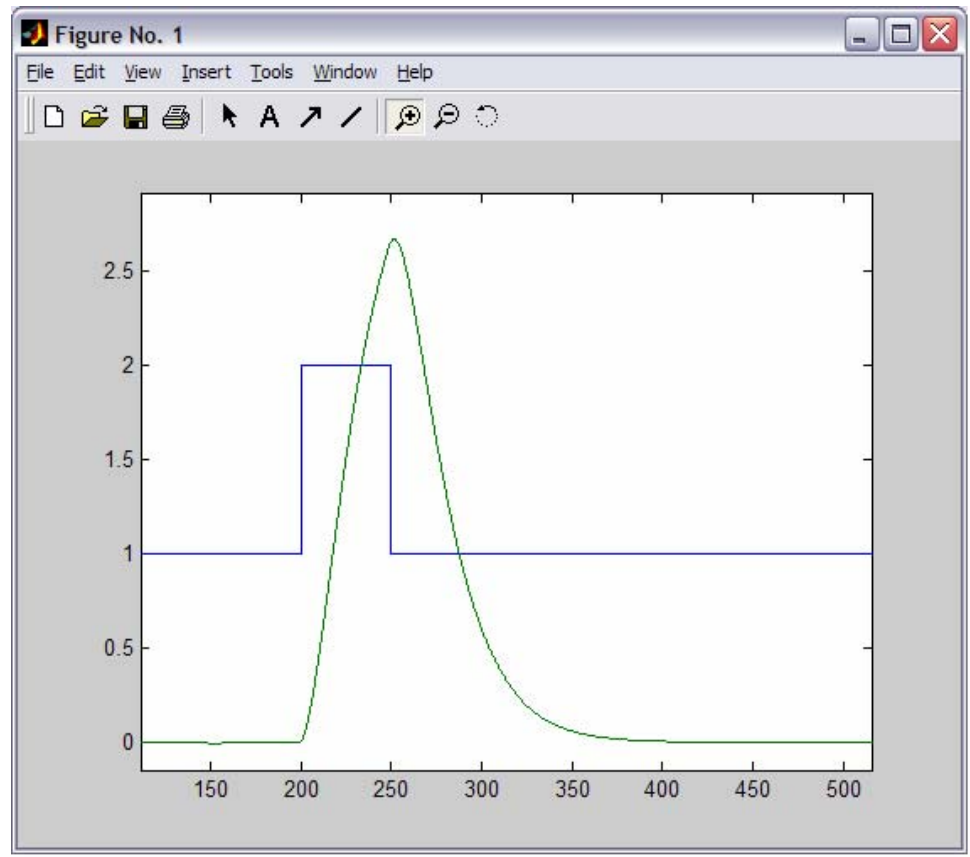

Figura 6-12. Simulação em Matlab/Simulink. 
Quando acionado o botão 2, o sinal a ser lido na porta paralela do computador será o sinal filtrado após o cálculo do filtro digital no CPLD. O pulso de entrada e o resultado da transformação com o filtro digital realizado no CPLD são mostrados na figura 5-13. Vemos então que a implementação de um filtro digital no CPLD foi realizada com sucesso.
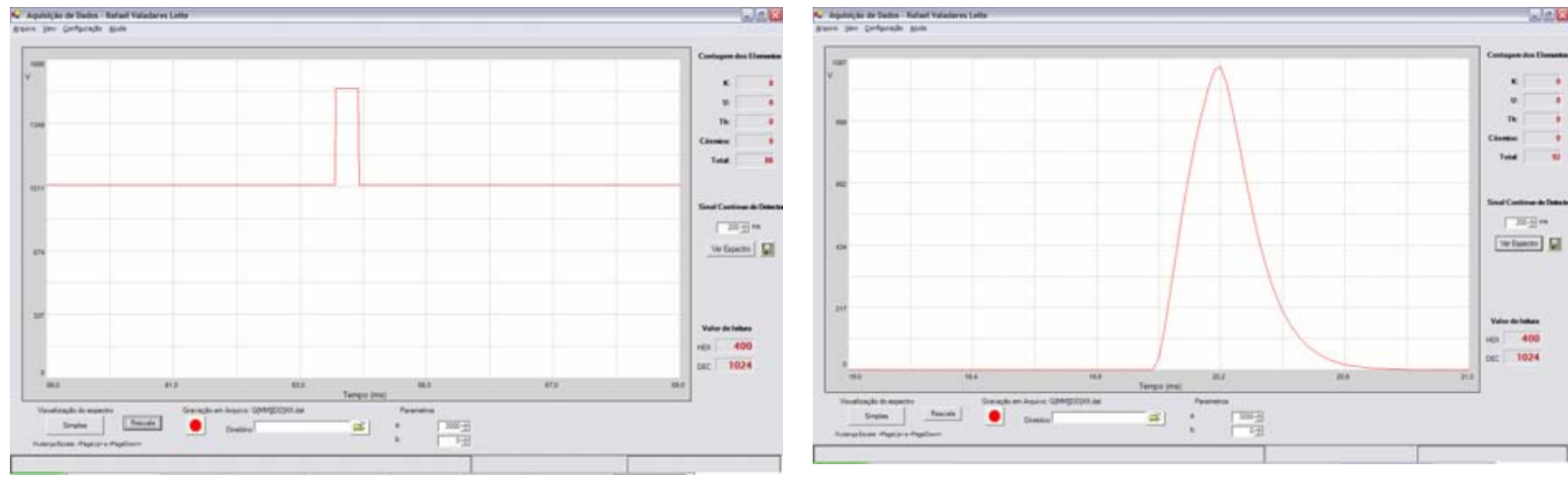

Figura 6-13. Forma do pulso de entrada (esquerda) e após tratamento com o filtro digital (direita).

\subsubsection{Sistema Lógico Indicador de deteç̧ão de pulso individual}

Na implementação do detector de pulso em linguagem VHDL podemos ver na figura 5-14 o discriminador e mensurador de pulso.

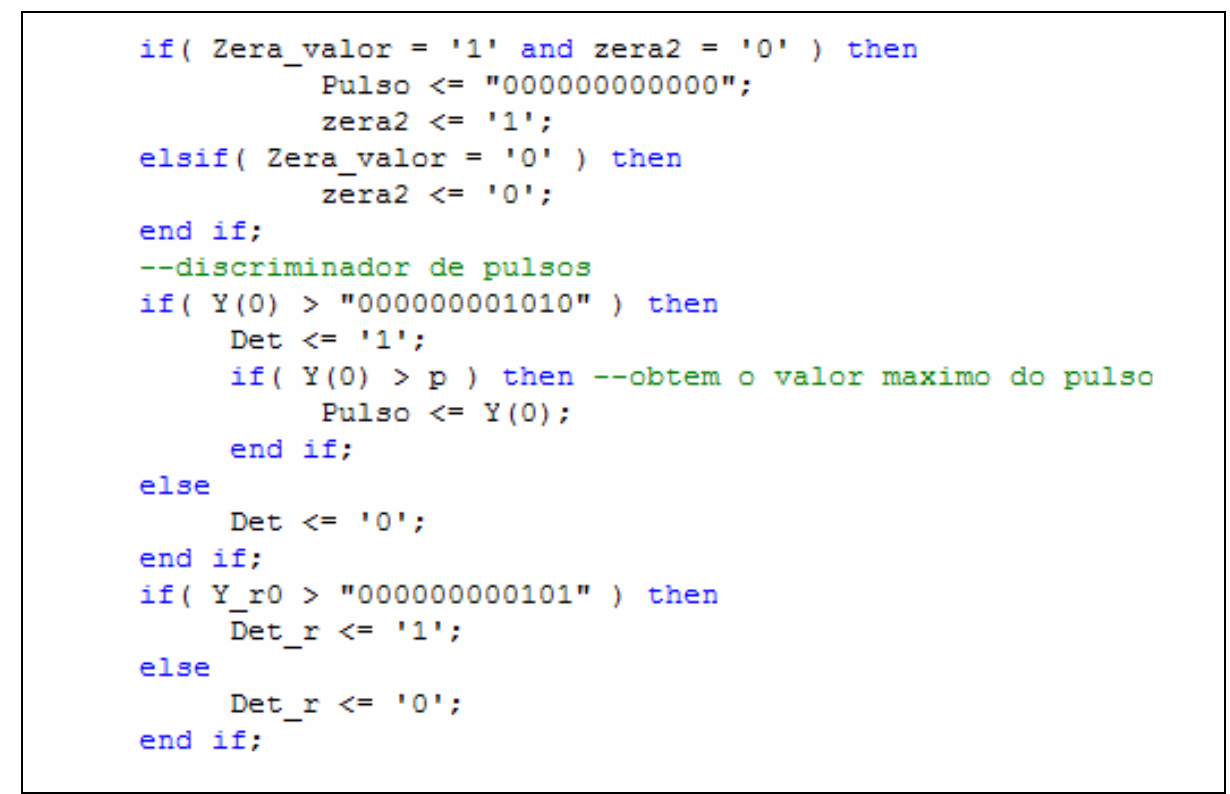

Figura 6-14. Função discriminadora de pulso.

Na figura 5-15 temos a lógica do redutor de empilhamento de pulsos (pile-up).

O Teste da lógica do detector de pulso foi realizado utilizando geração de pulsos com taxa de amostragem de $92 \mathrm{~Hz}$. O resultado foi obtido com sucesso porque todos os impulsos de amplitude igual foram relacionados a um único canal e número de contagem correta, o que mostra que todos os pulsos estão sendo detectados pelo circuito. 


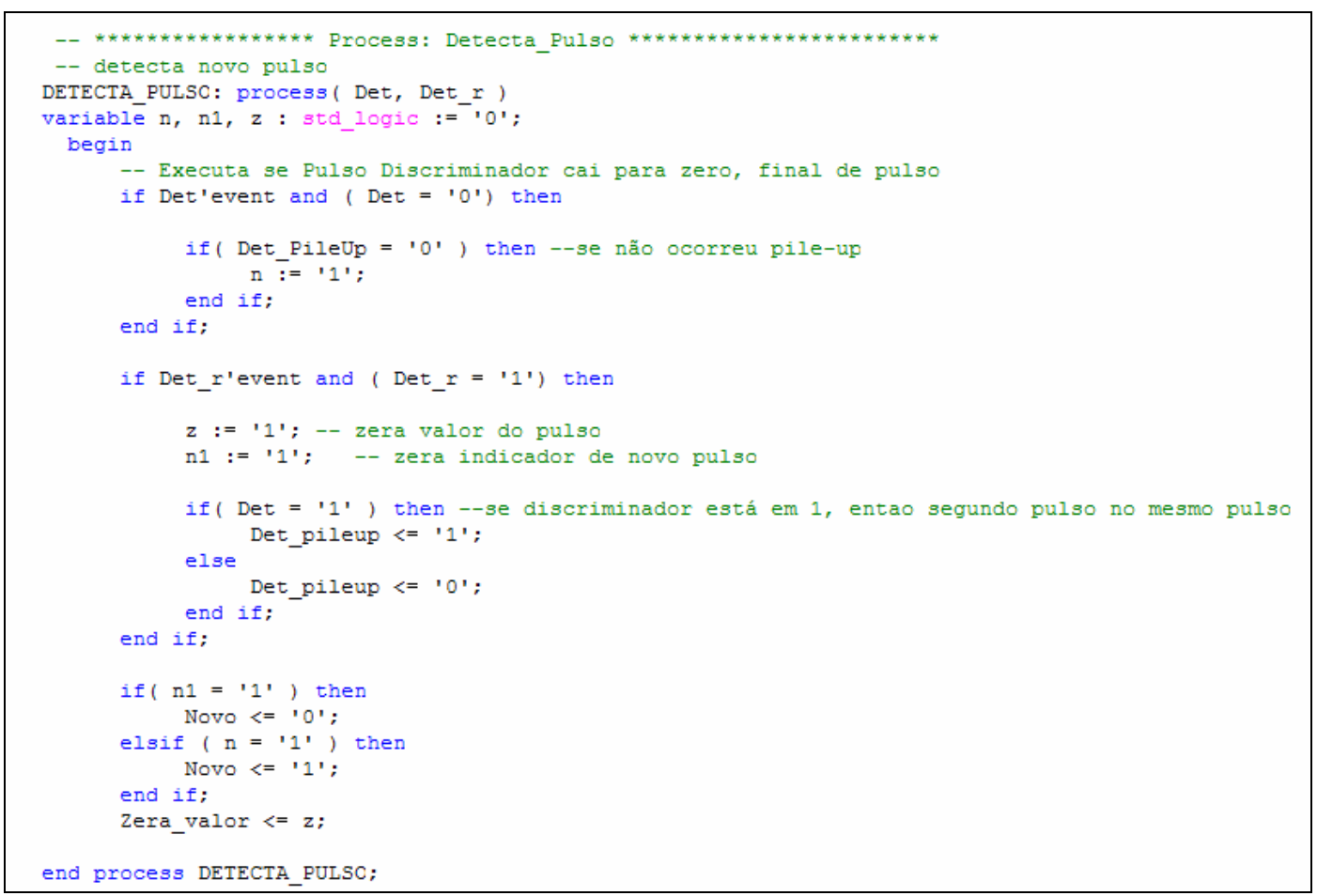

Figura 6-15. Função eliminador de Pile-Up.

\subsection{Parte Prática 4: Circuito lógico do Analisador Multicanal}

O analisador multicanal (MCA) é a parte mais fácil e não tem grande dificuldade matemática. Realizou-se o MCA no mesmo software de aquisição de dados, para descartar a necessidade de utilizar um kit de microcontrolador neste projeto.

A figura 5-16 mostra o diagrama de blocos necessário para o funcionamento do analisador multicanal.

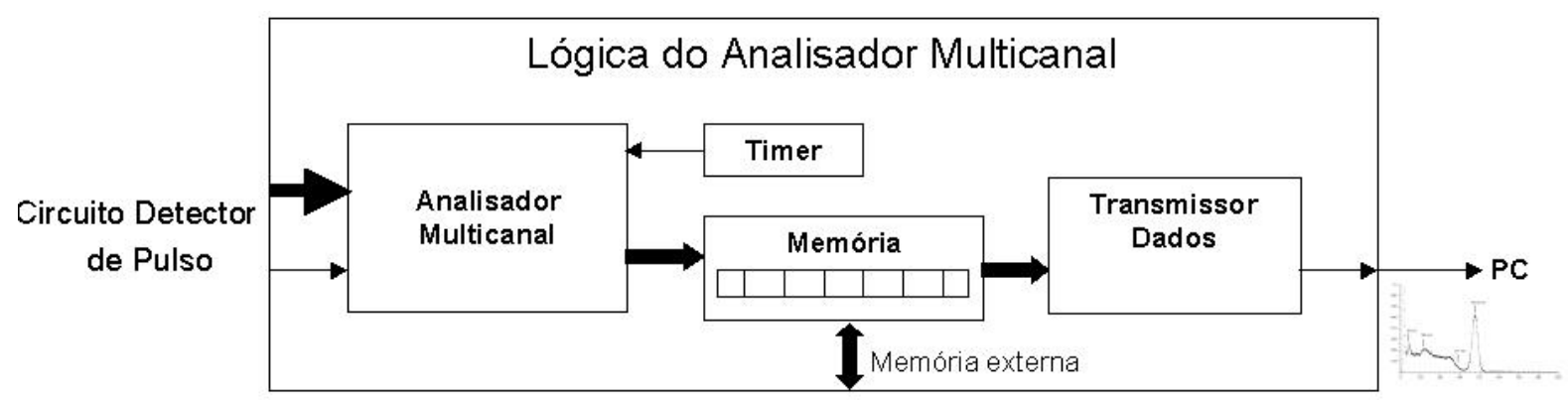

Figura 6-16. Diagrama de bloco do sistema do analisador multicanal.

\subsubsection{Contagem de Pulsos e Montagem do Espectro de Energia}

A contagem do pulso é controlada por um pulso de entrada que indica a presença de um novo fóton gama. Junto com a indicação de novo pulso, um sinal de 12 bits indica o valor da amplitude deste pulso que varia entre 0 e 4095.

Através da calibração linear o analisador multicanal determina em qual canal o valor do novo pulso se enquadra, com a equação abaixo:

$$
\text { Canal\#= } a \cdot P u l s o+b
$$


Durante a contagem de novos pulsos e montagem do histograma, deve-se enviar informações deste histograma de 512 canais a cada segundo controlado por um relógio interno.

Após a ordem de transmissão do histograma para o sistema de aquisição de dados, é atualizada a interface com o usuário, através da nova informação do espectro de freqüência de energia.

O protocolo de recepção da porta paralela no software de aquisição de dados (item 5.2) é mostrado na figura 5-17.

Cada novo pulso é indicado pela mudança do status do bit $R X R$ e é realizada a leitura de seu valor. Todos os pulsos são armazenados em um vetor. A cada segundo, uma nova Thread é chamada para trabalhar com a formação do histograma de contagem de energia de 512 canais e atualizar o gráfico do espectro.

Também é realizada a recepção do sinal de entrada quando selecionado o botão "ver sinal" pelo usuário, mudando o status do bit sel.

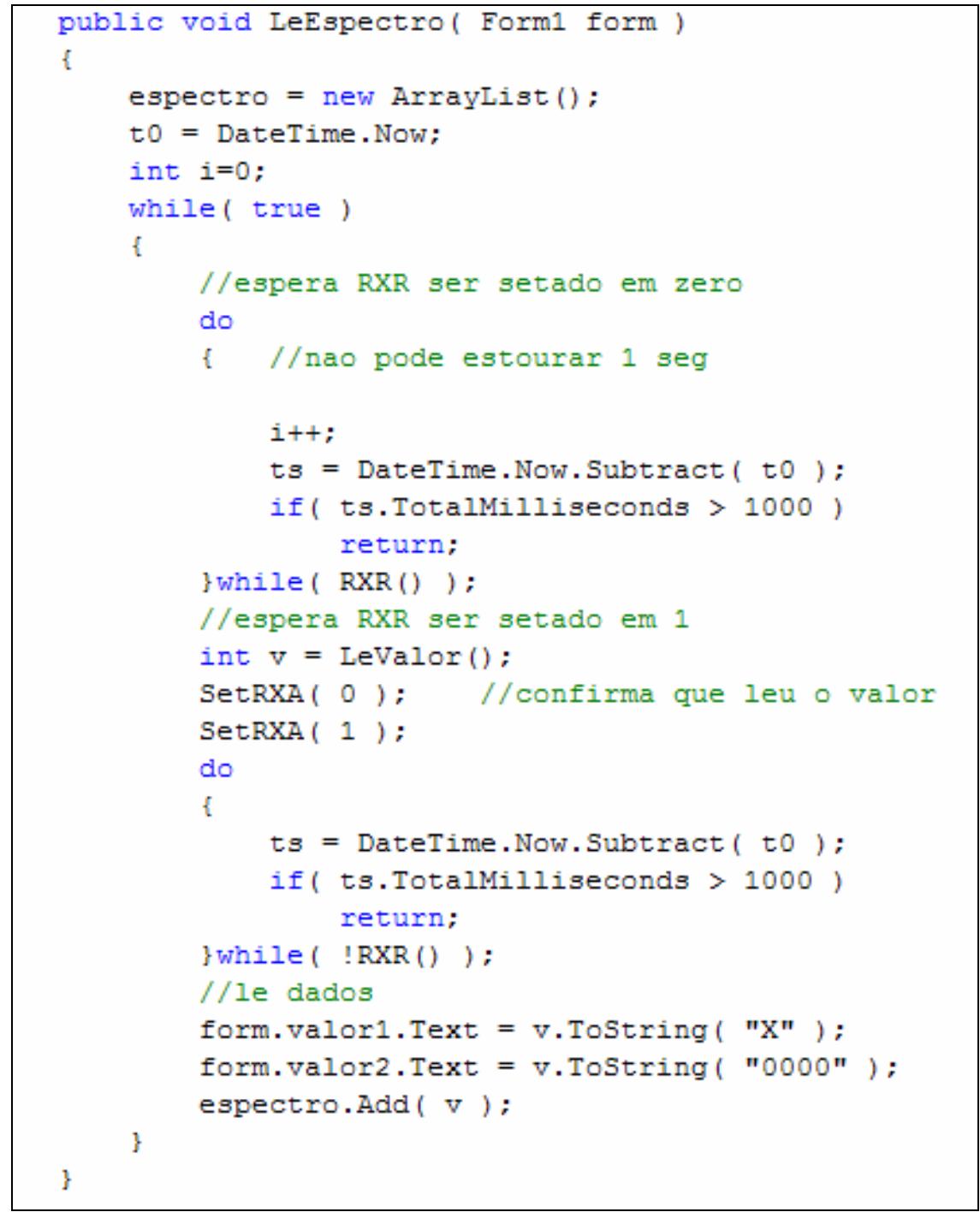

Figura 6-17. Lógica do analisador multicanal no PC. 
Realizando testes de tempo do processamento (veja tabela 5-3) vimos que é possível realizar o MCA no computador. Um problema seria se o computador não conseguisse ler um novo pulso informado pelo detector de pulso. O tempo crítico que poderia perder um sinal, avisando novo pulso sobre seu valor, seria que a indicação fosse menor do que 3,1 microsegundos, mas isto não acontece porque a largura do pulso é maior do que 5 microsegundos.

A ocorrência de tempo morto também não ocorreria porque o tempo de processamento total do pulso é de 5,8 microsegundos, basicamente a largura do pulso processado.

Tabela 6-3. Descrição da média do intervalo necessário para cada operação

\begin{tabular}{|c|c|c|}
\hline Tipo de Leitura de dados & Evento & Tempo (us) \\
\hline \multirow{2}{*}{ Leitura de Pulso } & $\begin{array}{c}\text { Cada leitura de RXR esperando o } \\
\text { evento de novo pulso }\end{array}$ & 3,1 \\
\cline { 2 - 3 } & $\begin{array}{c}\text { Leitura do valor de pulso quando } \\
\text { detectado RXR }\end{array}$ & 5,8 \\
\hline Leitura do Sinal & $\begin{array}{c}\text { Intervalo de cada leitura do valor } \\
\text { de sinal }\end{array}$ & 10,8 \\
\hline
\end{tabular}

Todo sistema de aquisição de novos dados é executado em um processo no computador com prioridade maior do que outros tais como cálculo do histograma e interface gráfica. 


\section{Resultados do Projeto}

Os resultados foram obtidos de duas formas diferentes. A primeira, utilizando um gerador de pulsos para o ajuste do circuito e a segunda, com aquisição real utilizando cristal detector com diferentes amostras radioativas.

\subsection{Resultados com Gerador de Pulsos}

Utilizando um gerador de pulsos, modelo 480 do fabricante Ortec, que simula a forma do impulso de saída do pré-amplificador do detector real, verificou-se o desempenho do detector de pico desenvolvido. O sinal do impulso é mostrado na figura 6-1.

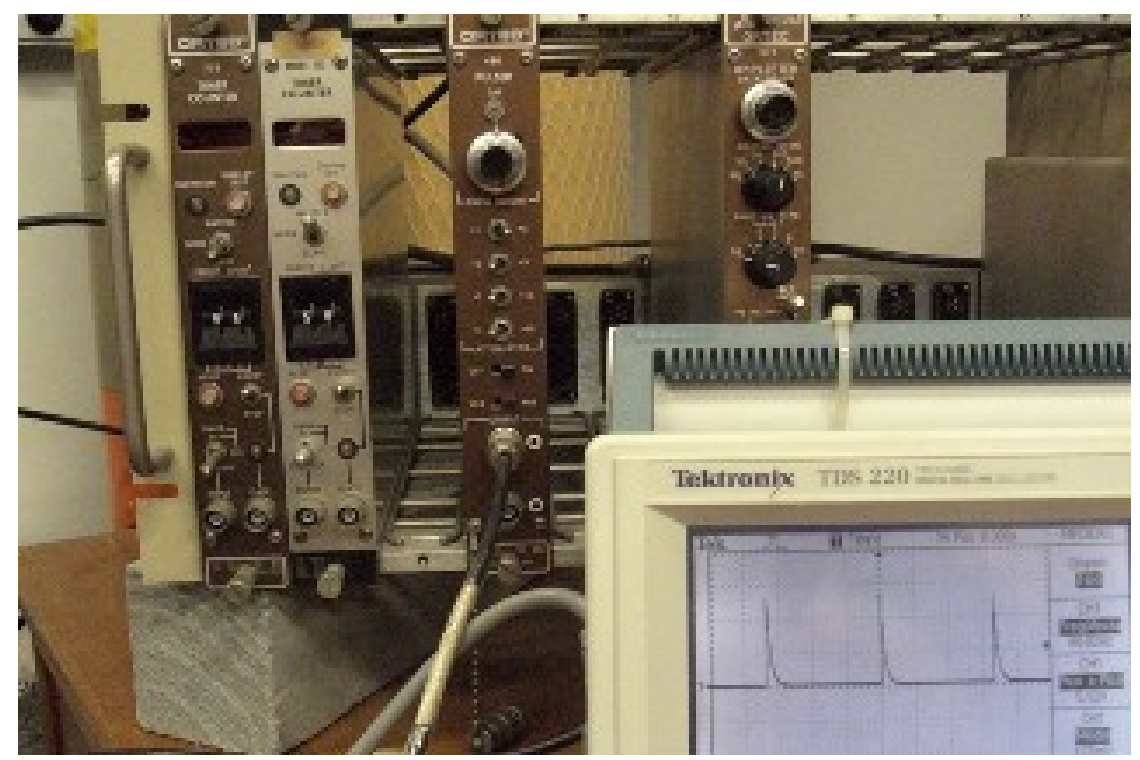

Figura 7-1. Gerador de impulsos exponenciais.

Como sabemos que todos os impulsos possuem a mesma amplitude pode-se verificar o formato do remodelamento do pulso após passar pelo circuito ADC e do filtro digital.

Primeiramente foi gravado no CPLD o filtro discreto mostrado na equação 6.1 para verificar o comportamento inicial neste gerador de pulsos simulando a forma de onda de saída do detector a ser utilizado.

$$
H(Z)=\frac{0,005+0,007 \mathrm{z}^{-1}+0,002 \mathrm{z}^{-2}}{1,000-1,138 \mathrm{z}^{-1}+0,142 \mathrm{z}^{-2}}
$$

Como a velocidade da leitura de sinal no computador não é rápida, não temos uma amostragem boa do sinal de saída do filtro digital. Mas podemos ver sua forma de pulso na figura 6-2 comprovando o funcionamento do filtro digital. 


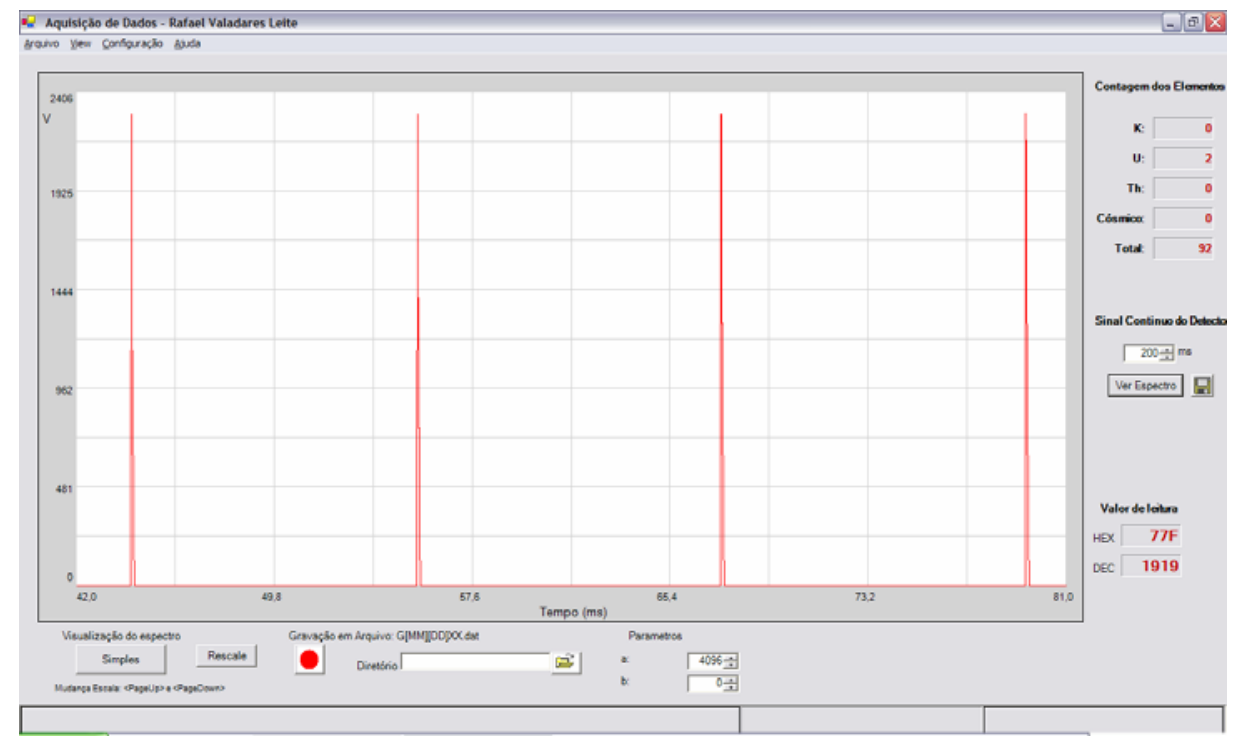

Figura 7-2. Sinal alongado do impulso de entrada no filtro digital.

Para comparação dos resultados obtidos com os resultados desejados, realizou-se três processos de análise: Resolução, Rejeição de pile-up e tempo morto do equipamento.

\subsubsection{Resolução do espectro}

Para verificar a resolução deste filtro digital realizou-se uma aquisição do sistema projetado por um determinado tempo que foi suficiente para termos mais de 10 mil pulsos gerados de mesma amplitude.

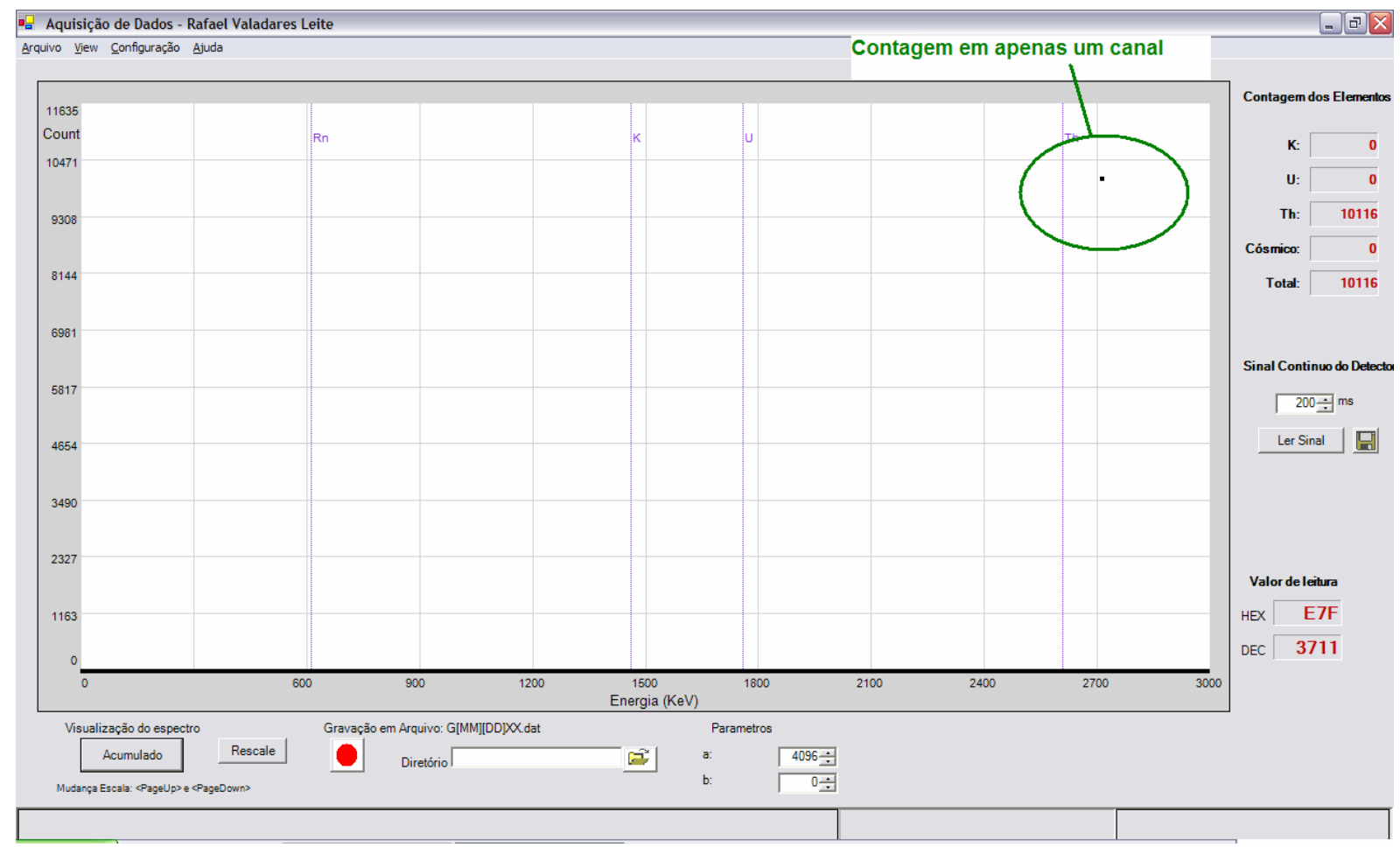

Figura 7-3. Espectro gerado pelo gerador de impulsos exponenciais.

$\mathrm{Na}$ figura 6-3 vemos que todos os impulsos foram detectados na mesma faixa de canal, demonstrando que o circuito ADC e o detector de pulso possuem uma resolução muito boa na parte eletrônica eliminando, assim, uma das fontes de erro, que prejudicava a resolução final. 
Além do circuito eletrônico, existem outras fontes de erro que são: produção de fótons no cristal detector e coleta destes fótons na fotomultiplicadora (veja itens 3.1 e 3.2).

\subsubsection{Rejeição de Pile-Up}

Utilizou-se um gerador de pulsos variando o intervalo entre dois pulsos para verificar a eficiência do sistema de rejeição de pile-up. Os pulsos foram incrementalmente aproximados, como visto na figura 6-4.

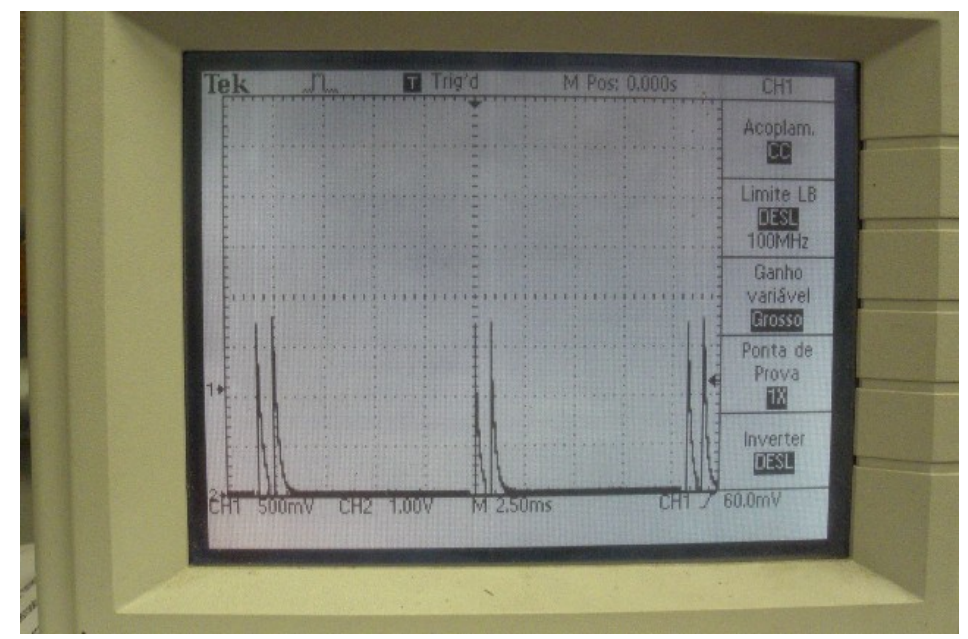

Figura 7-4. Simulação de empilhamento de dois pulsos próximos.

Realizou-se alguns testes simulando dois pulsos empilhados, ou seja, intervalo entre os dois pulsos é menor que o tempo do decaimento do primeiro pulso.

No teste houve rejeição dos pulsos quando estes estão empilhados, não possuindo contagem no sistema de aquisição.

\subsubsection{Tempo Morto}

Tempo morto é um problema em equipamentos lentos que não conseguem detectar alguns pulsos porque o computador ainda estaria processando informações do pulso anterior.

O tempo necessário para leitura do sinal indicando novo pulso é de aproximadamente 6 microsegundos neste projeto. Como este tempo é compatível à largura do pulso, normalmente de 5 microsegundos, então não há tempo morto para este sistema.

\subsection{Resultados com Amostras Radioativas Artificiais}

Foi utilizado um equipamento detector $\mathrm{NaI}(\mathrm{Tl})$ (veja item 5.1.1) para testar o projeto em uma situação real.

Para ajustar o filtro utilizou-se modelos considerando o pulso real de saída do detector real. A saída do sinal do detector real foi verificada no osciloscópio como mostrado na figura 6-5. 


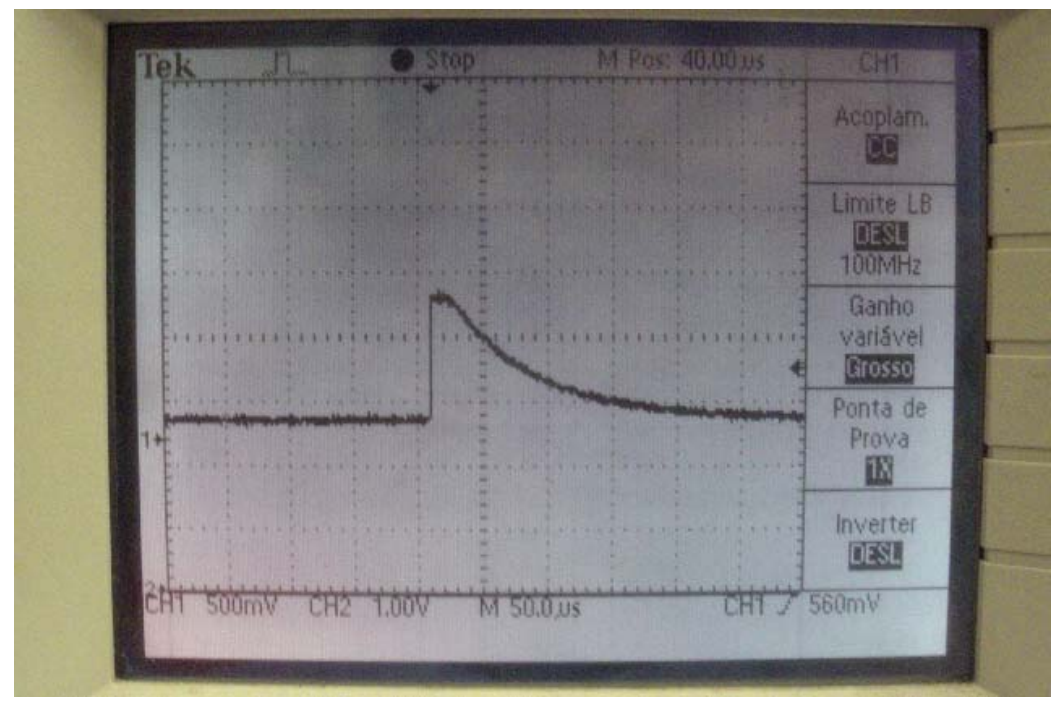

Figura 7-5. Pulso de saída do pré-amplificador do detector NaI(TI) utilizado.

Conhecendo o formato do pulso real modelou-se um novo filtro digital no Matlab. Também foi realizado um algoritmo detector de amplitude sem remodelar o pulso de entrada, os dois filtros são descritos a seguir.

- Filtro 1: Filtro CR-RC-RC com pólo-zero de ordem 3.

$$
H(Z)=\frac{1+1,59 z^{-1}}{1-0,223 \cdot z^{-1}} \cdot \frac{0,005 z^{-1}}{1-0,995 \cdot z^{-1}} \cdot \frac{0,007 z^{-1}}{1-0,993 \cdot z^{-1}}
$$

- Filtro 2: Detector direto de amplitude. Não há modificação ou remodelação do pulso de entrada. Há um detector de variação da amplitude do sinal, verifica-se o maior valor após ocorrer aumento no valor de entrada.

Foi realizada uma simulação no MATLAB utilizando estes dois filtros, utilizando-se na entrada o modelo do pulso real, obtido através da gravação do osciloscópio e modelamento. $\mathrm{O}$ resultado pode ser conferido na figura 6-6.

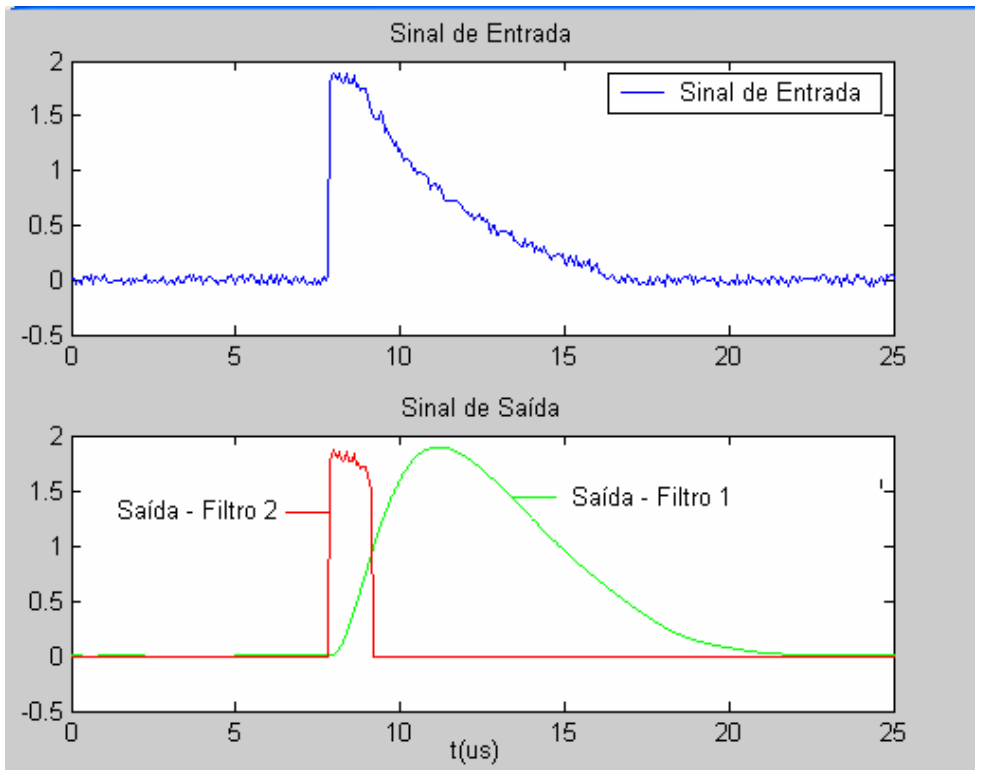

Figura 7-6. Simulação em Matlab da resposta nos dois filtros utilizados. 
Utilizando o filtro 1 obtivemos uma simples amostra de um espectro de contagem com uma amostra real de césio (Cs) como mostrado na figura 6-7. O radioelemento $\mathrm{Cs}^{137}$ tem um pico de energia de $662 \mathrm{keV}$.

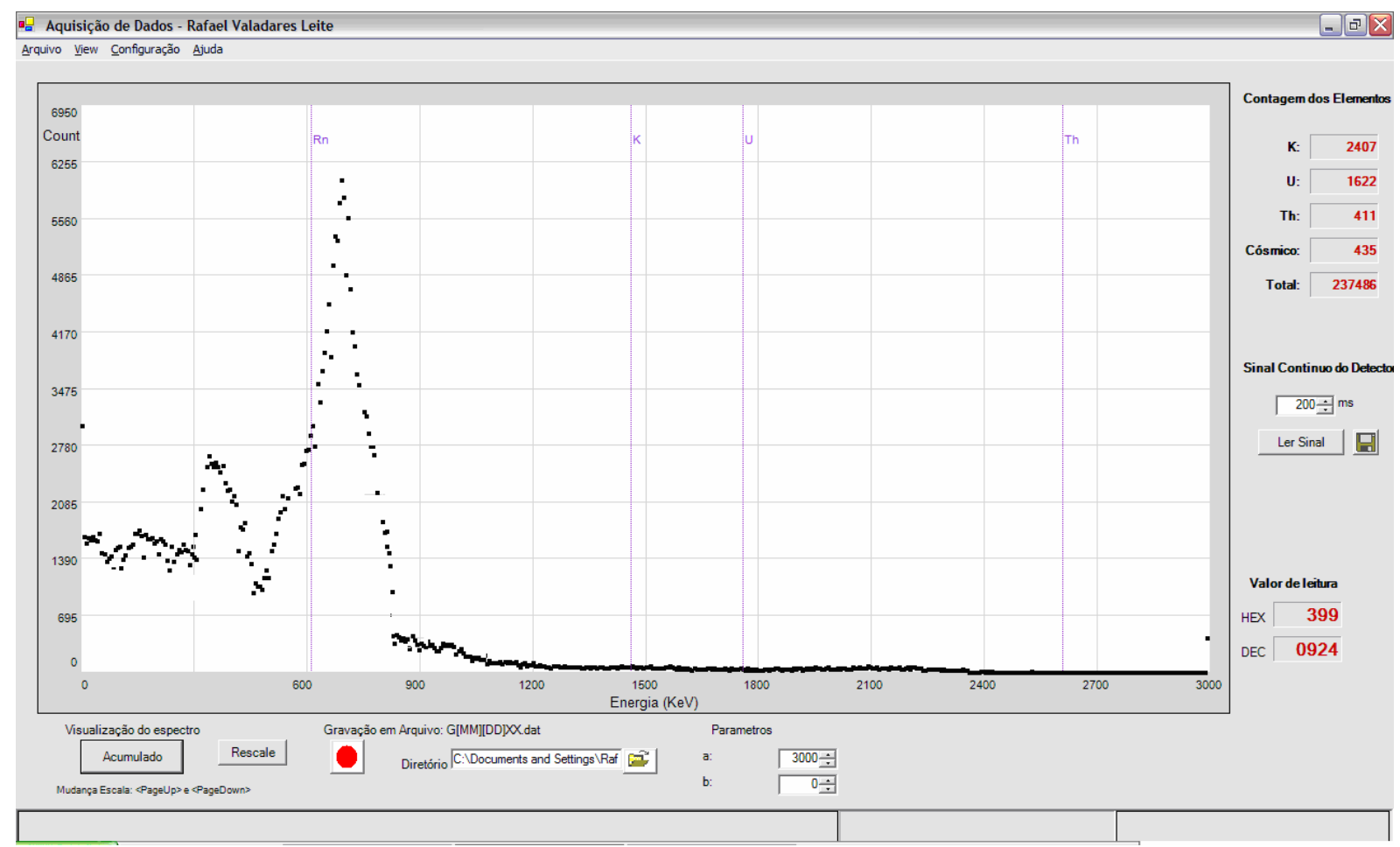

Figura 7-7. Espectro gerado pelo equipamento com uma amostra de $\mathrm{Cs}^{\mathbf{1 3 7}}$.

A resolução do pico no elemento césio deve estar entre 8,5 e $11 \%$. Nos teste realizados, obteve-se resolução de $9,8 \%$ utilizando o Filtro 1 e $10,1 \%$ utilizando o Filtro 2, comprovando o funcionamento dos dois filtros com amostras reais.

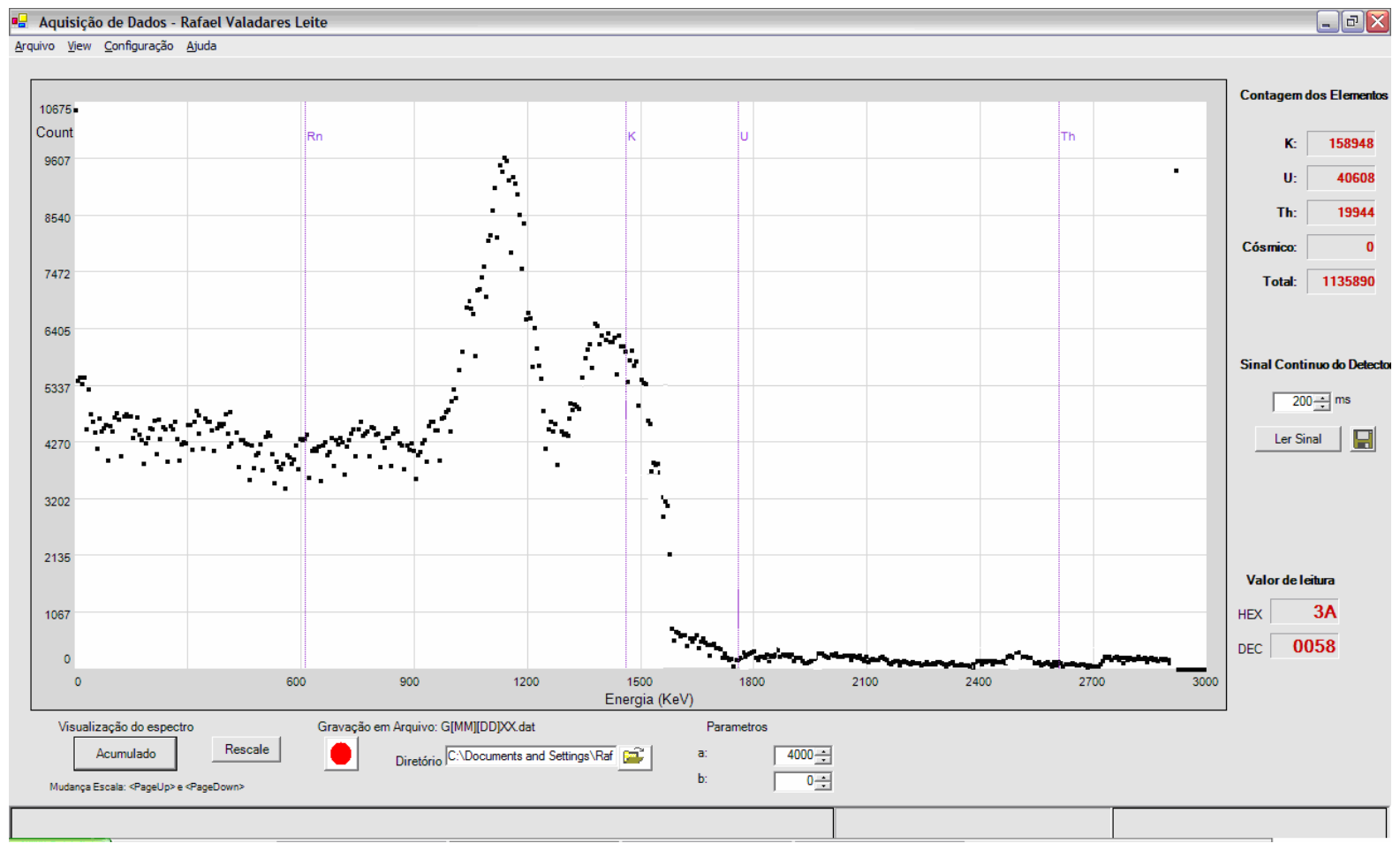

Figura 7-8. Espectro gerado pelo equipamento com uma amostra de Cobalto. 
Na figura 6-8 temos o resultado utilizando o algoritmo do segundo filtro para uma amostra de cobalto (Co). $\mathrm{O}$ radioelemento $\mathrm{Co}^{60}$ possui dois picos de energia nos valores de $1170 \mathrm{keV}$ e $1330 \mathrm{keV}$.

O radioelemento $\mathrm{Co}^{60}$ é utilizado em testes para realizar a comparação gráfica. Verificou-se que o teste realizado satisfaz a qualidade do projeto, onde os dois picos de energia e também uma pequena contagem na sobreposição dos dois picos somando a energia de $2500 \mathrm{keV}$.

O teste do Filtro 2 permitiu uma conclusão interessante na utilização de um conversor ADC de alta velocidade. Como não perdemos a informação da amplitude do impulso de entrada não é necessário conformar o pulso.

Ao invés de realizar um filtro digital que é uma operação matemática complexa, realizou-se uma simples operação matemática, onde a diferença entre o valor máximo e o valor anterior ao início de um novo impulso é a amplitude do pulso. A determinação dos coeficientes complexos do amplificador digital, cancelamento de pólo-zero e restaurador de linha de base não foi considerada.

Com este algoritmo, em lugar de eliminar empilhamentos consegue-se detectar dois pulsos mesmo quando empilhados como mostrado na simulação na figura 6-9. Vemos na simulação que apenas o algoritmo do Filtro 2 consegue detectar os dois pulsos separadamente, detectados pelo nível de threshold.

Com o mesmo teste realizado no item 6.1.2 (veja figura 6-4) conseguimos detectar dois pulsos empilhados obtendo duas contagens que seriam rejeitadas em um sistema com rejeição de pile-up.
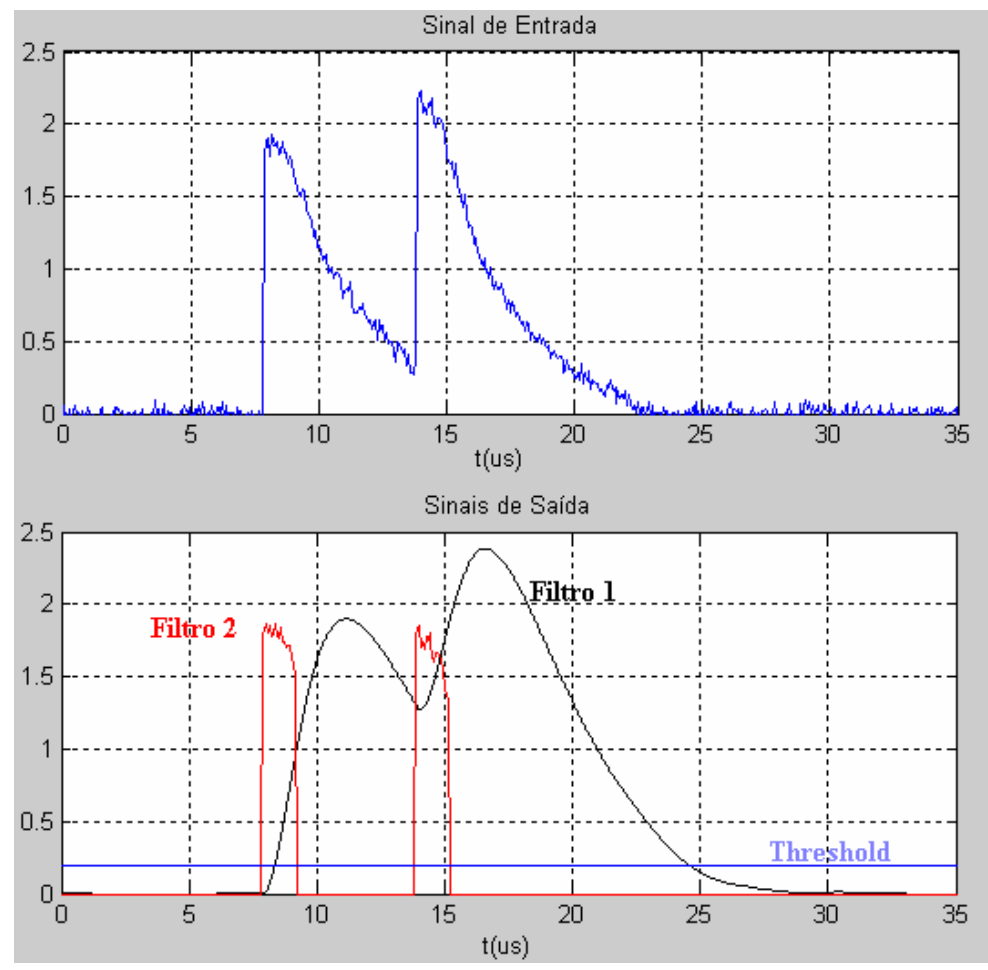

Figura 7-9. Detecção de dois pulsos mesmo quando empilhados utilizando o Filtro 2. 


\section{Conclusão}

Tive grande satisfação de concluir este projeto de pesquisa e realizar os testes de laboratório necessários para comprovar sua funcionalidade. Apesar do objetivo principal ser a substituição do conjunto analógico 'amplificador' de um gamaespectrômetro por um sistema totalmente digital, foi necessário desenvolver todo o conjunto da parte eletrônica e computacional de um gamaespectrômetro para realizar os testes.

Os testes como mostrados no capítulo anterior foram bem sucedidos e dois resultados importantes precisam ser destacados:

- Desenvolvimento do circuito amplificador totalmente digital, com a:

o Eliminação de certas desvantagens dos amplificadores analógicos como derivas e variações de propriedades físicas dos componentes, principalmente por variação de temperatura.

o Eliminação de ajuste manual, através de potenciômetros, para o cancelamento do pólo-zero.

o Redução das dimensões do circuito.

- Elaboração do software do circuito detector de dois pulsos mesmo empilhados, com:

o Melhoria na contagem de energias não rejeitando pulsos empilhados.

o Simplicidade no algoritmo, não precisando se preocupar com variações na forma do pulso, principalmente na parte de cancelamento de pólo-zero e restauração do nível de base.

O cronograma não foi cumprido na íntegra como apresentado no exame de qualificação devido à disponibilidade de um cristal detector $\mathrm{NaI}(\mathrm{Tl})$ de radiação gama, que é um sistema caro e difícil de ser encontrado. O prazo curto deixou algumas partes do projeto para futuras implementações que poderão ser realizadas, como:

- Calibração automática na parte conversora analógica para digital através de um potenciômetro digital na entrada do conversor ADC.

- Utilização de um microcontrolador para realizar o MCA e comunicação serial com o computador, evitando alguma perda de pulso devido a um processamento simultâneo que o computador esteja realizando no momento. 


\section{Referências}

[1] Carlos, D. U. Fundamentos de Gamaespectrometria. Barueri: Fornecido pela AeroGeoPhysica - LatinoAmerica; 2003.

[2] Cardoso, E. M. Radioatividade. CNEN; 1997.

[3] Silva, Nilton. Uso de microcontrolador na construção de espectrômetro gama com sensor de $\mathrm{NaI}(\mathrm{Tl})$, com ênfase em analisador multicanal, para aplicação em geofísica nuclear e ambiental. São Paulo: Dissertação de Mestrado IAG-USP; 2005.

[4] Minty, B. R. S. Fundamentals of airborne gamma-ray spectrometry. AGSO Journal of Australian Geology \& Geophysics, v.17, n.2, p. 39-50; 1997.

[5] Gilmore, G. and Hemingway, J. Practical Gamma-Ray Spectrometry. Chichester: John Wiley \& Son; 1995.

[6] TELFORD, W. M.; GELDART, L.P.; SHERIFF, R. E. Applied Geophysics. Cambridge [England]; New York : Cambridge University Press; 1990.

[7] Urquhart, W.E.S, Airborne Gamma-Ray Spectrometry Surveys http://www.geoexplo.com/airborne_survey_workshop_rad.html.

[8] Silva, N. C., Detecção da radiação nuclear. http://fsc.ufsc.br/ canzian/labfismod/radiacaonuclear.html

[9] Leo, W. R. Techniques for Nuclear and Particle Physics Experiments. Berlin; New York: Springer; 1994.

[10] Knoll, G. F. Radiation Detection and Measurement. New York: John Wiley; 1989.

[11] Ogata, K. Discrete-time Control Systems. Englewood Cliffs, N.J.: Prentice Hall; 1995.

[12] Smith, S. W. The Scientist and Engineer's Guide to Digital Signal Processing. California Technical Publishing; 1999.

[13] The Mathworks Inc. Communications Toolbox User’s Guide. 2002.

[14] Heath, R. L. Scintillation Spectrometry - Gamma-ray spectrum catalogue. 1997.

[15] Billings, S. and Hovgaard, J., 1999, Modeling detector response in airborne gammaray spectrometry: Geophysics, Vol. 64, NO. 5, P. 1378-1392.

[16] DOE Fundamentals Handbook - Instrumentation and Control. DOE-HDBK-1013/292 , volume 2.

[17] Duval, J. S. 1980. Radioactivity method. Geophysics, v. 45, n.11, p. 1690-1694.

[18] Kaplan, I. Física Nuclear, Rio de Janeiro: Guanabara Dois; 1978. 
[19] Natural Resources Canadá, Radiation Geophysics

http://gamma.gsc.nrcan.gc.ca/theory e.php

[20] Ribeiro, F. B., Gamaespectrometria. São Paulo: Curso ministrado pela AeroGeoPhysica - LatinoAmerica; 2003.

[21] Cardoso, J. M. R., Simões, J. B., Correia, C. A. A Mixed Analog-Digital Pulse Spectrometer. Coimbra: University of Coimbra; 2001.

[22] Ribas, R. V. Instrumentação Nuclear. São Paulo: IF-USP, 2002.

[23] Schroeder, W. The Visualization Toolkit User’s Guide. Kitware; 2001.

[24] Tutorial do software Geosoft. www.geosoft.com

[25] OrCAD, Inc. OrCAD PSpice A/D User's Guide. 1998.

[26] Saltuklaroglu, L., 2002, I/O Ports Uncensored - www.codeproject.com

[27] The Mathworks Inc. Using the Control System Toolbox. 2001.

[28] Proakis, J. G. e Manolakis, D. Digital Signal Processing: Principles, Algorithms and Applications. Upper Saddle River, N.J.: Prentice Hall, 1996. 